\title{
A synopsis of the scorpion fauna of French Guiana, with description of four new species
}

\author{
Eric Ythier ${ }^{1}$ \\ I SynTech Research, 613 route du Bois de Loyse, 71570 La Chapelle de Guinchay, France \\ Corresponding author: Eric Ythier (eythier@syntechresearch.com)
}

Academic editor: W. Lourenço | Received 18 March 2018 | Accepted 14 May 2018 | Published 5 June 2018

http://zoobank.org/8BB7E0E6-3154-46E9-A010-D8E52E7EEF4E

Citation: Ythier E (2018) A synopsis of the scorpion fauna of French Guiana, with description of four new species. ZooKeys 764: 27-90. https://doi.org/10.3897/zookeys.764.25108

\begin{abstract}
A synopsis is provided for all scorpion species collected in French Guiana, including thorough diagnoses and additional distributional records for each documented species. Four new species are also described in this paper (one Ananteris from northeastern Guiana, two Auyantepuia from central and northeastern Guiana and one Hadrurochactas from western Guiana), raising the total number of species described from French Guiana to 30. Most of the species are illustrated, geographical distribution maps are presented, and a key to the species is proposed.
\end{abstract}

\section{Keywords}

Ananteris, Auyantepuia, French Guiana, geographical distribution, Hadrurochactas, key, new scorpion species, synopsis

\section{Introduction}

Since the comprehensive work of Lourenço on the scorpion fauna of French Guiana published in 1983, several genera, species, and subspecies were described, few species were synonymized or transferred to other genera and additional collection material increased our knowledge of the geographical distribution of several species. Lourenço (1983) documented a total of 18 species belonging to eight genera and three families, while the present paper records a total of 30 species belonging to 12 genera and three 
families. All new species described since 1983 were by Lourenço (eight species; 1997b, 2001b, 2003b, 2008, 2012c, 2012d, 2016a, 2016b), Lourenço and Monod (one species; 1999), Lourenço and Ythier (one species; 2011) and Ythier (five species; 2015 and present paper).

As discussed in several publications (Lourenço 1986, 1991, 2001a, 2016a, 2016b) the scorpion fauna of the Guianan region (Guayana floristic province as described in Mori 1991) presents a great complexity of endemism. The Guianan rainforests are one of the largest continuous tracts of relatively pristine lowland tropical rainforest in the World. This ecoregion is characterized by high species richness and local and regional endemism, as well as relatively intact ecological processes. Species assemblages are shared with the Amazon and Orinoco basins, and with the Guianan highlands and Tepuy formations, and the ecoregion is thus a convergence zone for species diversity. The degree of endemism for the scorpion species present in the region is high, with 21 of the 30 species presented in this paper possibly endemic to French Guiana. Despite its reasonably small size of $83,000 \mathrm{~km}^{2}$, French Guiana is a biodiversity hotspot presenting remarkable scorpion diversity and the present paper probably represents only a small part of the scorpion fauna actually present, since most of the region has not been studied yet and several specific areas with potentially high degrees of endemism (e.g., inselbergs) have only been recently started to be studied. For several sections of the lowland rainforest such as the canopy, knowledge of the scorpion fauna is also still almost nonexistent.

French Guiana has a wide range of habitats (Fig. 33). Most of its land area (90\%) is covered by lowland tropical rainforest (Fig. 34) interspersed with forests of higher altitude (Fig. 35), 95\% of these rainforests consisting or primary forest. Along the coast there are also patches of dry forest including white sand forests (Fig. 36) and savannas (Fig. 37), as well as many types of wetlands including mangroves and swamps. While several species are commonly found in many different habitats across French Guiana (e.g., T. obscurus, T. silvestris, B. gervaisii, B. granulatus) including zones impacted by human activities, some others remain endemic elements from specific ecosystems like e.g., coastal dry forests or savannas (e.g., A. elisabethae, A. kalina sp. n., J. pintoi kourouensis, $O$. heurtaultae, T. mana) or French Guiana massifs represented by inselbergs (e.g., A. polleti, A. sabineae, S. mitaraka).

\section{Materials and methods}

Material presented herein is deposited in the following collections:

MNHN Muséum national d'Histoire naturelle, Paris, France,

MHNG Muséum d'histoire naturelle, Geneva, Switzerland, EYPC Eric Ythier Private Collection, Romanèche-Thorins, France,

RNA Reserve Naturelle de l'Amana, Awala-Yalimapo, French Guiana, France. 
With the exception of the specimens deposited in the MHNG, most of the presented material was examined by the author. For each species documented in this work, geographical distribution is presented based on the studied material (see material section for each species and corresponding distribution maps in Figs 31, 32). Distribution data for specimens not deposited in one of the above-mentioned collections was not taken into account.

Thorough diagnoses are presented for the species described previously to this note, extracted from original descriptions and in some cases translated from French, German, Spanish, and Portuguese. For detailed descriptions or additional information, readers can refer to the publications indicated in the references. Photographs of alive or fixed specimens are presented, when available. Measurements and illustrations were made using a Motic DM143 digital stereo-microscope together with a Nikon D810 camera and a Wacom Intuos drawing tablet. Measurements follow Stahnke (1970) and are given in mm. Trichobothrial notations are those developed by Vachon (1974) and the morphological terminology mostly follows Hjelle (1990).

\section{List of scorpion species from French Guiana}

Family Buthidae C. L. Koch, 1837

Genus Ananteris Thorell, 1891

Ananteris coineaui Lourenço, $1982\left(^{*}\right)$

Ananteris elisabethae Lourenço, $2003\left(^{*}\right)$

Ananteris guyanensis Lourenço \& Monod, $1999\left(^{*}\right)$

Ananteris intermedia Lourenço, $2012\left(^{*}\right)$

Ananteris kalina sp. n. (*)

Ananteris polleti Lourenço, $2016\left(^{*}\right)$

Ananteris sabineae Lourenço, $2001\left(^{*}\right)$

Genus Isometrus Hemprich \& Ehrenberg, 1828

Isometrus maculatus (DeGeer, 1778)

Genus Jaguajir Esposito, Yamaguti, Souza, Pinto da Rocha \& Prendini, 2017

Jaguajir pintoi kourouensis (Lourenço, 2008)

Genus Microananteris Lourenço, 2003

Microananteris minor Lourenço, $2003\left(^{*}\right.$

Genus Tityus C. L. Koch, 1836

Tityus (Tityus) gasci Lourenço, 1981

Tityus (Archaeotityus) mana Lourenço, $2012\left(^{*}\right)$

Tityus (Atreus) obscurus (Gervais, 1843)

Tityus (Archaeotityus) silvestris Pocock, 1897

Family Chactidae Pocock, 1893

Genus Auyantepuia Gonzalez-Sponga, 1978

Auyantepuia aluku sp. n. $\left(^{*}\right)$ 
Auyantepuia aurum sp. n. $\left({ }^{*}\right)$

Auyantepuia fravalae Lourenço, $1983\left(^{*}\right)$

Auyantepuia gaillardi Lourenço, $1983\left(^{*}\right)$

Auyantepuia kelleri Lourenço, $1997\left(^{*}\right)$

Auyantepuia laurae Ythier, $2015\left(^{*}\right)$

Auyantepuia sissomi Lourenço, $1983\left({ }^{*}\right)$

Genus Broteochactas Pocock, 1893

Broteochactas delicatus (Karsch, 1879)

Genus Brotheas C. L. Koch, 1837

Brotheas gervaisii Pocock, 1893

Brotheas granulatus Simon, 1877

Genus Guyanochactas Lourenço, 1998

Guyanochactas flavus Lourenço \& Ythier, $2011\left(^{*}\right)$

Guyanochactas gonzalezspongai (Lourenço, 1983) $\left({ }^{*}\right)$

Genus Hadrurochactas Pocock, 1893

Hadrurochactas cristinae sp. n. $\left({ }^{*}\right)$

Hadrurochactas schaumii (Karsch, 1880)

Genus Spinochactas Lourenço, 2016

Spinochactas mitaraka Lourenço, $2016\left(^{*}\right)$

Family Hormuridae Laurie, 1896

Genus Opisthacanthus Peters, 1861

Opisthacanthus heurtaultae Lourenço, $1980\left(^{*}\right)$

Total 30 species. $21\left(^{*}\right)$ are possibly endemic elements to French Guiana. Other species also occur in Brazil (J. pintoi, T. gasci, T. obscurus, T. silvestris, B. delicatus, B. gervaisii, B. granulatus), Peru (T. gasci, T. silvestris), Ecuador (T. gasci), Suriname (T. obscurus, T. silvestris, H. schaumii), Guyana ( $R$. pintoi, H. schaumii), Venezuela ( $H$. schaumii) or have cosmopolitan distribution (I. maculatus).

\section{Taxonomic treatment}

\section{Family BUTHIDAE C. L. Koch, 1837}

Genus Ananteris Thorell, 1891

\section{Ananteris coineaui Lourenço, 1982}

Fig. 1

References. Lourenço 1982, Lourenço and Cuellar 1999, Fet et al. 2000, Lourenço 2003a.

Material. Downstream from Saut Pararé on Arataye river, Approuague tributary, one female (holotype), MNHN-RS-8504, J.P. Gasc coll., IV-V/1979. Right bank of 


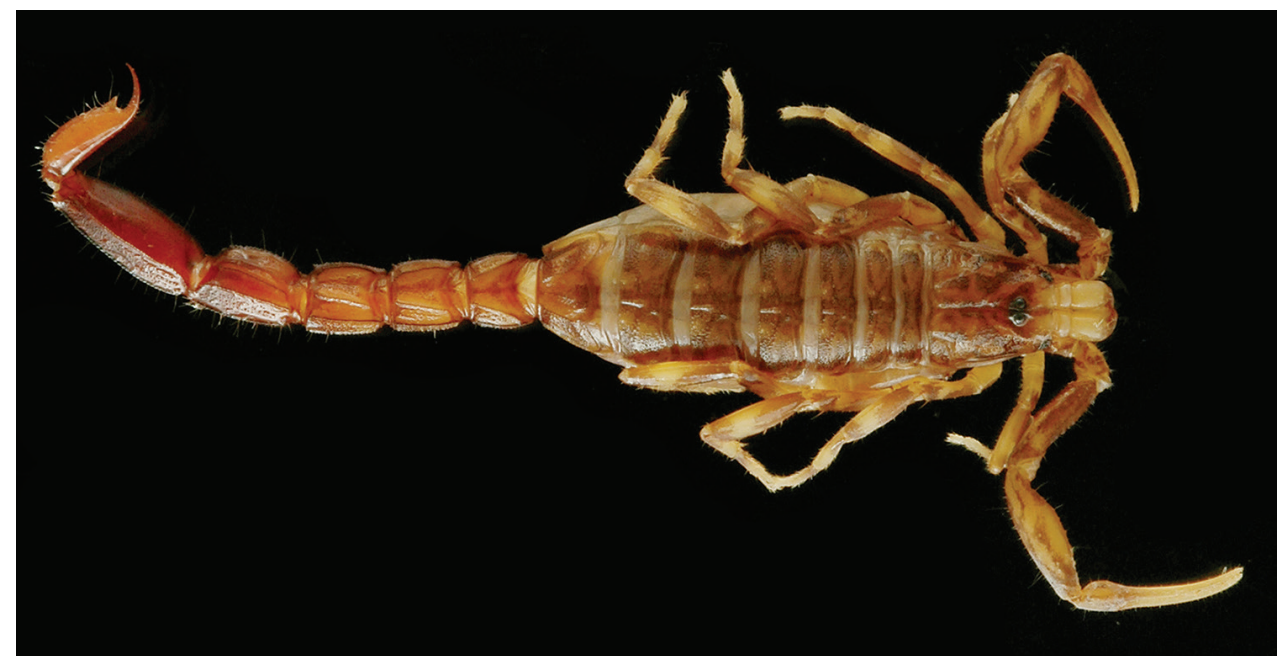

Figure I. Ananteris coineaui, female holotype from Saut Pararé (photo MNHN / E.-A. Leguin).

Arataye river, downstream from Saut Pararé, in a palm tree (Astrocaryum paramaca) in forest, two females (paratypes), J.P. Gasc coll., I/1981. Saül, in a palm tree, one female, deposited in the MNHN, W. Lourenço leg.

Diagnosis. Species of medium to large size compared to the average size of the other species within the genus (32.7 $\mathrm{mm}$ in total length for female holotype). General coloration dark yellow with brown to dark brown variegated pigmented zones. Carapace dark yellow with dark brown spots mainly on the anterior edge; lateral and posterior edges with less spots; eyes surrounded by black pigment. Mesosoma dark yellow with confluent brownish spots on all tergites; the VII with a triangular brownish spot; the lateral edges with square spots with the center lighter. Venter yellow ochre to brownish, with dark brown spots on edges of sternites V to VII, especially on the VII. Metasomal segments I to III reddish yellow, IV and V reddish; one triangular brownish spot on I to IV, dorsally. Vesicle reddish yellow, lighter than metasomal segment V; base of aculeus yellowish, tip reddish. Chelicerae yellow with a dark brown spot anteriorly, at the base of fingers; fingers reddish black. Pedipalps dark yellow; femur, patella, and chela strongly marked with dark brown spots; chela almost entirely dark brown; fingers reddish yellow. Legs reddish yellow, with numerous dark brown spots. Carapace with moderately marked granulation; anterior margin almost straight; all furrows moderate to weak. Tergites with moderately marked granulation, similar to that of carapace, better marked posteriorly; median carina well-marked on all tergites. Pectinal tooth count 16-16 to 17-17 in female. Sternites with spiracles linear. Metasomal segments with 10-10-8-8-5 crenulate carinae; intercarinal spaces strongly granular on all segments; segment $\mathrm{V}$ rounded. Vesicle with some granulation lateraly; subaculear tooth strongly marked. Pedipalp femur pentacarinate; patella and chela with weak to vestigial carinae; movable fingers with seven linear rows of granules. 


\section{Ananteris elisabethae Lourenço, 2003}

References. Lourenço 1983, Lourenço 1993, Lourenço 2003a, Lourenço 2016b.

Material. Kourou, in the forest, one male (holotype), MNHN-RS-8086, mission M. Boulard \& P. Pompanon coll., 3-7/VIII/1975.

Diagnosis. Species of small size when compared with the average size of the other species of the genus $(17.7 \mathrm{~mm}$ in total length for male holotype). Generally pale yellow without any spots or pigmented zones on the body and its appendages. Carapace yellowish; only the eyes surrounded by black pigment. Mesosoma yellowish with some pale reddish zones on the posterior edges of tergites. Venter pale yellow. All segments of metasoma yellowish; segment $V$ slightly darker. Vesicle yellowish and aculeus yellowish. Chelicerae and teeth globally yellowish. Pedipalps yellowish overall, including the rows of granules on the dentate margins of the fingers. Legs yellowish. Carapace moderately to weakly granular; anterior margin weakly emarginated; all furrows moderate to weak. Tergites moderate to weakly granular; median carina moderate to weak in all tergites; tergite VII pentacarinate. Pectinal tooth count 16-16 in male. Sternites weakly granular with moderately elongate stigmata; VII with vestigial carinae. Metasomal segments with 10-8-8-8-5 crenulate carinae; intercarinal spaces weakly granular; segment $\mathrm{V}$ rounded. Telson elongated and weakly granular with three ventral carinae; the latero-ventral vestigial; aculeus short and moderately curved; subaculear tooth strong and spinoid. Pedipalp femur pentacarinate; patella and chela with a few vestigial carinae; internal aspect of patella with 7-8 spinoid granules; all aspects weakly granular, almost smooth; fixed and movable fingers with six almost linear rows of granules; two small accessory granules present at the base of each row. Leg tarsus with very numerous fine median setae ventrally; tibial spurs strongly developed on legs III and IV.

\section{Ananteris guyanensis Lourenço \& Monod, 1999}

Fig. 2

References. Lourenço and Monod 1999, Fet et al. 2000, Lourenço 2003a, Lourenço $2016 b$.

Material. Saint Eugène, rainforest, in rotten log, one female (holotype), deposited in the MHNG, R. Boistel leg., 15/IV/1998. Mana, near Saut Sabbat, Gîte Angoulème, one male, deposited in the EYPC, EY0106, J. Chevalier \& B. Tan coll., 04/XI/2017. Mana, near Saut Sabbat, Gîte Angoulème, one female, deposited in the RNA, J. Chevalier \& B. Tan coll., 07/I/2018.

Diagnosis. Species of medium size when compared with the average size of the other species of the genus, ranging from 25 to $30 \mathrm{~mm}$ in total length. General coloration yellowish brown, symmetrically marbled with dark reddish brown, producing an overall spotted appearance. Carapace yellowish brown and heavily spotted; 


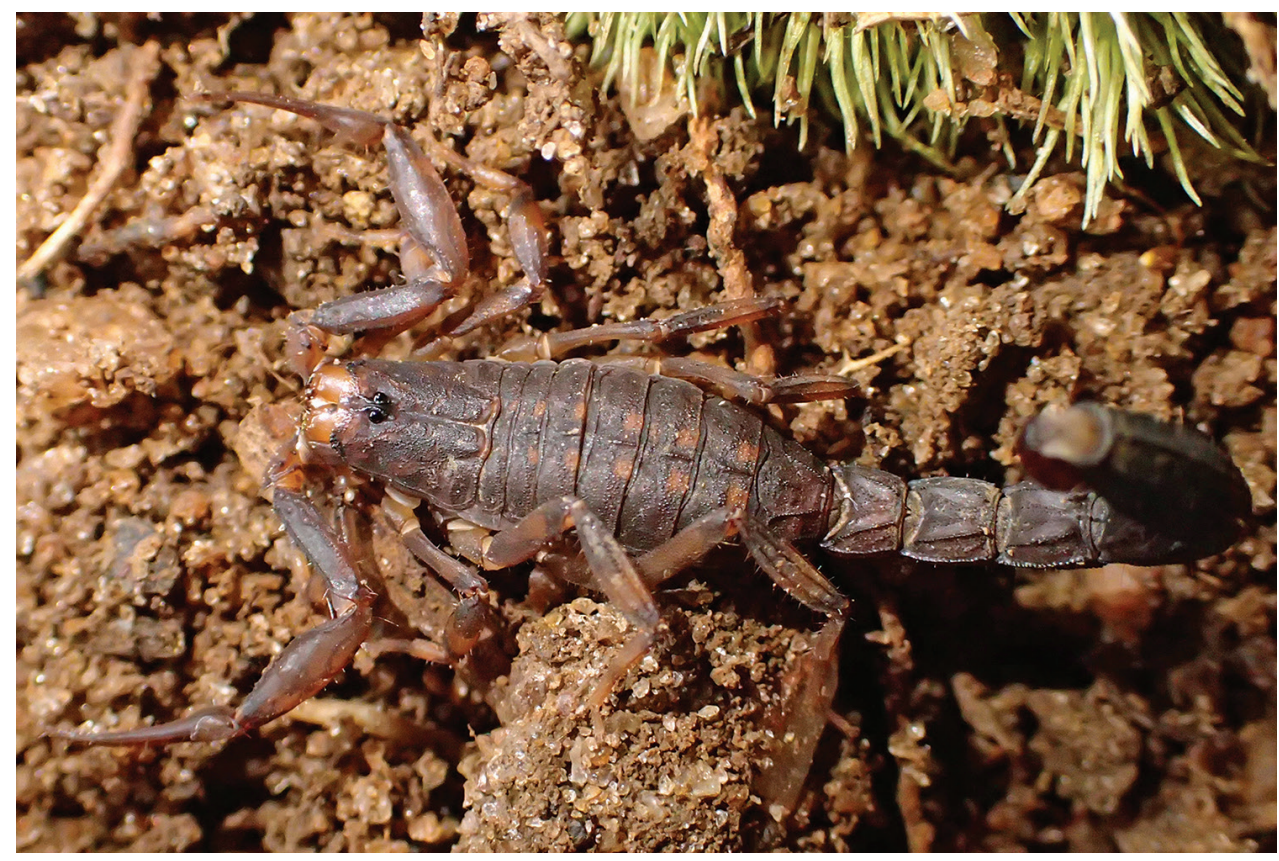

Figure 2. Ananteris guyanensis, female from Saut Sabbat (photo J. Chevalier).

eyes surrounded with black pigment. Mesosoma yellowish brown with confluent brown stripes and two longitudinal yellowish stripes. Venter yellowish with spots only on sternite VII. Metasomal segments I to V yellowish brown, with numerous brown spots; segments IV and V reddish, darker than the others. Vesicle reddish yellow without spots, but with some darker areas over the carinae. Chelicerae yellowish without variegated spots over their entire surface, and with only a dark thin zone at the base of the fingers; fingers reddish. Pedipalps dark brown with spots on the femur and patella; chelae yellowish; fingers brownish. Legs brownish with fuscous spots. Carapace feebly to moderately granular; anterior margin with a slight median concavity; all furrows moderate to feeble. Tergites moderately granular; median carina moderate to strong in all tergites. Pectinal tooth count 17-16 in female. Sternites almost smooth with moderate elongate stigmata; VII with four vestigial carinae. Metasomal segments with 10-10-10-8-5 crenulate carinae; intercarinal spaces moderately granular; segment $\mathrm{V}$ rounded. Telson moderately granular with one ventral carina and with a fairly short and moderately curved aculeus; subaculear tooth strong and spinoid. Pedipalp femur pentacarinate; patella and chelae with a few carinae but moderately crenulate; internal side of patella with only vestigial spinoid granules; all sides moderately to feebly granular; movable fingers with seven oblique rows of granules; only one accessory granule present at the base of each row. Leg tarsus with very numerous fine median setae ventrally; tibial spurs strongly developed on legs III and IV. 


\section{Ananteris intermedia Lourenço, 2012}

Fig. 3

References. Lourenço 2012c.

Material. St. Jean du Maroni, road to Saint Laurent, primary forest, winkler, one male (holotype), deposited in the MNHN, W. Lourenço coll., 12/VI/1987.

Diagnosis. Very small species when compared with the average size of the other species of the genus $(9.3 \mathrm{~mm}$ in total length for male holotype). General coloration yellow to pale yellow with carapace and tergites intensely marbled with dark brown spots, producing an overall spotted appearance. Carapace yellow, almost totally covered with brown spots; eyes surrounded by black pigment. Mesosoma yellowish brown with three longitudinal stripes. Venter pale yellow with infuscations only on sternite VII. Metasomal segments I to V yellow to pale yellow, with several brown annular spots distally; segment $\mathrm{V}$ with better marked spots. Vesicle yellow without spots; aculeus yellow at the base and reddish at the tip. Chelicerae pale yellow with diffused variegated spots over their entire surface; better marked anteriorly; fingers pale yellow with reddish teeth. Pedipalps pale yellow, only slightly infuscate on the femur and patella; chela paler than patella; fingers pale yellow with the rows of granules slightly reddish. Legs yellow, densely marked with brownish spots. Carapace weakly granular to smooth; anterior margin almost straight; all furrows weak. Tergites weakly granular to smooth; median carina weak in all tergites. Pectines rather long; pectinal tooth count 17-18 in male. Sternites smooth with short semi-oval to round spiracles; VII with a few granulations and vestigial carinae. Metasomal segments with 10-10-8-8-5 weakly crenulate carinae; intercarinal spaces weakly granular to smooth. Telson with a fusiform shape, smooth with one vestigial ventral carina; aculeus moderately long and weakly curved; subaculear tubercle extremely reduced to vestigial. Pedipalps rather short; femur pentacarinate, with carinae weakly marked; patella with a few vestigial carinae; chela smooth; internal side of patella with some vestigial granules; all sides weakly granular, almost smooth; movable fingers with six almost linear rows of granules; two accessory granules present at the base of each row; extremity of movable fingers with three accessory granules. Leg tarsus with very numerous fine median setae ventrally; tibial spurs weakly developed on legs III and IV.

\section{Ananteris kalina sp. $\mathrm{n}$.}

http://zoobank.org/B08E25E5-D903-4C47-94F8-508E5BE467EF Figs 4-5

Type material. French Guiana, Mana, path of the Forêt des Sables Blancs, one male (holotype), deposited in the MNHN, J. Chevalier coll., 13/I/2018. French Guiana, Mana, path of the Forêt des Sables Blancs, one male (paratype), deposited in the EYPC, EY0107, J. Chevalier \& B. Tan coll., 08/VII/2017. 


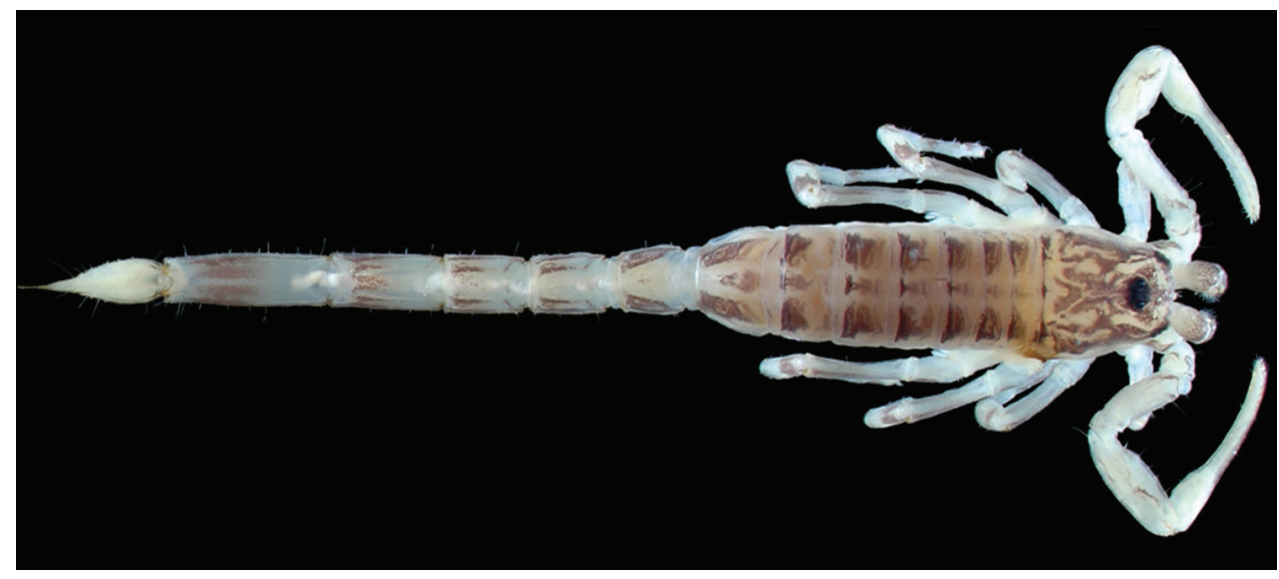

Figure 3. Ananteris intermedia, male holotype from St. Jean du Maroni (photo MNHN / E.-A. Leguin; 2012 Elsevier Masson SAS)

Etymology. The specific name refers to the ethnic group Kali'na, living in the area where the new species was found.

Diagnosis. Total length $18.9 \mathrm{~mm}$ for male holotype (see morphometric values after the description). General coloration dark yellow, intensely marked with brownish variegated spots. Chelicerae pale yellow with variegated dark brown spots over the entire surface. Fingers with six rows of granules. Pectines of males holotype and paratype rather long with 16-17 and 17-17 teeth, respectively; female unknown. Telson with a fusiform shape and strong and spinoid subaculear tubercle. Carinae and granulation moderately to strongly marked. Metasomal segments with 10-8-8-8-5 weakly crenulate carina. Trichobothriotaxy, type A- $\beta$.

Description based on male holotype. Coloration. Generally dark yellow with brown to dark brown variegated pigmented zones on the carapace, the tergites, and the appendages. Carapace dark yellow with dark brown spots on anterior, lateral and posterior edges; eyes surrounded by black pigment. Mesosoma dark yellow with confluent brown to dark brown zones forming three longitudinal stripes, one brownish surrounded by two reddish yellow ones. Venter yellow to pale yellow; coxapophysis and sternites with light brown zones on lateral edges. Metasomal segments I to V dark yellow with brown to dark brown variegated pigmented zones. Vesicle reddish yellow marbled with light brown zones; base of aculeus yellow, tip reddish. Chelicerae pale yellow with variegated dark brown spots over the entire surface; fingers yellowish with dark brown spots; teeth reddish yellow. Pedipalps yellowish, all segments almost entirely covered with brownish spots, dark brown on dorsal side and light brown on ventral side; tip of fingers pale yellow. Legs yellowish, intensely marked with brown to dark brown spots.

Morphology. Carapace with moderately to strongly marked granulation; anterior margin almost straight, with a small median concavity; anterior median superciliary 


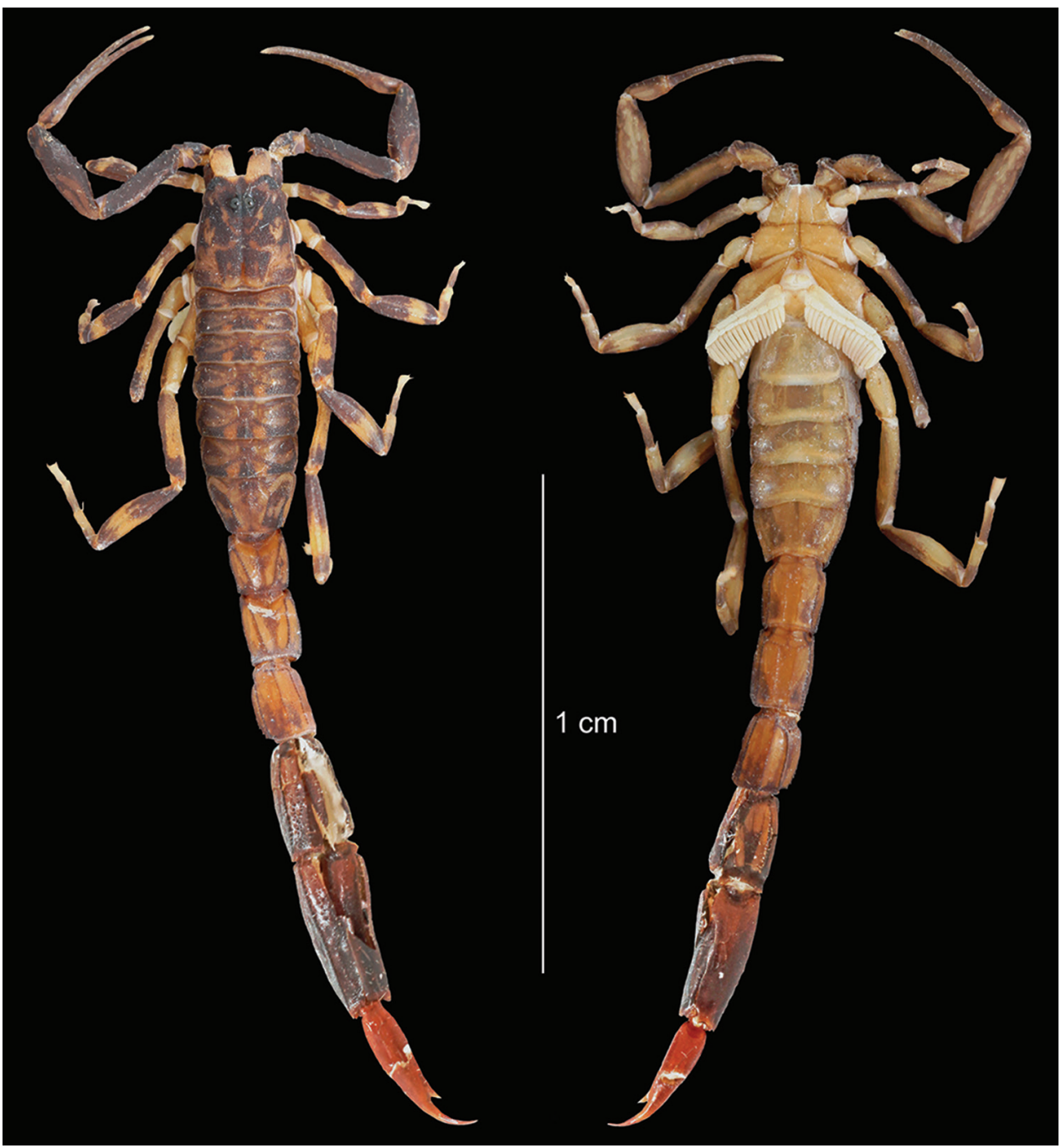

Figure 4. Ananteris kalina sp. n., male holotype from Mana. Habitus, dorsal and ventral aspect.

and posterior median carinae weak or absent; all furrows moderate to weak; median ocular tubercle distinctly anterior to the center of carapace; median eyes separated by approximately half of one ocular diameter; three pairs of reduced lateral eyes. Tergites with moderately to strongly marked granulation, similar to that of carapace; median carina moderately to weakly marked on all tergites, better marked posteriorly; tergite VII pentacarinate. Sternum subpentagonal. Pectines rather longs; pectinal tooth count 16-17 in male holotype (17-17 in male paratype); basal middle lamellae of pectines not dilated; fulcra absent. Sternites almost smooth, only VI and VII slightly granular; spiracles rather short, semi-oval; setation moderate; sternite VII with vestigial carinae; genital operculum divided longitudinally, each plate more or less suboval in shape. Metasomal segments with 10-8-8-8-5 weakly crenulate carinae; intercarinal spaces moderately to 

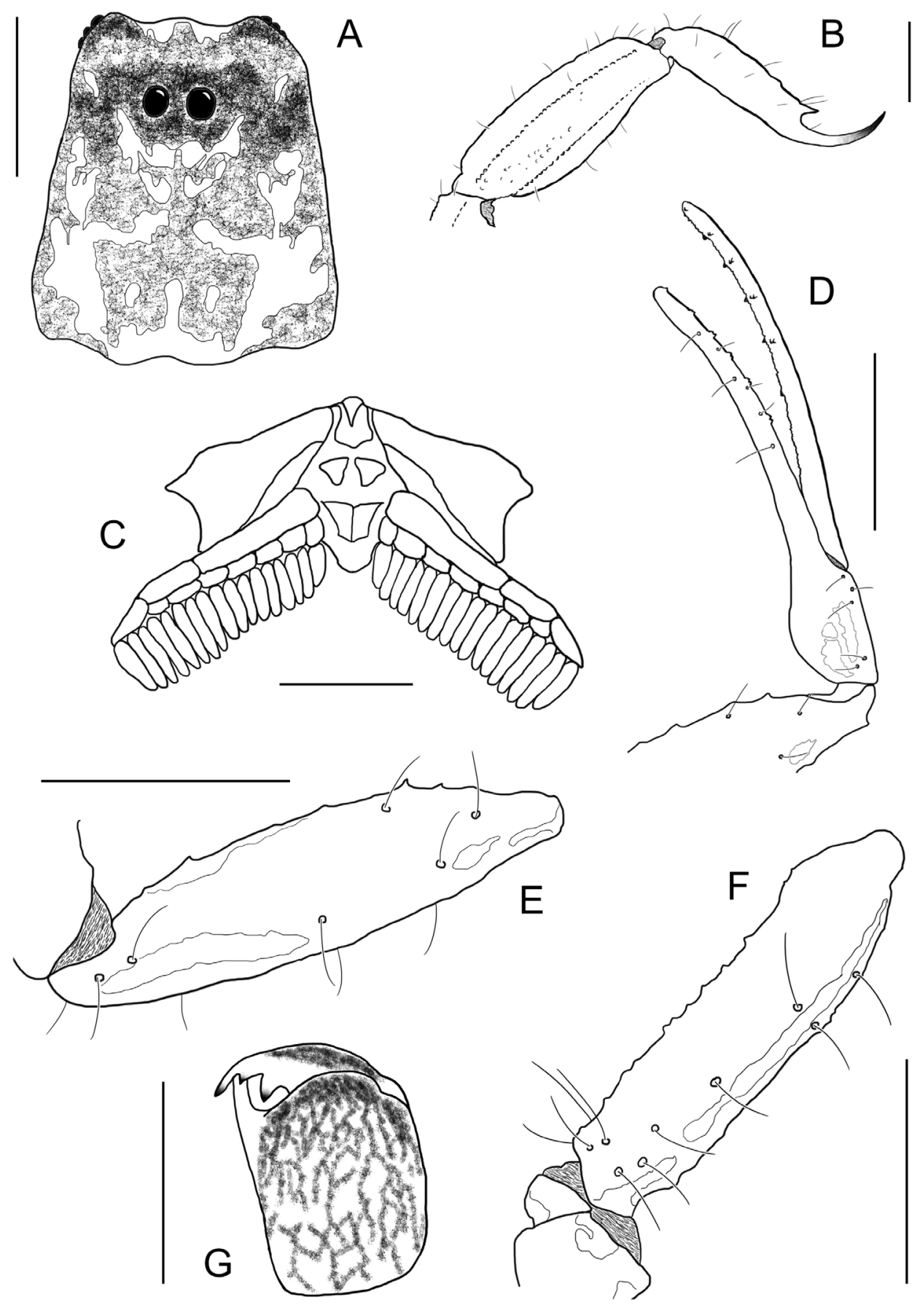

Figure 5. Ananteris kalina sp. n. male holotype. A Carapace B Metasomal segment V and telson, lateral aspect $\mathbf{C}$ Sternum, genital operculum, and pectines $\mathbf{D}$ Chela, dorso-external aspect E Patella, dorsal aspect F Femur, dorsal aspect $\mathbf{G}$ Chelicera. Scale bars: $1 \mathrm{~mm}$ except chelicera $(\mathbf{G}) 0.5 \mathrm{~mm}$. 
weakly granular; segment $\mathrm{V}$ slightly rounded and smooth. Telson with a fusiform shape, smooth; aculeus moderately long and weakly curved; subaculear tooth strong and spinoid. Pedipalp femur pentacarinate; patella and chela with weak to vestigial carinae, internal face of patella with some vestigial spinoid granules, all faces weakly granular, almost smooth; fixed and movable fingers with six rows of granules, two small external and one internal accessory granule present at the base of each row, three granules at the extremity of the fingers. Leg tarsus with very numerous, fine, median setae ventrally; tibial spurs strongly developed on legs III and IV. Cheliceral dentition characteristic of family Buthidae (Vachon, 1963); fixed finger with two strong basal teeth; movable finger with two vestigial basal teeth; ventral surface of both finger and manus with long, dense setae. Trichobothriotaxy of type A- $\beta$ (Vachon, 1974). Morphometric values (in $\mathrm{mm}$ ) of the male holotype. Total length including telson, 18.9. Carapace: length, 2.2; anterior width, 1.1; posterior width, 2.1. Mesosoma length, 5.1. Metasomal segments. I: length, 1.0; width, 1.2; II: length, 1.3; width, 1.1; III: length, 1.2; width, 1.1; IV: length, 1.8; width, 1.1; V: length, 3.1; width, 1.3; depth, 1.1. Telson: length, 3.2; width, 0.5; depth, 0.5. Pedipalp: femur length, 2.1, width, 0.4; patella length, 2.2, width, 0.5; chela length, 2.9, width, 0.3, depth, 0.3; movable finger length, 1.9.

Relationships. Ananteris kalina sp. n. can be readily distinguished from other species of the genus Ananteris and, in particular, from the three species occurring in the northern part of French Guiana, by the following main features:

- A. guyanensis Lourenço \& Monod, 1999 (described from Saint-Eugène (PetitSaut) and also found in Saut Sabbat (Mana)): (i) different pigmentation pattern on pedipalps and legs, (ii) chelicerae with variegated dark brown spots over the entire surface (uniformly yellow in A. guyanensis), (iii) metasomal segments with 10-8-8-8-5 carinae (10-10-10-8-5 in A. guyanensis).

- A. intermedia Lourenço, 2012 (described from Saint Jean du Maroni): (i) larger size (9.3 $\mathrm{mm}$ in total length for $A$. intermedia), (ii) subaculear tooth strong and spinoid (extremely reduced to vestigial in $A$. intermedia), (iii) metasomal segments with 10-8-8-8-5 carinae (10-10-8-8-5 in A. intermedia).

- A. elisabethae Lourenço, 2012 (described from Kourou): (i) darker general coloration (no spots or pigmented zones in A. elisabethae), (ii) chelicerae with variegated dark brown spots over the entire surface (uniformly yellow in A. elisabethae).

- The biotope where the new species occurs (coastal white-sand dry forest) is also different from biotope where other species of the genus are found in French Guiana (moist rainforest). The new species may be a possible endemic element of the white-sand coastal dry forest of Mana, French Guiana.

\section{Ananteris polleti Lourenço, 2016}

Fig. 6

References. Lourenço 2016b. 


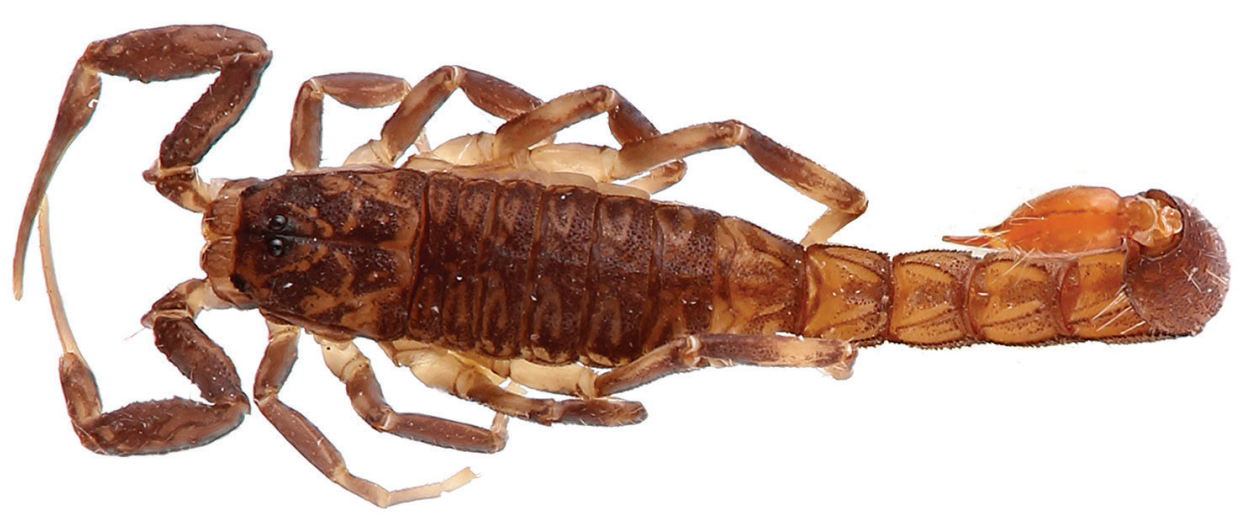

Figure 6. Ananteris polleti, male holotype from Mitaraka (photo MNHN / E.-A. Leguin; 2016 Elsevier Masson SAS).

Material. Mitaraka massif, $433 \mathrm{~m}$, tropical moist forest, in plateau, one male (holotype), deposited in the MNHN, MNHN/PNI Guyane 2015 (APA 973-1), M. Pollet coll., 2-8/III/2015. Mitaraka massif, $352 \mathrm{~m}$, tropical moist forest, in slope, one male (paratype), deposited in the MNHN, MNHN/PNI Guyane 2015 (APA 973-1), M. Pollet coll., 25/II/2015-3/III/2015.

Diagnosis. Species of small size compared to the average size of the other species within the genus ( $14.7 \mathrm{~mm}$ in total length for male holotype). General coloration yellow to brownish yellow with brown to dark brown variegated pigmented zones on the carapace, the tergites, and the appendages. Carapace yellow with dark brown spots on anterior, lateral and posterior edges; eyes surrounded by black pigment. Mesosoma yellow with confluent brownish zones on posterior and lateral edges of tergites. Venter yellow to pale yellow; coxapophysis and sternites infuscate. Metasomal segments I to V yellow; all segments marked with diffused brown spots. Vesicle yellow marbled with light brown zones; base of aculeus yellow, tip reddish. Chelicerae yellow with variegated blackish spots over the entire surface; fingers with blackish spots; teeth yellow. Pedipalps yellow; femur, patella, and chela strongly marked with dark brown spots; chela hand and fingers dark brown. Legs yellow, intensely marked with dark brown spots. Carapace with moderately to strongly marked granulation; anterior margin almost straight; all furrows moderate to weak. Tergites with moderately to strongly marked granulation, similar to that of carapace; median carina moderately to weakly marked on all tergites. Pectines small; pectinal tooth count $11-11$ to $12-12$ in male. Sternites smooth; only VII slightly granular; spiracles rather short; setation moderate; sternite VII with very weakly marked carinae and granulation. Metasomal segments I to III with ten crenulate carinae; segment IV with eight crenulate carinae; segment $V$ slightly rounded and smooth, with vestigial carinae; intercarinal spaces moderately granular on all segments; dorsal and laterodorsal carinae on segments II to IV with 3-4 posterior spinoid granules. Telson elon- 
gate and smooth; aculeus short and weakly curved; subaculear tooth strongly marked and spinoid. Pedipalps moderately short; femur pentacarinate; patella and chela with weak to vestigial carinae; internal side of patella with only vestigial spinoid granules; all sides weakly granular, almost smooth; fixed and movable fingers with six, almost linear, rows of granules; two small external and one internal accessory granule present at the base of each row; three granules at the extremity of the fingers. Leg tarsus with very numerous, fine, median setae ventrally; tibial spurs strongly developed on legs III and IV.

\section{Ananteris sabineae Lourenço, 2001}

Fig. 7

References. Lourenço 2001b, Lourenço 2003a, Lourenço 2016 b.

Material. Upper Ouarimapan river, trailhead camp of sentier indien, one female (holotype), MNHN-RS-6272, J. P. Gasc coll., VII/1972. Mitaraka Massif, layon D, in slope, winkler, one female, deposited in the MNHN, MNHN/PNI Guyane 2015 (MI15-0237-36), J. Orivel \& F. PetitClerc coll., 23/II/2015-11/III/2015.

Diagnosis. Species of medium size when compared with the average size of the other species of the genus $(27.7 \mathrm{~mm}$ in total length for female holotype). General coloration basically brownish yellow, symmetrically marbled with dark reddish brown, producing an overall spotted appearance. Carapace dark yellow, almost totally covered with brown spots; eyes surrounded by black pigment. Mesosoma yellowish brown with confluent brown stripes and two diffused longitudinal yellowish stripes. Venter yellowish; sternite VII reddish yellow. Metasomal segments I to IV reddish yellow, with a few brown spots; segment $\mathrm{V}$ reddish brown, with less marked spots. Vesicle reddish yellow without spots. Chelicerae yellowish without any spots over their entire surface; fingers reddish brown. Pedipalps yellowish with a few diffused spots better marked on the femur; chelae darker than patella; fingers yellowish with the rows of granules slightly reddish. Legs yellowish with diffused spots, better marked than on pedipalps. Carapace moderately granular; anterior margin with a slight median concavity; all furrows moderate to feeble. Tergites moderately granular; median carina moderate in all tergites. Pectinal tooth count 19-18 in female. Sternites smooth with moderately elongate stigmata; VII granulated with vestigial carinae. Metasomal segments with 10-8-8-8-5 crenulate carinae; intercarinal spaces moderately to weakly granular. Telson moderately granular with three ventral carinae and with a fairly short and moderately curved aculeus; subaculear tooth strong and spinoid. Pedipalp femur pentacarinate; patella and chelae with a few vestigial carinae; internal side of patella with eight to nine spinoid granules; all sides feebly granular, almost smooth; movable fingers with seven oblique rows of granules; two accessory granules present at the base of each row. Leg tarsus with very numerous fine median setae ventrally; tibial spurs strongly developed on legs III and IV. 


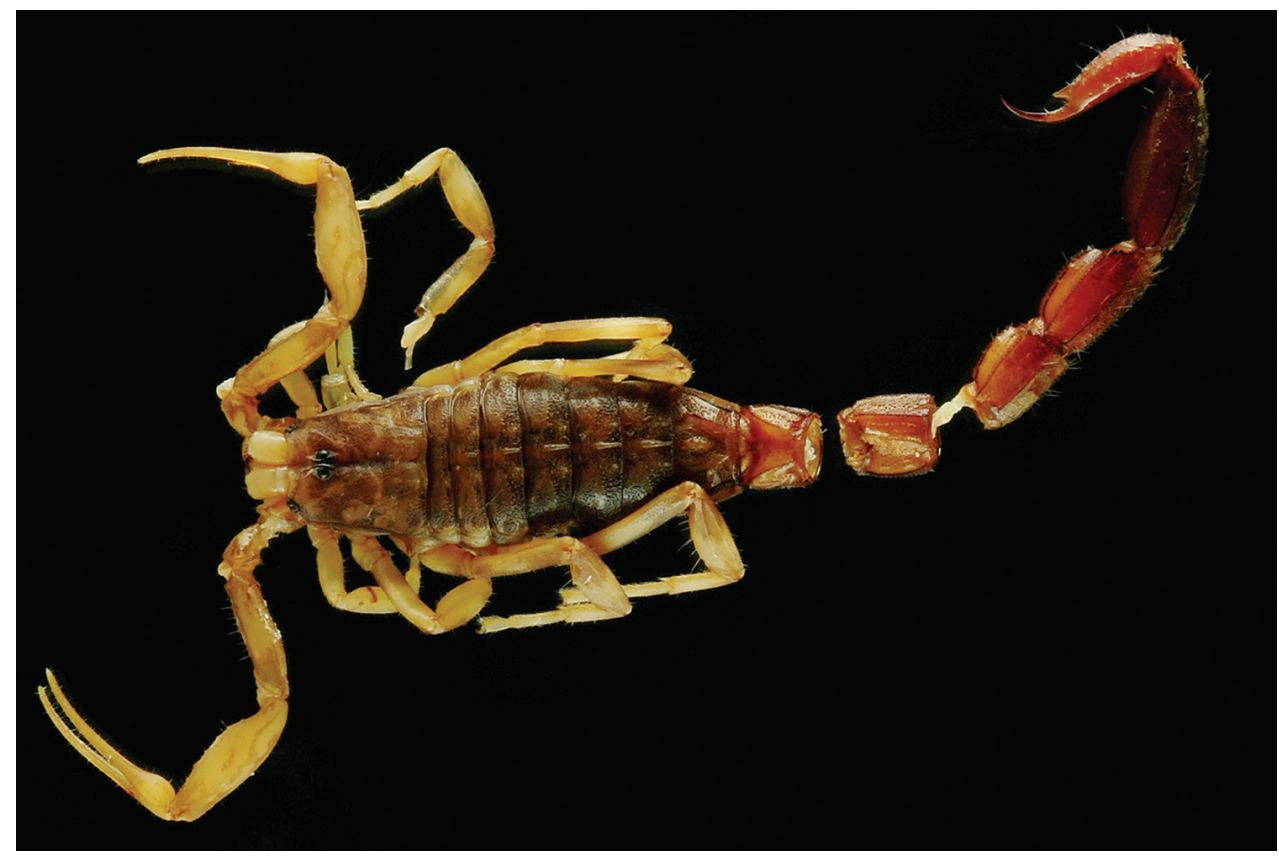

Figure 7. Ananteris sabineae, female holotype from upper Ouarimapan river (photo MNHN / E.-A. Leguin).

\section{Genus Isometrus Hemprich \& Ehrenberg, 1828}

\section{Isometrus maculatus (DeGeer, 1778)}

Fig. 8

References. DeGeer 1778, Lourenço 1983, Fet et al. 2000.

Material. Cayenne, four males and three females, MNHN-RS-0899, M. Richard coll. Cayenne, one male and two females, MNHN-RS-3315, E. Abonnenc coll. Charvein-Maroni river, one male, MNHN-RS-3323, F. Geay coll., 1903. Coswine river, under rotten wood, one female, MNHN-RS-8299, J. Fretey coll., 16/V/1977. Morne-Cépéron, one male, MNHN -RS-3324, F. Geay coll., 1902. St. Jean du Maroni, two males, three females and two immatures, MNHN-RS-3322, R. Benoist coll., 1914. St. Jean du Maroni, one male, MNHN-RS-7286, F. Geay coll., 1903. Disputed area between Oyapock and Amapa, one female, MNHN-RS-0925. D. Villecourt coll., 1899. Disputed area between Oyapock and Amapa, one male, MNHN-RS-0914, F. Geay coll., 1899. Disputed area between Oyapock and Amapa, five males, sic females and one immature, MNHN-RS-0893, Lafon coll., 1872.

Diagnosis. Species of medium to large size when compared with the average size of the other species of the genus, ranging from $50.1 \mathrm{~mm}$ (female) to $61.2 \mathrm{~mm}$ (male) in total length. General coloration yellowish to pale yellow, symmetrically marbled with blackish brown spots in both adults and juveniles. Carapace yellow- 


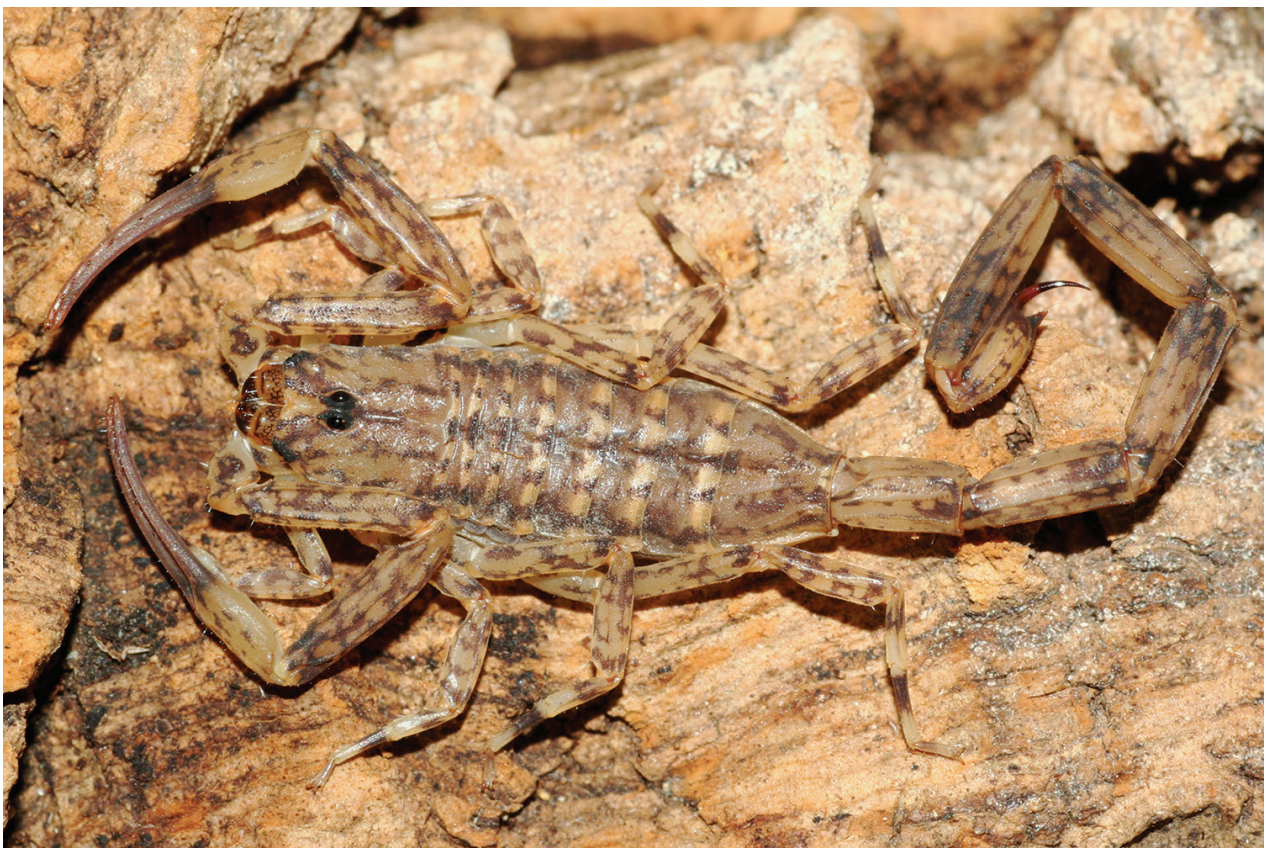

Figure 8. Isometrus maculatus, female from St. Jean du Maroni.

ish with blackish brown patterns; eyes surrounded by black pigment. Mesosoma yellowish with symmetrical blackish brown stripes. Venter yellowish; sternites IIIVII with symmetrical brown spots. Metasomal segments pale yellow, with some diffuse, brownish spots. Vesicle pale yellow with basis of aculeus yellowish and tip of aculeus reddish brown. Chelicerae pale yellow with brownish variegated spots; base of fingers pale yellow, rest of fingers blackish brown, teeth reddish. Pedipalps pale yellow with brownish spots; chela fingers reddish brown; rows of granules on dentate margins of fingers dark reddish. Legs yellowish with diffuse spots. Carapace coarsely granular with a few smooth patches; anterior margin strongly emarginated, with an open $\mathrm{V}$-shaped angle; carinae weakly developed. Tergites moderately granular; median carinae weak to moderate on I-VI, tergite VII with two lateral pairs of carinae moderate to strong. Pectinal tooth count ranging from 16-19 in male and 17-19 in female. Sternites smooth and shiny, VII with four granular carinae. Metasomal segments with 10-10-8-8-5 crenulate carinae; intercarinal spaces very weakly granular to smooth. Telson very weakly granular, almost smooth, with one vestigial ventral carina; subaculear tubercle marked and triangular, with two granules on the ventral surface. Pedipalp femur with all carinae crenulate; patella with seven crenulate carinae; chela with vestigial carinae; dentate margins of fixed and movable fingers with six linear rows of granules. Leg tibia with few setae, without spurs; basitarsus with some setae and two lateral pedal spurs; tarsus ventrally with two rows of short setae. 


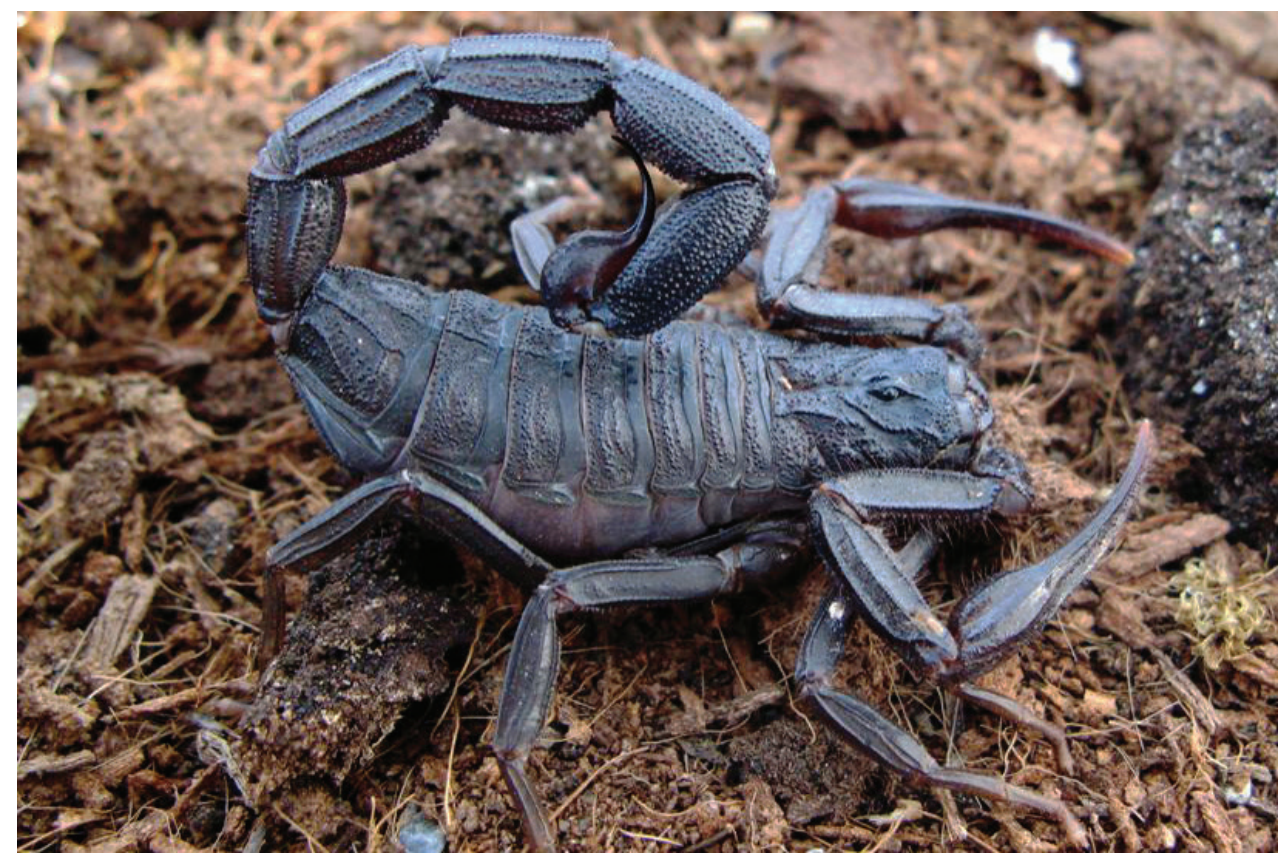

Figure 9. Jaguajir pintoi kourouensis, female from Kourou (photo G. Molisani).

\section{Genus Jaguajir Esposito, Yamaguti, Souza, Pinto da Rocha \& Prendini, 2017}

Jaguajir pintoi kourouensis (Lourenço, 2008)

Fig. 9

References. Lourenço 1986, Lourenço and Pinto-da-Rocha 1997, Fet et al. 2000, Lourenço 2008, Esposito et al. 2017.

Material. Region of Kourou, forest patches of Degrad path, one male (holotype), MNHN-RS-8631, mission M. Boulard \& P. Pompanon coll., VIII/1975.

Diagnosis. Large scorpion in relation to the species of the genus, with 89.7 $\mathrm{mm}$ in total length for the male holotype. Very dark coloration, uniformly blackish. Carapace and mesosoma blackish. Venter dark reddish to blackish. Metasomal segments I to V blackish. Vesicle dark reddish to blackish. Chelicerae dark reddish with a blackish thread; fingers dark. Pedipalps blackish; fingers reddish. Legs dark reddish, intensely spotted with blackish. Carapace strongly granular; anterior margin with a median concavity; anterior median and posterior median carinae strong; all furrows moderately deep. Tergites strongly granular; median carina strong in all tergites; tergite VII pentacarinate. Sternum triangular. Pectinal tooth count 24-25 in male. Sternites smooth with elongate spiracles; VII with four carinae and some lateral granulations. Metasomal segments I and II with ten carinae; III and IV with eight carinae; V with five carinae; inframedian carinae complete on II. Telson weakly 
granular, with a long and strongly curved aculeus; dorsal surface smooth; ventral surface granular; subaculear tooth absent. Pedipalp femur pentacarinate; patella with seven carinae; chela with nine carinae; internal side of patella with spinoid granules; all sides moderately to weakly granular; a very intense chaetotaxy can be observed in all segments; fixed and movable fingers with 9-10 oblique rows of granules; internal and external accessory granules strongly marked. Leg tarsus ventrally with numerous short fine setae.

\section{Genus Microananteris Lourenço, 2003}

\section{Microananteris minor Lourenço, 2003}

References. Lourenço 2003b, Botero-Trujillo and Noriega 2011, Lourenço 2012c.

Material. Central region, near the village of Saül, two $\mathrm{km} \mathrm{SW}$ of the air field, dense humid forest at low altitude, in organic soil, extracted from Berlese method, one female (holotype), MNHN-RS-8602, J.M. Betsch leg., 19/III/1999.

Diagnosis. Very small species when compared with the average size of most species of micro-buthid genera (11.7 mm in total length for female holotype). General coloration brownish yellow, symmetrically marbled with darker brown, producing an overall spotted appearance. Carapace yellowish, almost totally covered with brown spots; eyes surrounded by black pigment. Mesosoma yellowish brown with confluent brown stripes. Venter pale yellow. Metasomal segments I to V yellowish, with several pale brown spots; segment $\mathrm{V}$ with more marked spots. Vesicle yellowish with pale brownish spots laterally and ventrally; aculeus reddish. Chelicerae yellowish with variegated spots over their entire surface; more marked anteriorly; fingers yellowish with reddish teeth. Pedipalps yellowish densely marked with brownish spots better marked on the femur and patella; chela paler than patella; fingers brownish with the rows of granules slightly reddish. Legs yellowish, densely marked with brownish spots. Carapace moderately granular; anterior margin with a very slight median concavity, almost straight; all furrows moderate to weak. Tergites moderately to weakly granular; median carina moderate to weak in all tergites; tergite VII pentacarinate. Sternum subpentagonal. Pectines very small; pectinal tooth count 10-10 in female. Sternites smooth with short semi-oval spiracles; VII with a few granulations and vestigial carinae. Metasomal segments with 10-10-10-8-5 crenulate carinae; intercarinal spaces moderately to weakly granular. Telson with a pear-like shape, almost smooth with three ventral carinae; aculeus very short and moderately curved; subaculear tooth strong and almost rhomboid. Pedipalp femur pentacarinate; patella and chela with a few vestigial carinae; internal side of patella with some vestigial granules; all sides feebly granular, almost smooth; movable fingers with 6/7 almost linear rows of granules; two accessory granules present at the base of each row; extremity of movable fingers with three accessory granules. Leg tarsus with very numerous fine median setae ventrally; tibial spurs developed on leg IV but reduced on leg III. 


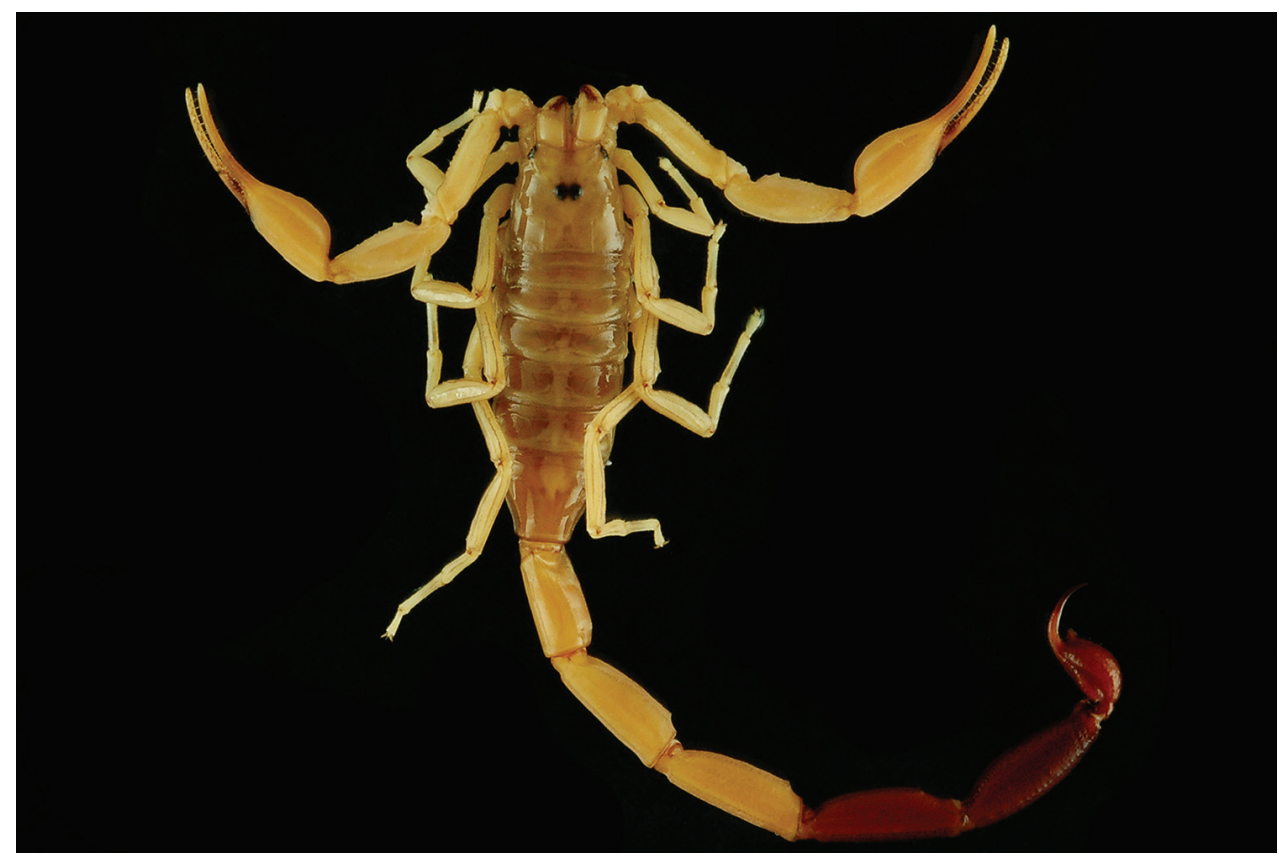

Figure 10. Tityus gasci, male holotype from Inini region (photo MNHN / E.-A. Leguin).

\section{Genus Tityus C. L. Koch, 1836}

\section{Tityus (Tityus) gasci Lourenço, 1981}

Fig. 10

References. Lourenço 1981, Lourenço 1983, Fet et al. 2000, Lourenço 2008.

Material. Inini region, between Maripasoula and Antecume-Pata, one male (holotype), MNHN-RS-7921, J.P. Gasc coll., VII-IX/1972, leg., 1975.

Diagnosis. Species of medium size compared to the average size of the other species of the genus, with a total length of $63.4 \mathrm{~mm}$ for the male holotype. General coloration yellowish. Carapace yellowish with some shades of brownish; eyes surrounded with black pigment. Tergites yellowish with confluent pale yellow zones on tergites, making an incomplete rhomb on the tergite VII. Sternites dark yellow with a lighter triangular area on the posterior part of sternite $\mathrm{V}$; sternum, genital operculum and pectines yellow ochre. Metasomal segments I to III yellowish, IV and V dark reddish. Vesicle dark reddish with basis of aculeus reddish yellow and tip of aculeus reddish black. Chelicerae yellowish with reddish teeth. Pedipalp femur and patella yellowish; chela reddish yellow with reddish fingers; base of movable finger dark, almost black. Legs yellowish with blackish pigment on carinae. Anterior margin of carapace moderately emarginated; carapace carinae weakly developed; anterior median carinae weak; intercarinal spaces weakly granular, almost smooth. Tergites almost smooth with only few granules on posterior area; tergites I-VI with one very weakly marked median carina; tergite VII 
pentacarinate with weakly marked carinae. Pectinal tooth count 17-18 in male; basal middle lamella not dilated. Sternites with spiracles almost linear. Metasomal segments with 10-10-8-8-5 weakly marked carinae; dorsal carinae of segments I to IV with one distal slightly spinoid granule; intercarinal spaces almost smooth. Telson with aculeus almost as long as the vesicle, strongly curved; subaculear tubercle well developed, with two dorsal teeth. Pedipalp femur pentacarinate; patella with seven carinae; chelae with nine carinae; dentate margins of fixed and movable fingers composed of 15-15 rows of granules.

\section{Tityus (Archaeotityus) mana Lourenço, 2012}

Fig. 11

References. Lourenço 1984, Lourenço 1992, Fet et al. 2000, Lourenço 2012 d.

Material. Path between Mana and Les Hattes, very sandy soil, one male (holotype), MNHN-RS-8084, M. Boulard \& P. Pompanou coll., 8/VIII/1975. Mana, Organabo river, one female and one male, deposited in the RNA, J. Chevalier \& Q. Uriot coll., 28/VII/2017. East Couachi, Organabo road, dry forest, one female (paratype), deposited in the MNHN, W. Lourenço coll., 22/VI/1987. Awala Yalimapo, Kanawa path, two males and one immature, deposited in the RNA, J. Chevalier coll., 03/ VIII/2017. Awala Yalimapo, RNA path, three females and three immatures, deposited in the RNA, J. Chevalier coll., 01/IX/2017. Sinnamary, path of the Pripris de Yiyi, seven females and two immatures, deposited in the RNA, J. Chevalier \& P. Gallier coll., 05/VIII/2017. Iracoubo, Savanne Grand Macoua, one female and one male, deposited in the RNA, J. Chevalier \& Q. Uriot coll., 28/VII/2017. Iracoubo, sand quarry Moticase, one female and one male, deposited in the RNA, J. Chevalier \& Q. Uriot coll., 28/VII/2017.

Diagnosis. Small to moderate species when compared with the average size of the other species of the genus, ranging from $29.9 \mathrm{~mm}$ (male) to $38.5 \mathrm{~mm}$ (female) in total length. General coloration yellowish to pale yellow with only residual variegated pale brown spots over the body and appendages. Carapace yellowish with residual spots on the posterior and central zones; eyes surrounded with black pigment. Mesosoma yellowish with pale brown variegated spots on the posterior margins of tergites. Venter yellowish; sternites yellowish with pale brown variegated spots on the posterior margins; sternum, genital operculum and pectines pale yellow. Metasomal segments I to IV yellowish, V reddish yellow, with dark spots laterally and ventrally. Vesicle reddish to dark reddish; aculeus reddish. Chelicerae yellowish with variegated dark brown spots on the front part; fingers yellowish with dark brown spots at their basis; teeth

reddish. Pedipalps yellowish with only some vestigial spots on the femur and patella of male. Legs yellowish with residual variegated spots on all segments. Anterior margin of carapace only moderately emarginated; carapace carinae weakly developed; all furrows weak; intercarinal spaces weakly granular. Tergites I-VI with one moderately marked median carina; tergite VII pentacarinate, lateral pairs of carinae moderately marked, 


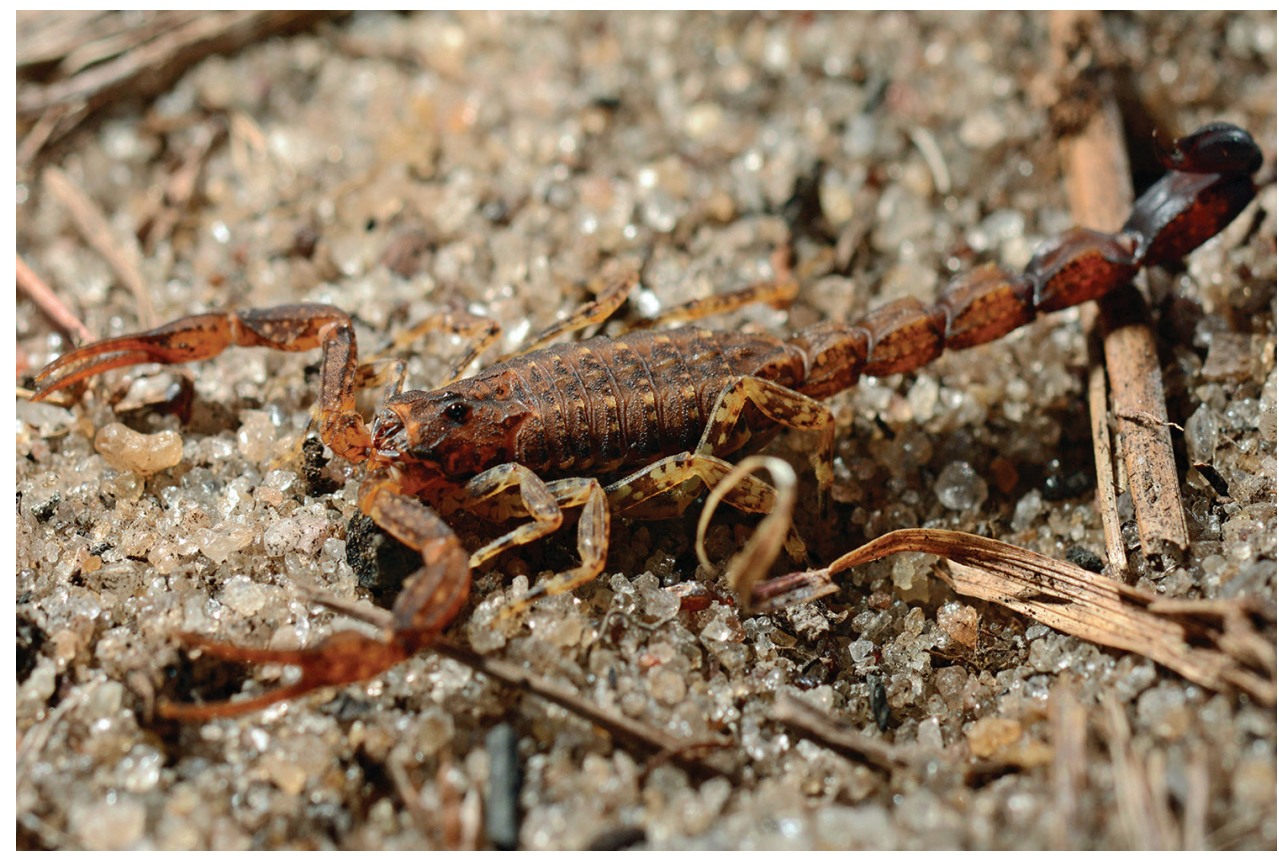

Figure I I. Tityus mana, female from Awala Yalimapo (photo J. Chevalier).

median carinae marked only on proximal third; intercarinal spaces weakly granular. Pectines small with moderate fulcra; basal middle lamella not dilated in female; pectinal tooth count ranging from 16-17 in male and 14-17 in female. Sternites surface with a residual granulation, almost smooth; carinae absent on III-VI, four weak to moderate carinae on VII; spiracles slit-like but short. Metasomal segments with 10-108-8-5 carinae; dorsal carinae of segments I to IV with one strong distal spinoid granule, better marked in female; intercarinal spaces weakly granular. Telson smooth in males; with one ventral and four vestigial lateral carinae in the female; aculeus shorter than vesicle, moderately curved; subaculear tubercle short and strongly rhomboid, with two dorsal teeth. Pedipalp femur pentacarinate; all carinae moderately to strongly crenulate; patella with seven carinae; internal carina with strong spinoid granules; chelae with 8-9 strongly marked carinae; all sides weakly granular; carinae and granules better marked in female; dentate margins of fixed and movable fingers composed of 13-14 oblique rows of granules. Ventral aspect of leg tarsi with numerous thin setae; tibial spurs absent; pedal spurs present but vestigial in all legs.

\section{Tityus (Atreus) obscurus (Gervais, 1843)}

Figs $12-13$

References. Gervais 1843, Pocock 1897, Lourenço 1983, Lourenço 1997b, Fet et al. 2000, Lourenço 2002a, Lourenço and Leguin 2008, Stockmannn and Ythier 2010. 


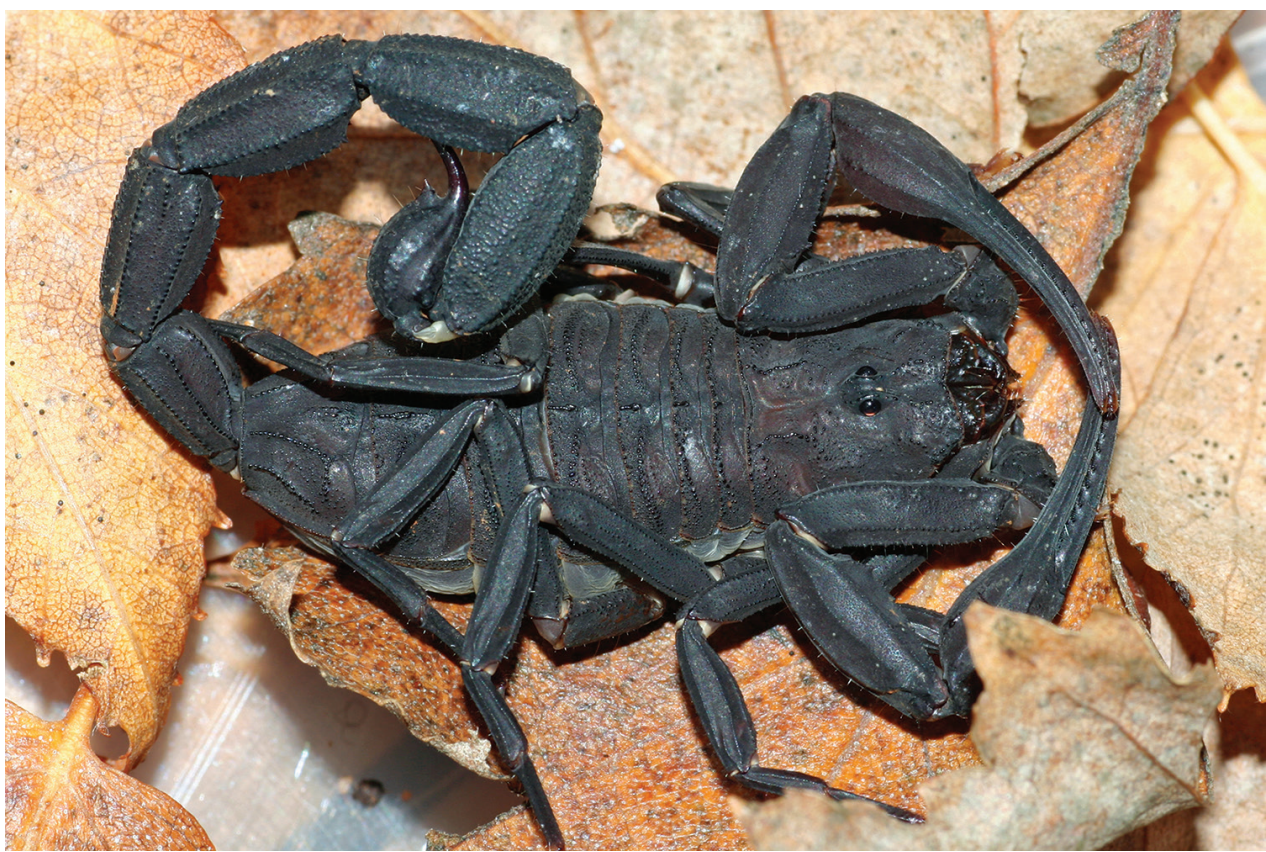

Figure 12. Tityus obscurus, adult female from Cayenne.

Material. Cayenne, one adult female (lectotype) and one immature female (paralectotype), MNHN-RS-3298, Mr. Leschenault \& Mr. Doumerc coll. Cayenne, one female, MNHN-RS-0855, Noirot coll., 1890. Cayenne, one male and one female, MNHN-RS-0861, M. Melinon coll., 1877. Cayenne, three females, MNHN-RS-3297, M. Melinon coll., 1876. Cayenne, two females, MNHN-RS-3299, R. Pinchon leg., 1953. Cayenne, three males, MNHN-RS-3314, E. Abonnenc coll., two males, MNHN-RS-3317, E. Abonnenc coll., Inst. Pasteur leg. Cayenne, Montabo, in forest, one female, MNHN-RS-3319, III/1949. Cayenne, caught from a cat in a house, one female, MNHN-RS-3321, D. Destombes coll., VI/1950. Cayenne, one female, MNHN-RS-3325, F. Geay coll., 1902. Cayenne, one female, MNHN-RS-0846, St. Laurent coll., 1899. Border with Para, one male and one female, MNHN-RS-3286, 1900. Cayenne, Mt. St. Martin, forest, one female, MNHN-RS-7926, D. Quintero coll., 10/XII/1972. Cayenne, one male, MNHN-RS-8081, M. Condamin leg., 25/ VI/1976. Cayenne, Mont Bourda, one immature, deposited in the RNA, J. Chevalier $\&$ B. Tan coll., 09/VII/2017. Cayenne region, one male, deposited in the MHNG, Freitag leg., IX/1987. Amarone-Baraquin, one male and one female, MNHN-RS-0849, 1900. Antecume-Pata, in forest, one female, MNHN-RS-6268, J.P. Gasc coll., 18/ VII/1972. Antecume-Pata, in forest, one female, MNHN-RS-6269, J.P. Gasc coll., 18/VII/1972. Antecume-Pata, one female, MNHN-RS-7918, J.P. Gasc leg., 1975. Antecume-Pata, one male, MNHN-RS-7919, J.P. Gasc leg., 1975. Antecume-Pata, one female, MNHN-RS-7920, J.P. Gasc leg., 1975. Downstream from Saut Pararé on Arataye river, Approuague tributary, two males and one female, MNHN-RS-7389, 
J.P. Gasc coll., IV-V/1979. Downstream from Saut Pararé on Arataye river, Approuague tributary, one male, MNHN-RS-7391, J.P. Gasc coll., IV-V/1979. Camopi, Oyapock valley, one male and one female, MNHN-RS-3393, mission E. Aubert de la Rüe coll., 18/XII/1948. Upper Approuage, in forest, one male, MNHN-RS-3301, III/1946. Upper Oyapock, between Mount Orière and Dégrad Galoupa, two females, MNHN-RS-3310, mission E. Aubert de la Rüe coll., 1948-49. Kaw, one female, MNHN-RS-8296, J. Lescure coll., 27-30/IV/1977. Mitaraka Massif, hand catch, one male, two females and one immature female, deposited in the MNHN, MNHN/ PNI Guyane 2015, E. Poirier, P.H. Dalens \& J. Touroult coll., 11-18/III/2015. Mitaraka Massif, camp, layon $\mathrm{D}$, tropical moist forest, in plateau, winkler, two females, deposited in the MNHN, MNHN/PNI Guyane 2015, J. Orivel \& F. PetitClerc coll., 23/II/2015-11/III/2015. Apatou, Crevette river, one male, one female and one immature male, deposited in the RNA, J. Chevalier \& P. Gallier coll., 30/VI/2017. Sinnamary, path of the Canceler river, under a palm tree's bark, one female and one male, deposited in the RNA, J. Chevalier \& P. Gallier coll., 05/VIII/2017. Iracoubo, Savanne Grand Macoua, one female, deposited in the RNA, J. Chevalier \& Q. Uriot coll., 28/VII/2017. Mounts of Montsinery, one female, MNHN-RS-5252, F. Geay coll., II/1902. Oyapock, two males, MNHN-RS-0845, F. Geay coll., 1900. Oyapock, one female, MNHN-RS-0862, F. Geay coll., 1900. Oyapock, one male, MNHNRS-3305, mission E. Aubert de la Rüe coll., 1/XII/1948. Saül, one male and three females, MNHN-RS-5286, Balachowsky leg., 27/X/1969. Saül, Gros Arbres trail, one female, deposited in the RNA, J. Chevalier coll., 23/VIII/2017. Saül, Belvédère, one juvenile, deposited in the RNA, J. Chevalier coll., 21-22/VIII/2017. Saut Sabbat, one female, MNHN-RS-8208, D. Kopp coll., 8/VII/1976. Saut Sabbat, one immature female, deposited in the MNHN, E. Ythier coll., 03-11/XI/2010. St. Jean du Maroni, one female, MNHN-RS-0856, R. Benoist coll., 1914. Yanioué, upper Oyapock, upper Camopi, upstream waterfall, one male, MNHN-RS-3295, mission E. Aubert de la Rüe coll., II/1949. Cacao, four males and one immature, deposited in the MHNG, Chippaux leg., X/1983. Cacao, one male, deposited in the MHNG, W. Lourenço leg., II/1989. Cacao, one male, deposited in the MHNG, P. Soler leg., I/1992. Kourou, one male, deposited in the MHNG, R. Garrouste leg., 16/II/1995. Kourou, one male, deposited in the MHNG, Freitag leg., 9/X/1987. Petit-Saut, in canopy with radeau des cimes, one immature female, deposited in the MHNG, H.P. Aberlenc coll., 4/XI/1989. Trinité reserve, Aya river, pitfall trap, one immature female, deposited in the MNHN, C. Courtial coll., X/2009. Trinité reserve, Aya river, one immature male, deposited in the MNHN, C. Courtial coll., X/2008. Trinité reserve, Aya River, two males and one female, deposited in the MNHN, C. Courtial coll., XII/2010. Matoury, one male and one immature, deposited in the EYPC, EY0042, E. Ythier coll., 03-11/XI/2010. Salobroc, two immatures, MNHN-RS-0812. Guyane, three females, MNHN-RS-0810, M. Lafon coll., 1872. Guyane, two males and one female, MNHN-RS-0844, G. Dewer coll., 1897. Guyane, one female, MNHN-RS-0850, Viguier coll., 1877. Guyane, one female, MNHN-RS-8250, D. Kopp coll., 3/VII/1976. Between Oyapock and Amapa (disputed area), one female, MNHN-RS-0852, Villecourt coll., 1899. 


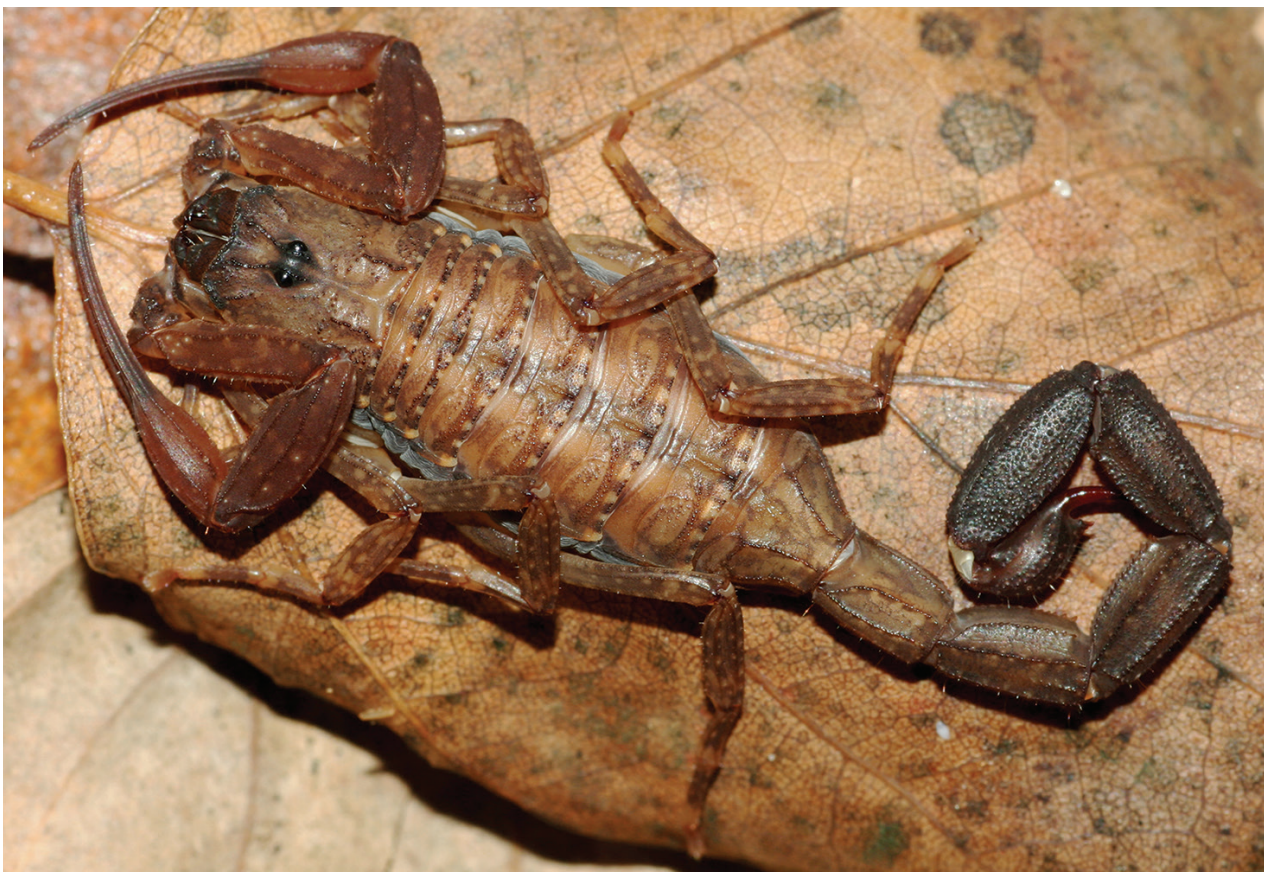

Figure 13. Tityus obscurus, juvenile from Saut Sabbat.

Between Oyapock and Mount Sociat-Marcel, on the ground, base camp, river bank, Eleuponsin, one female, MNHN-RS-8076, J. P. Gasc coll. III/1976. Paranama, one female, MNHN-RS-8251, D. Kopp coll., 3/VII/1976. Franco-brazilian region, two females, MNHN-RS-0839, F. Geay coll., 1899. Le Para (?), five males and five females, MNHN-RS-0854.

Diagnosis. Species of large size when compared with the average size of the other species within the genus, ranging from 75.7 to $100 \mathrm{~mm}$ in total length. General coloration uniformly dark brown to blackish. Carapace and mesosoma uniformly dark brown to blackish. Sternites with some pale zones; a triangular smooth testaceous area on the middle of the posterior border of the sternite III; pectines testaceous. Metasomal segments I to $\mathrm{V}$ and telson uniformly dark brown to blackish. In most cases the juvenile instars are yellowish or reddish yellow, with very numerous variegated spots, these spots being not visible in the adults as a result of the very marked sclerification of the cuticle. Chelicerae yellowish with variegated dark brown spots over the entire surface; fingers brownish; teeth dark reddish. Pedipalps dark reddish; chela fingers dark brown to blackish with tip yellowish. Legs yellowish almost entirely covered with brownish spots, except on telotarsus. Number of pectine teeth ranging from 18 to 22 teeth in both sexes; the basal middle lamellae strongly dilated in females. Metasomal segments I and II with ten carinae; segments III and IV with eight carinae; segment $\mathrm{V}$ with five carinae. Telson with a strong spinoid subaculear 
tooth present that can be moderate in size or almost totally absent in very large specimens. Dentate margins of pedipalp chela fixed and movable fingers with 15-17 oblique rows of granules. Very strong sexual dimorphism; male pedipalps are longer and more slender than those of the females; metasoma of the male is also longer than the one of the female.

\section{Tityus (Archaeotityus) silvestris Pocock, 1897}

Fig. 14

References. Pocock 1897, Lourenço 1983, Lourenço 1984, Lourenço 1988a, Lourenço 1992, Lourenço 1997b, Fet et al. 2000, Lourenço 2002a, Lourenço 2008, Stockmannn and Ythier 2010.

Material. Downstream from Saut Pararé on Arataye River, Approuague tributary, one male, MNHN-RS-7390.1, J.P. Gasc coll., IV-X/1979. Ilet la Mère, one female, MNHN-RS-8298, J. Lescure coll., 25/VII/1977. St. Jean du Maroni, one female, MNHN-RS-3322, R. Benoist coll., 1914. Cacao, one male, deposited in the MHNG, Chippaux coll., X/1983. Mitaraka Massif, $433 \mathrm{~m}$, tropical moist forest, in plateau, one male, deposited in the MNHN, MNHN/PNI Guyane 2015 (APA 973-1), M. Pollet coll., 2-8/III/2015. Mitaraka Massif, pointe Macaria, hand catch, one female, deposited in the MNHN, MNHN/PNI Guyane 2015 (APA 973-1), E. Poirier, P.H. Dalens $\&$ J. Touroult coll., 24-27/II/2015. Saül, Popote Kanawa, one immature, deposited in the RNA, J. Chevalier coll., 24/VIII/2017. Cayenne, Mont Bourda, two females and six immatures, deposited in the RNA, J. Chevalier coll., 09/VII/2017. Disputed area between Oyapock and Amapa, one female, MNHN-RS-0820, D. Villecourt coll., 1899.

Diagnosis. Small to moderate species when compared with the average size of the other species of the genus, with a very variable size ranging from 25 to $45 \mathrm{~mm}$ in total length. General coloration yellowish to pale yellow densely spotted with brownish to blackish pigmentation. Carapace yellowish with brownish yellow pigmentation and brownish spots; a conspicuous bright yellow T-shaped mark on the anterior part. Tergites yellowish with brownish yellow pigmentation and brownish spots. Sternites yellowish with brownish spots. Metasomal segments I-III yellowish with brownish spots, IV and V reddish yellow. Vesicle reddish brown; aculeus reddish brown at the base and blackish at the tip. Pedipalps yellowish with brownish spots; chela fingers reddish yellow. Legs yellowish with brownish spots. This species presents a very complex pattern of polymorphism. Number of pectine teeth ranging from 14 to 16 in male and 12 to 15 in female; basal middle lamellae of female pectines not dilated. Metasomal segments I to IV without any spinoid posterior granule; segments IV and V of males bigger than those of females. Telson with a strong and rhomboid subaculear tooth. Dentate margins of pedipalp fingers composed of 15-16 oblique rows of granules in both males and females; male patella and metasomal segments generally much more bulky than those of females. 


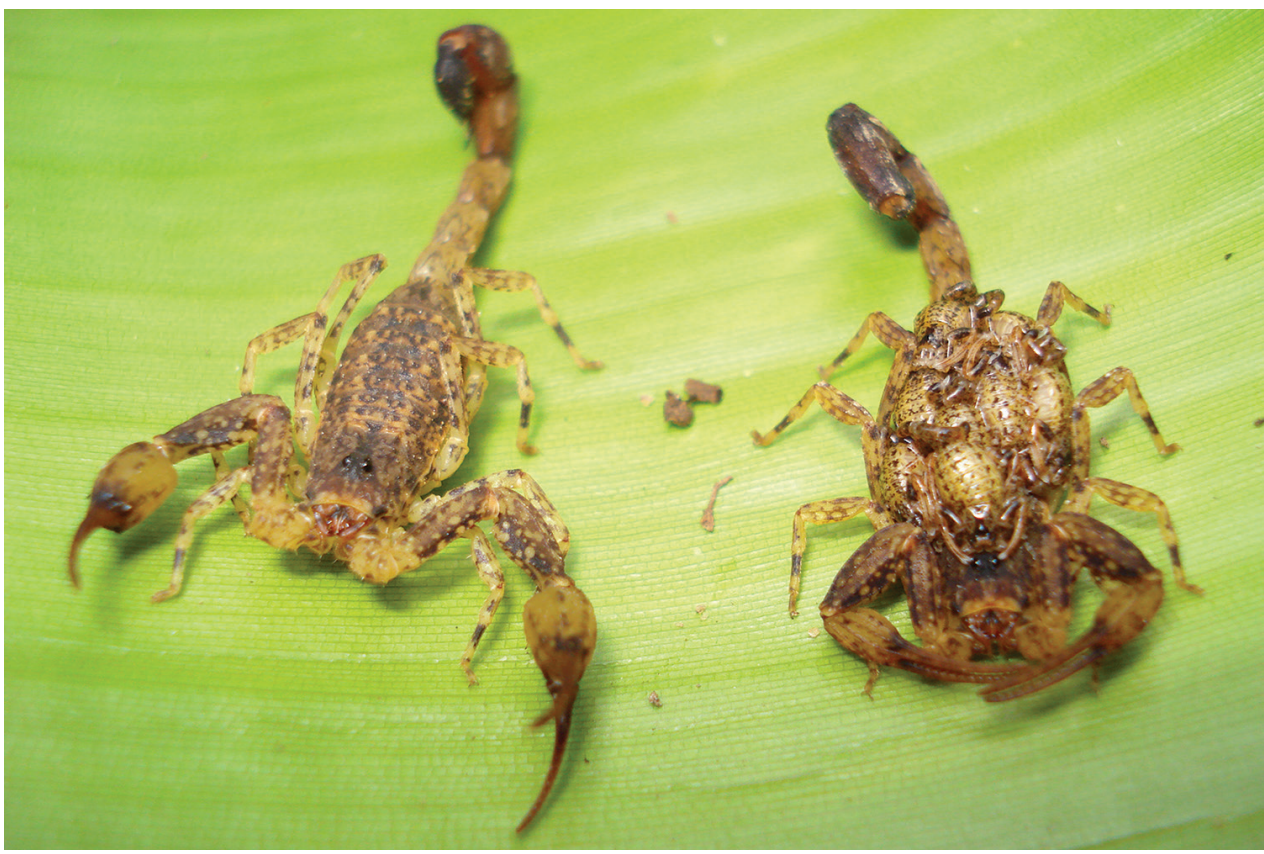

Figure 14. Tityus silvestris, male (left) and female with juveniles (right) from Saül (photo A. Thillien).

\section{Family CHACTIDAE Pocock, 1893 \\ Genus Auyantepuia Gonzalez-Sponga, 1978}

\section{Auyantepuia aluku sp. n.}

http://zoobank.org/5A303DD8-21BA-46BF-9F85-F25C43991E42

Figs 15-16

Type material. French Guiana, Apatou, Crevette river, one female (holotype), deposited in the MNHN, J. Chevalier \& P. Gallier coll., 30/VI/2017. Apatou, Crevette river, four females (paratypes), deposited in the EYPC, EY0094, J. Chevalier \& P. Gallier coll., 30/VI/2017.

Etymology. The specific name refers to the ethnic group Aluku, living in the area where the new species was found.

Diagnosis. Total length ranging from 20.4 to $21.5 \mathrm{~mm}(20.9 \mathrm{~mm}$ in total length for female holotype; see morphometric values after the description). Coloration reddish brown, with carapace, chelicerae, pedipalps and legs marked with darker spots. Tergites brownish with confluent reddish yellow spots, on the sides and the middle of tergites, forming a yellowish longitudinal median stripe. Posterior half of ventral side of segments I to IV yellowish, without spots. Body and appendages almost smooth, shiny; chela weakly granulated, dorso-internal carina inconspicuous; ventral posterior spinoid granulations on metasomal segment V. Pectines of female holotype and paratypes with 5-6 to 6-6 teeth; male unknown. Trichobothrial pattern of type $C$ neobothriotaxic 'majorante'. 


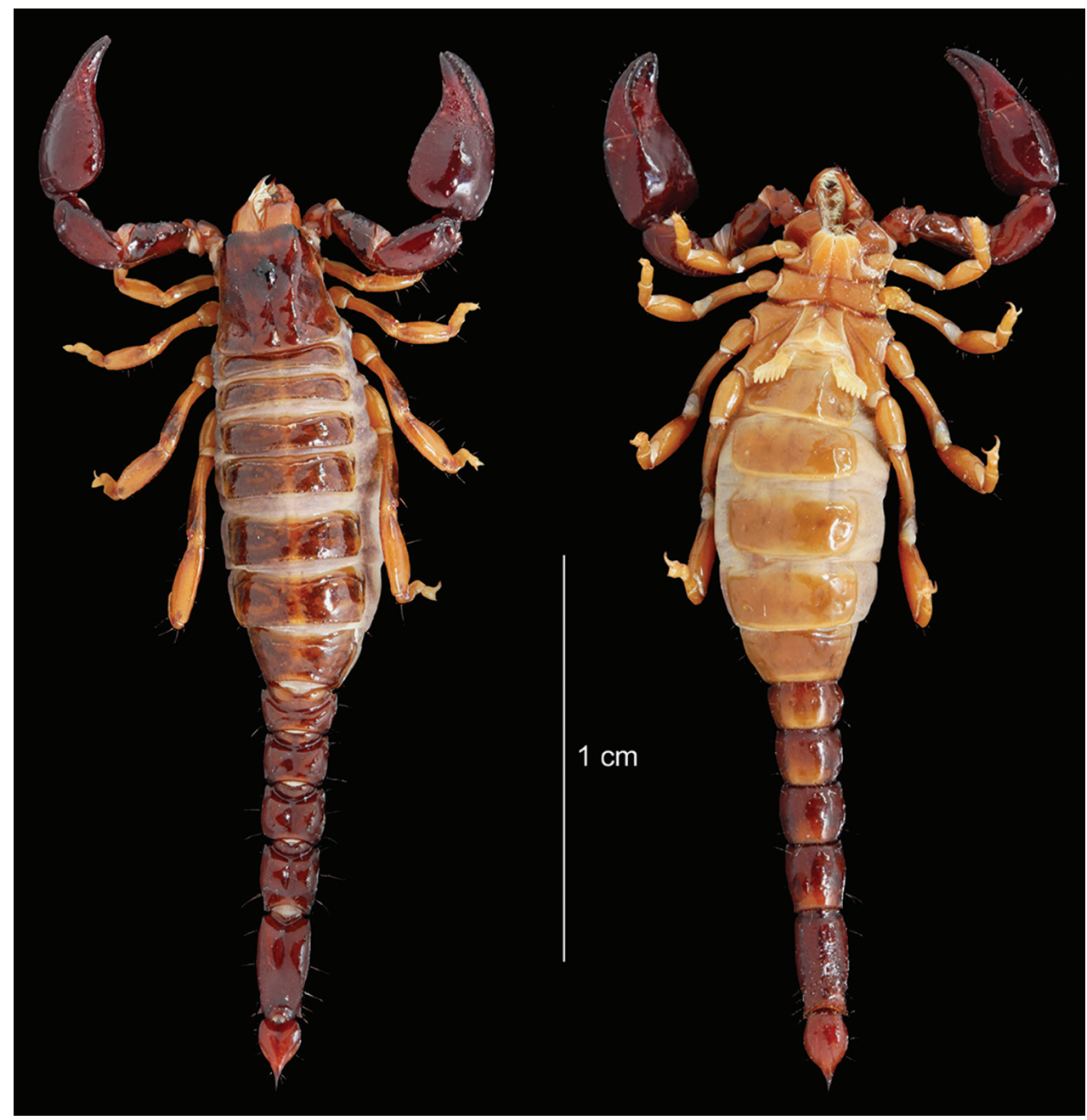

Figure I5. Auyantepuia aluku sp. n., female holotype from Apatou. Habitus, dorsal and ventral aspect.

Description based on female holotype. Coloration. General coloration reddish brown. Carapace reddish yellow, marked with brownish variegated spots around the ocular tubercle and on the anterior and posterior edges of the carapace; ocular tubercle darker, almost black. Tergites brownish with confluent reddish yellow spots, on the sides and the middle of tergites, forming a yellowish longitudinal median stripe. Venter and sternites yellowish; sternum yellowish with darker spots on the middle and anterior edge; genital opercle yellowish; pectines pale yellow. Metasomal segments reddish yellow, marked with variegated brownish spots on lateral and dorsal sides of segments I to $\mathrm{V}$ and on ventral side of segments IV and V; posterior half of ventral side of segments I to IV yellowish, without spots. Vesicle reddish yellow with basis of aculeus blackish and tip of aculeus reddish. Chelicerae yellowish, with variegated dark brown 

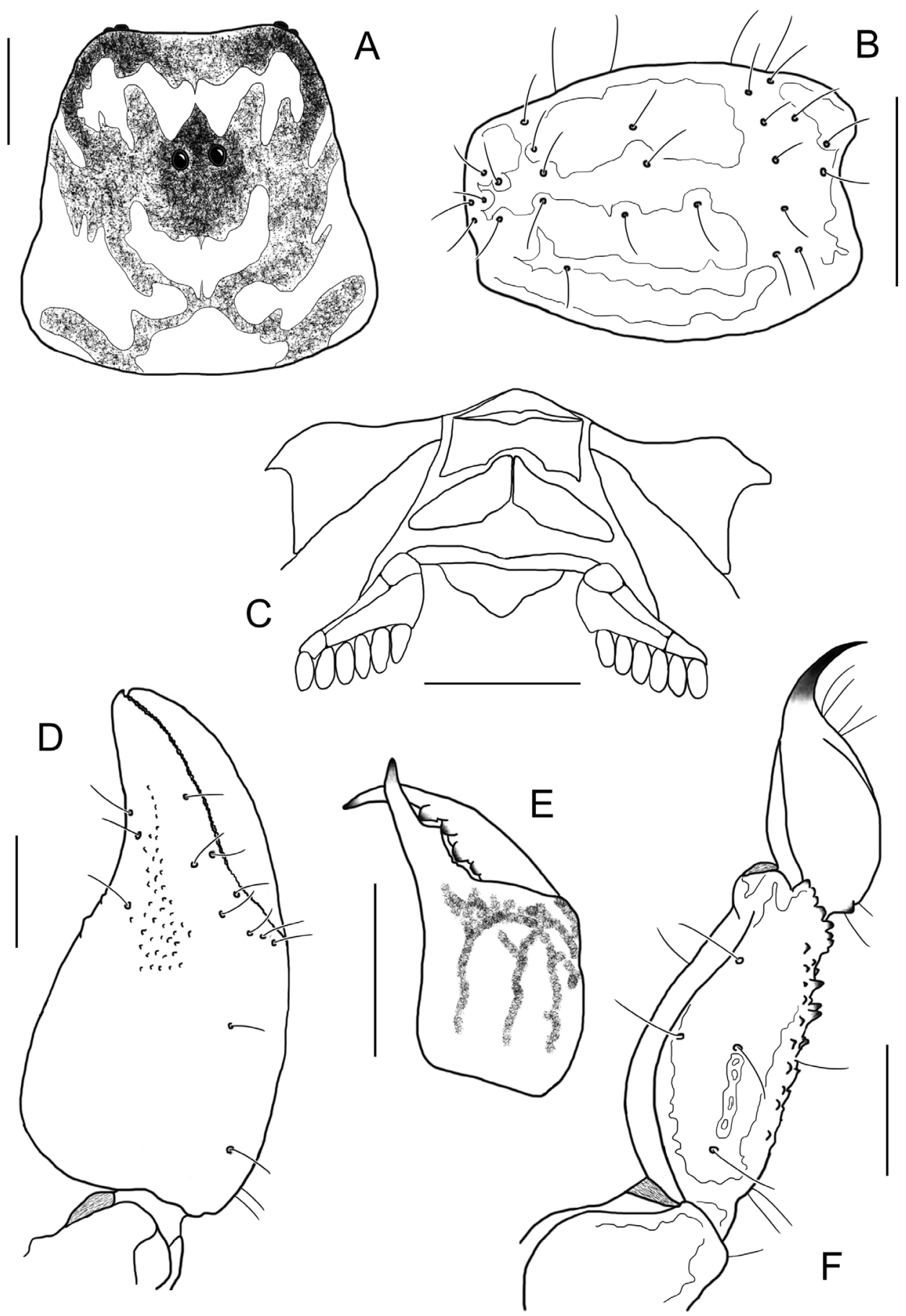

Figure 16. Auyantepuia aluku sp. n. female holotype. A Carapace B Patella, external aspect C Sternum, genital operculum and pectines $\mathbf{D}$ Chela, dorso-external aspect $\mathbf{E}$ Chelicera $\mathbf{F}$ Metasomal segment $\mathrm{V}$ and telson, lateral aspect. Scale bars: $1 \mathrm{~mm}$ except chelicera $0.5 \mathrm{~mm}(\mathbf{E})$. 
spots; fingers reddish yellow; teeth reddish. Pedipalps reddish yellow, with longitudinal dark brown spots. Legs yellowish, intensely marked with brownish spots.

Morphology. Carapace acarinate, shiny, and almost smooth, with only some minute granulations on lateral edges; furrows shallow; anterior edge emarginate. Tergites acarinate, shiny, and almost smooth. Sternum pentagonal, wider than long. Pectinal tooth count 6-6 in female holotype (5-6 to 6-6 in females paratypes), fulcra absent. Sternites smooth and shiny, VII acarinate; spiracles rounded in shape. Only metasomal segments IV and V longer than wide; metasomal tegument almost lustrous, without granulation, and with a few punctations; segment $\mathrm{V}$ with posterior spinoid granulation ventrally; carinae on segments I-V vestigial or absent; only dorso-lateral carinae are weakly marked on segments I to IV. Pedipalp femur with dorsal internal, dorsal external and ventral internal carinae moderately marked, internal face weakly granular, other faces smooth; patella smooth, with vestigial carinae; chela weakly granulated, almost smooth, with dorso-internal carina weakly marked; dentate margins on fixed and movable fingers with six rows of granules. Chelicerae with dentition typical of the family Chactidae (Vachon, 1963), and with dense setation ventrally and internally. Trichobothriotaxy of type C; neobothriotaxic 'majorante' (Vachon, 1974). Morphometric values (in $\mathrm{mm}$ ) of the female holotype. Total length including telson, 20.9. Carapace: length, 3.2; anterior width, 1.9; posterior width, 3.2. Mesosoma length, 7.2. Metasomal segments. I: length, 1.3; width, 2.0; II: length, 1.3; width, 1.7; III: length, 1.4; width, 1.5; IV: length, 1.7; width, 1.4; V: length, 2.6; width, 1.2; depth, 1.2. Telson: length, 2.2; width, 1.1; depth, 0.8. Pedipalp: femur length, 1.5, width, 0.9; patella length, 2.1, width, 1.0; chela length, 4.6, width, 2.1, depth, 1.7; movable finger length, 2.3.

Relationships. Auyantepuia aluku sp. n. can be readily distinguished from other species of the genus Auyantepuia and, in particular, from the three species occurring in the northern part of French Guiana and Suriname, by the following main features:

- A. laurae Ythier, 2015 (described from Saut Sabbat, Mana): (i) smaller size (27.5 to $28.2 \mathrm{~mm}$ in total length for $A$. laurae), (ii) tergites with confluent reddish yellow spots forming a yellowish longitudinal median stripe (no stripe in $A$. laurae), (iii) posterior half of ventral side of segments I to IV yellowish, without spots (ventral side of segments I to III entirely yellowish, without spots in $A$. laurae).

- A. gaillardi Lourenço, 1983 (described from Saint-Laurent-du-Maroni): (i) smaller size (26.9 $\mathrm{mm}$ in total length for the female of $A$. gaillardi), (ii) carapace, tergites, chelicerae, pedipalps and legs marked with darker spots (uniform coloration without darker spots in $A$. gaillardi), (iii) posterior half of ventral side of segments I to IV yellowish, without spots (all segments uniformly reddish in A. gaillardi).

- A. surinamensis Lourenço \& Duhem, 2010 (described from Albina/Moengo, Suriname): (i) tergites with confluent reddish yellow spots forming a yellowish longitudinal median stripe (no stripe in A. surinamensis), (ii) posterior half of ventral side of segments I to IV yellowish, without spots (all segments reddish uniformly and intensely marked with brownish spots in A. surinamensis). 


\section{Auyantepuia aurum sp. n.}

http://zoobank.org/71974C08-003E-4D34-9882-D4882268AF6B

Figs 17-18

Type material. French Guiana, Saül, Gros arbres trail, one male (holotype), deposited in the MNHN, J. Chevalier, B. Tan \& R. Legallic coll., 21-22/VIII/2017. Saül, Gros arbres trail, one male (paratype), deposited in the EYPC, EY0095, J. Chevalier, B. Tan \& R. Legallic coll., 21-22/VIII/2017.

Etymology. The specific name is allusive to gold (Latin aurum) panning, for which the village of Saül (where the new species occurs) was founded at the beginning of the $19^{\text {th }}$ century.

Diagnosis. Total length $25.2 \mathrm{~mm}$ for male holotype and $28.1 \mathrm{~mm}$ for male paratype (see morphometric values after the description). Coloration reddish brown, with carapace, chelicerae, pedipalps and legs marked with darker spots. Tergites brownish with confluent yellowish spots, on the sides and the middle of tergites, forming a yellowish longitudinal median stripe. Ventral side of segments I and II yellowish, without spots. Body and appendages weakly to moderately granulated; chela moderately granulated, dorso-internal carina inconspicuous; granulations on lateral sides of all metasomal segments and on ventral side of segments III to V, spinoid on V. Pectines of males holotype and paratypes with 7-7 and 5-7 teeth, respectively; female unknown. Trichobothrial pattern of type C neobothriotaxic 'majorante'.

Description based on male holotype. Coloration. General coloration reddish brown. Carapace reddish yellow, marked with brownish variegated spots around the ocular tubercle and on the anterior and posterior edges of the carapace; ocular tubercle darker, almost black. Tergites brownish with confluent yellowish spots, on the sides and the middle of tergites, forming a yellowish longitudinal median stripe. Venter and sternites yellowish; sternum yellowish with darker spots on the middle and anterior edge; genital opercle yellowish; pectines pale yellow. Metasomal segments reddish yellow, marked with variegated brownish spots on lateral and dorsal sides of segments I to V and on ventral side of segments III, IV and V; ventral side of segments I and II yellowish, without spots. Vesicle reddish yellow with basis of aculeus blackish and tip of aculeus reddish. Chelicerae yellowish, with variegated dark brown spots; fingers reddish yellow with dark brown spots at their basis; teeth reddish. Pedipalps reddish yellow, with longitudinal dark brown spots. Legs yellowish, intensely marked with brownish spots.

Morphology. Carapace acarinate, with some fine granulations on central, lateral and posterior parts; furrows shallow; anterior edge emarginate. Tergites acarinate, with some fine granulations, stronger on their posterior edges. Sternum pentagonal, wider than long. Pectinal tooth count 7-7 in male holotype (5-7 in male paratype), fulcra absent. Sternites smooth and shiny, VII acarinate; spiracles rounded in shape. Metasomal segments III, IV and V longer than wide; metasomal tegument with medium size granulation on lateral sides of all segments and on ventral side of segments III to $\mathrm{V}$, spinoid on $\mathrm{V}$; carinae on segments I-V vestigial, only dorso-lateral carinae are 


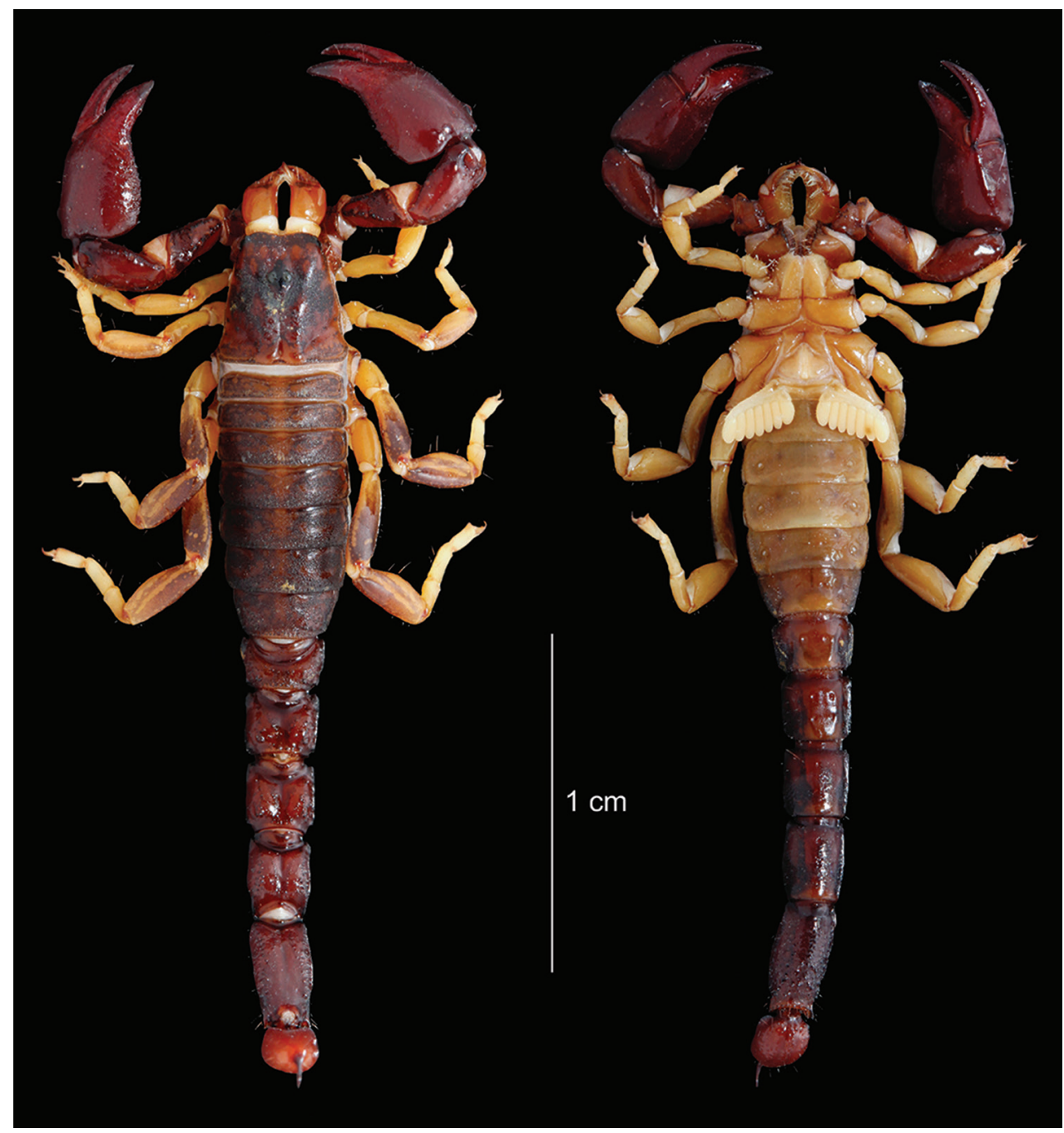

Figure I 7. Auyantepuia aurum sp. n., male holotype from Saül. Habitus, dorsal and ventral aspect.

weakly marked on all segments. Pedipalp femur with dorsal internal, dorsal external and ventral internal carinae moderately marked, internal face weakly granular, other faces smooth; patella smooth, with vestigial carinae; chela moderately granulated, with dorso-internal carina weakly marked; dentate margins on fixed and movable fingers with six rows of granules. Chelicerae with dentition typical of the family Chactidae (Vachon, 1963), and with dense setation ventrally and internally. Trichobothriotaxy of type C; neobothriotaxic 'majorante' (Vachon, 1974). Morphometric values (in mm) of the male holotype. Total length including telson, 25.2. Carapace: length, 3.9; anterior width, 2.2; posterior width, 3.6. Mesosoma length, 7.7. Metasomal segments. I: length, 1.4; width, 2.0; II: length, 1.9; width, 2.0; III: length, 2.0; width, 1.7; IV: length, 2.3; width, 1.7; V: length, 3.3; width, 1.6; depth, 1.4. Telson: length, 2.7; 

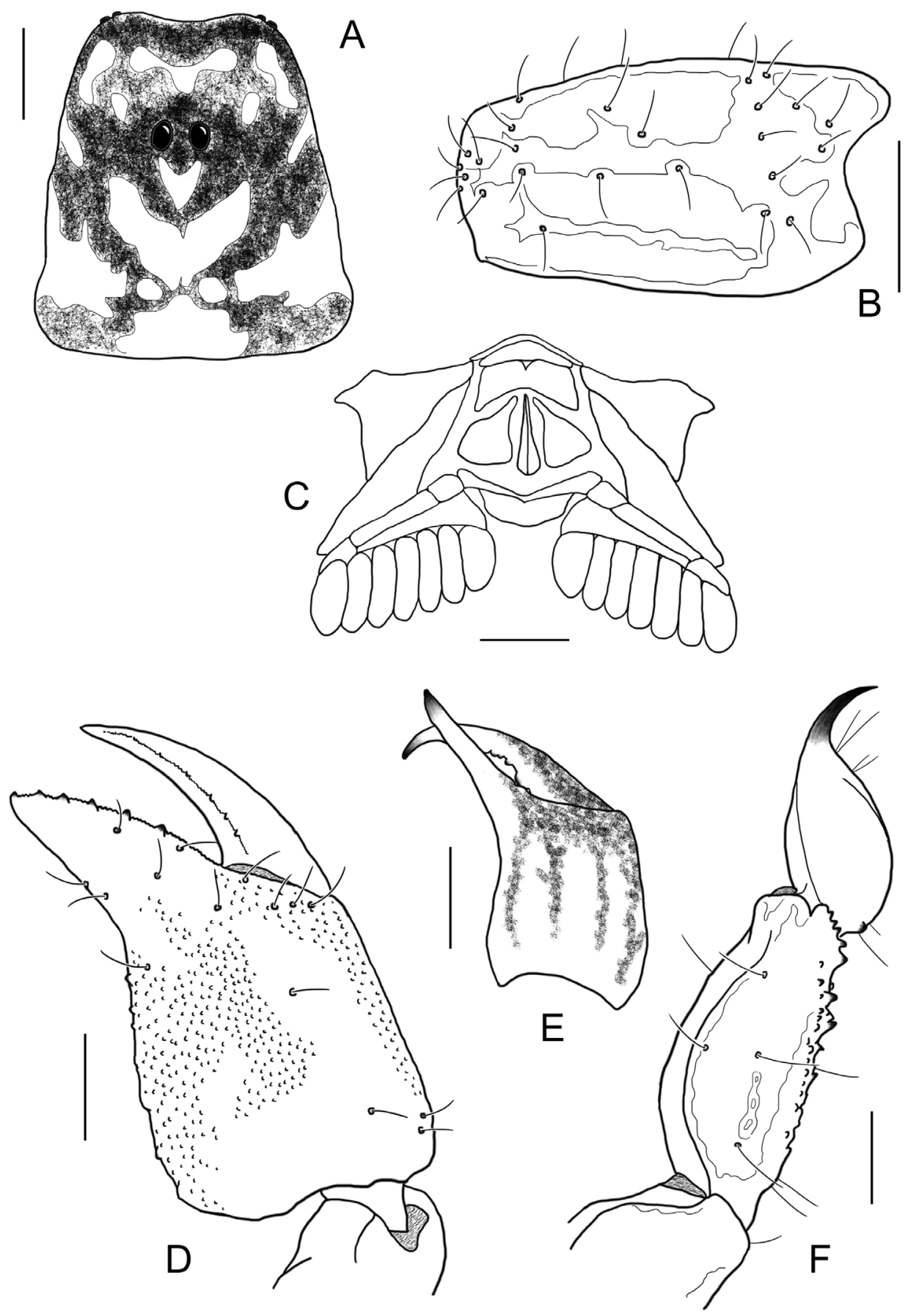

Figure 18. Auyantepuia aurum sp. n. male holotype. A Carapace B Patella, external aspect C Sternum, genital operculum and pectines D Chela, dorso-external aspect $\mathbf{E}$ Chelicera $\mathbf{F}$ Metasomal segment $\mathrm{V}$ and telson, lateral aspect. Scale bars: $1 \mathrm{~mm}$ except chelicera $0.5 \mathrm{~mm}(\mathbf{E})$. 
width, 1.4; depth, 1.2. Pedipalp: femur length, 2.1, width, 1.0; patella length, 2.8, width, 1.1; chela length, 5.2, width, 2.3, depth, 1.8; movable finger length, 2.9.

Relationships. Auyantepuia aurum sp. n. can be readily distinguished from other species of the genus Auyantepuia and, in particular, from the three species occurring in the central and southern part of French Guiana, by the following main features:

- A. fravalae Lourenço, 1983 (described from Saut Pararé on Arataye river (Approuage tributary), and also found in Saül): (i) tergites with confluent yellowish spots forming a yellowish longitudinal median stripe (no stripe in $A$. fravalae), (ii) ventral side of segments I and II yellowish, without spots (brownish spots on ventral side of segments I to $\mathrm{V}$ and ventral side of segments I to II well pigmented in $A$. fravalae).

- A. sissomi Lourenço, 1983 (described from upper Oyapok): (i) general coloration reddish brown (yellowish in $A$. sissomi), (ii) metasomal tegument with medium size granulation on ventral side of segments III to $\mathrm{V}$ (only segment $\mathrm{V}$ is granulated ventrally in $A$. sissomi).

- A. kelleri Lourenço, 1997 (described from Cacao): (i) tergites with confluent yellowish spots forming a yellowish longitudinal median stripe (no stripe in $\mathrm{A}$. kelleri), (ii) ventral side of segments I and II yellowish, without spots (all segments uniformly dark reddish in A. kelleri), (iii) ocular tubercle darker, almost black (clear in A. kelleri).

\section{Auyantepuia fravalae Lourenço, 1983}

Fig. 19

References. Lourenço 1983, Lourenço 1997b, Fet et al. 2000, Soleglad and Fet 2005, Prendini and Wheeler 2005, Lourenço and Qi 2007, Ythier 2015.

Material. Downstream from Saut Pararé on Arataye river, Approuague tributary, one male (holotype), MNHN-RS-8505, J.P. Gasc coll., IV/V/1979. Downstream from Saut Pararé on Arataye river, at the base of Astrocaryum paramaca, one female (allotype), MNHN-RS-8506, J.P. Gasc coll., I/1981. Saül, under dead wood, one female, deposited in the MHNG, P.K. Moritz coll., VIII/1987.

Diagnosis. Total length $28.8 \mathrm{~mm}$ for male holotype and $28.6 \mathrm{~mm}$ for female allotype. General coloration reddish brown. Carapace dark reddish brown with blackish spots around the ocular tubercle and on lateral edges of the carapace; ocular tubercle dark, almost black. Tergites reddish with several confluent lighter zones. Venter greyish yellow, the sternite VII darker; pectines and genital operculum yellow ochre. All metasomal segments reddish, slightly darker than the mesosoma; several reticular blackish spots on the ventral and lateral sides of segments I to V. Vesicle reddish yellow with several darker spots corresponding to granules; basis of aculeus reddish and tip of aculeus reddish black. Chelicerae dark yellowish with blackish spots starting at the basis of fingers and spreading along the chelicerae; fingers reddish. Pedipalps reddish with several longitudinal blackish spots on the three segments (femur, patella, and chela). 


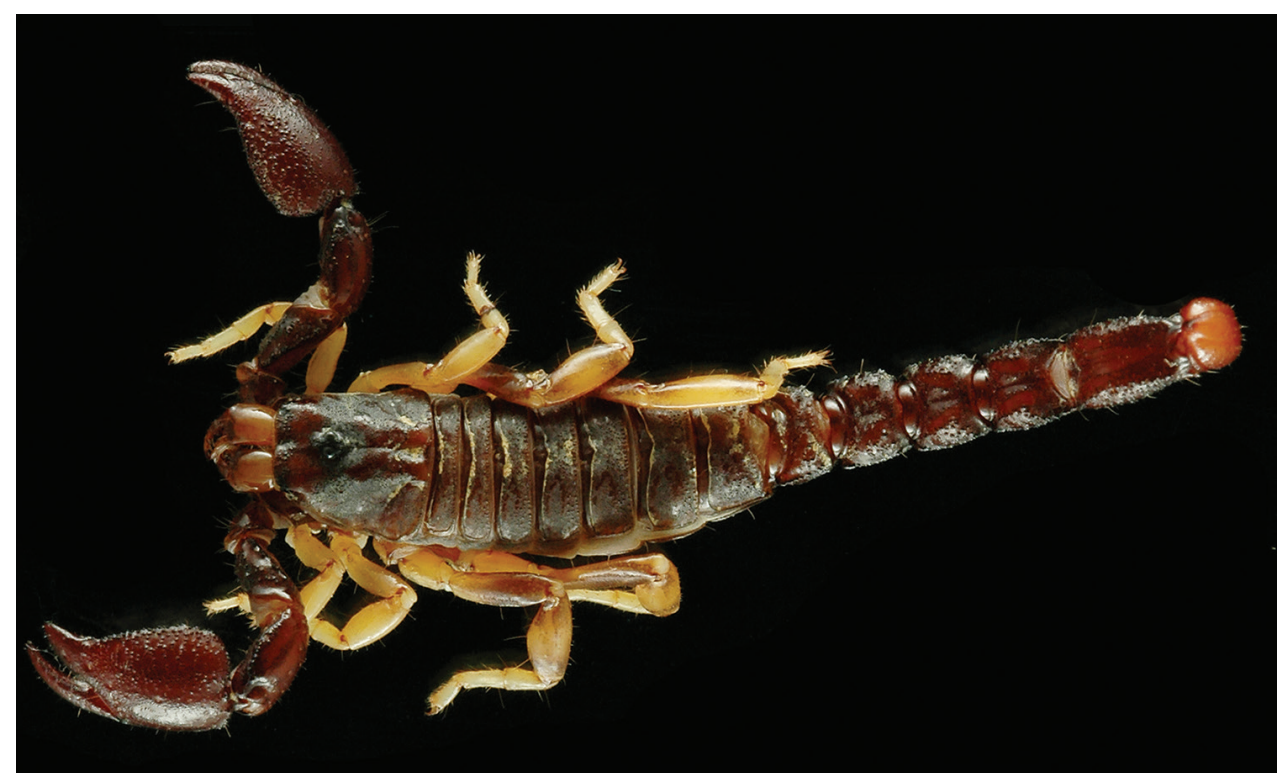

Figure 19. Auyantepuia fravalae, male holotype from Saut Pararé (photo MNHN / E.-A. Leguin).

Legs light yellow with several diffuse light brown spots. Carapace with a fine granulation with bigger granules on the anterior part; anterior edge very slightly concave, almost straight. Tergites with a medium size granulation, especially on the posterior part. Pectinal tooth count 8-8 in both sexes. Sternites smooth with spiracles rounded in shape. Ventral side of metasomal segments IV and V with medium size granulation on IV, important and spinoid on V; dorsal carinae weakly marked on segments I to IV; latero-dorsal carinae well-marked on segments I to IV and weakly marked on V; other carinae absent. Vesicle large and flattened, with medium size granulation on ventral and lateral sides; aculeus short. Pedipalp femur with four almost complete carinae; patella and chela with vestigial carinae; dorsal and internal sides of femur granular; chela strongly granulated dorsally, only few scattered granules internally; dentate margins on movable fingers with six rows of granules separated by bigger granules.

\section{Auyantepuia gaillardi Lourenço, 1983}

References. Lourenço 1983, Fet et al. 2000, Soleglad and Fet 2005, Prendini and Wheeler 2005, Lourenço and Qi 2007, Ythier 2015.

Material. St Jean du Maroni, one male (holotype), one female (allotype) and six females (paratypes), MNHN-RS-3311, R. Benoist coll., XII/1913. St Jean du Maroni, four females (paratypes), MNHN-RS-3307, R. Benoist coll., III-IV/1914. St Jean du Maroni, one male (paratype), MNHN-RS-3326, R. Benoist coll., 18/XII/1913. 
Diagnosis. Total length $25.2 \mathrm{~mm}$ for male holotype and $26.9 \mathrm{~mm}$ for female allotype. General coloration reddish yellow. Carapace light reddish with yellowish spots on the posterior and lateral edges of the carapace; ocular tubercle blackish. Tergites yellowish with several confluent darker spots, greyish. Venter pale yellow, the sternite VII darker; pectines and genital operculum yellow ochre. All metasomal segments uniformly reddish, slightly darker than the prosoma. Vesicle of same coloration as metasomal segment V; aculeus dark reddish. Chelicerae uniformly yellowish; tip of fingers reddish. Pedipalps reddish, the femur slightly yellowish. Legs uniformly pale yellow. Carapace with a fine granulation in males, smooth in female; anterior edge very slightly concave, almost straight. Tergites with a fine granulation similar to the one on carapace in males, smooth in females. Number of pectine teeth ranging from seven to eight in male and six to seven in female. Sternites smooth with spiracles rounded in shape. Metasomal segment $\mathrm{V}$ with spinoid granulation ventrally; dorsal and laterodorsal carinae on segments I to V weakly marked; other carinae absent. Vesicle with few scattered granules ventrally, other sides smooth; aculeus short. Pedipalp femur with dorsal internal, dorsal external and ventral internal carinae well-marked; internal side granular; patella and chela with vestigial carinae; chela weakly granular dorsally; dentate margins on movable fingers with six rows of granules separated by bigger granules.

\section{Auyantepuia kelleri Lourenço, 1997}

References. Lourenço 1997b, Fet et al. 2000, Soleglad and Fet 2005, Prendini and Wheeler 2005, Lourenço and Qi 2007, Ythier 2015.

Material. Cacao, one female (holotype), deposited in the MHNG, W. Lourenço leg., II/1989.

Diagnosis. General coloration brownish. Carapace brownish with darker spots on the anterior part of the carapace; posterior part and furrows lighter; ocular tubercle light. Tergites brownish with confluent yellowish spots. Venter yellowish brown. All metasomal segments uniformly dark reddish. Vesicle reddish with basis of aculeus reddish and tip of aculeus reddish black. Chelicerae yellowish red with greyish spots; fingers yellowish with reddish teeth. Pedipalps dark reddish, chela reddish. Legs yellowish with slightly variegated greyish spots. Carapace without granules, almost smooth; anterior edge very slightly concave. Tergites with few minute and scattered granules. Pectinal tooth count 6-6 in female. Sternites smooth with spiracles rounded in shape. Metasomal segment $V$ with spinoid granulation ventrally; dorsal and latero-dorsal carinae on segments I to $\mathrm{V}$ weakly marked; other carinae absent. Vesicle flattened with few scattered granules ventrally; aculeus of medium size. Pedipalp femur with dorsal internal, dorsal external and ventral internal carinae well-marked; internal side granular; patella and chela with vestigial carinae; chela weakly granulated dorsally and with few scattered granules internally; dentate margins on movable fingers with five rows of granules separated by bigger granules. 


\section{Auyantepuia laurae Ythier, 2015}

Fig. 20

References. Ythier 2015.

Material. Near Saut Sabbat, $50 \mathrm{~km}$ South of Mana and $50 \mathrm{~km}$ East of Saint-Laurentdu-Maroni, under wood log, one female (holotype) and two females (paratypes), deposited in the MNHN, E. Ythier \& G. Roy coll., I/2015. Mana, path of the Forêt des Sables Blancs, one female, deposited in the EYPC, EY0097, J. Chevalier \& B. Tan coll., 08/VII/2017.

Diagnosis. Size ranging from 27.5 to $28.2 \mathrm{~mm}$ in total length for the females. General coloration reddish brown. Carapace reddish yellow, intensely marked with brownish variegated spots around the ocular tubercle and on the anterior and posterior edges of the carapace; ocular tubercle darker, almost black. Tergites reddish brown with confluent reddish yellow spots, on the sides and the middle of tergites, without forming a longitudinal stripe. Venter and sternites yellowish to reddish yellow; sternum reddish yellow with darker spots; genital operculum reddish yellow; pectines pale yellow. Metasomal segments reddish yellow, marked with variegated brownish spots on lateral and dorsal sides of segments I to $\mathrm{V}$ and on ventral side of segments IV and V; ventral side of segments I to III yellowish, without spots. Vesicle reddish yellow with basis of aculeus blackish and tip of aculeus reddish. Chelicerae yellowish, with variegated dark brown spots; fingers reddish yellow with dark brown spots at their basis, reddish teeth. Pedipalps reddish brown, with longitudinal dark brown spots. Legs yellowish, intensely marked with brownish spots. Carapace lustrous and acarinate, with some minute punctations; furrows shallow; anterior edge emarginated. Tergites acarinate, almost smooth and shiny, with only minute granulations on their posterior edges. Pectinal tooth count 5-6 to 6-6 in females. Sternites smooth and shiny, VII acarinate; spiracles rounded in shape. Only metasomal segments IV and V longer than wide; metasomal tegument almost lustrous, without granulation, and with a few punctations; segment $V$ with spinoid granulation ventrally, weakly marked; carinae on segments I to $\mathrm{V}$ vestigial or absent; only dorso-lateral carinae are weakly marked on segments I to IV. Pedipalp femur with dorsal internal, dorsal external and ventral internal carinae moderately marked; internal side weakly granular; other sides smooth; patella smooth, with vestigial carinae; chela weakly granulated, almost smooth, with dorso-internal carina weakly marked; dentate margins on fixed and movable fingers with six rows of granules.

\section{Auyantepuia sissomi Lourenço, 1983}

Fig. 21

References. Lourenço 1983, Fet et al. 2000, Soleglad and Fet 2005, Prendini and Wheeler 2005, Lourenço and Qi 2007, Ythier 2015.

Material. Upper Oyapock, between Montaquoère junction and Dégrad Galoupa, equatorial forest, one female (holotype), MNHN-RS-3304 and one female (paratype), MNHN-RS-3309, mission E. Aubert de la Rüe coll., 10/I/1949. 


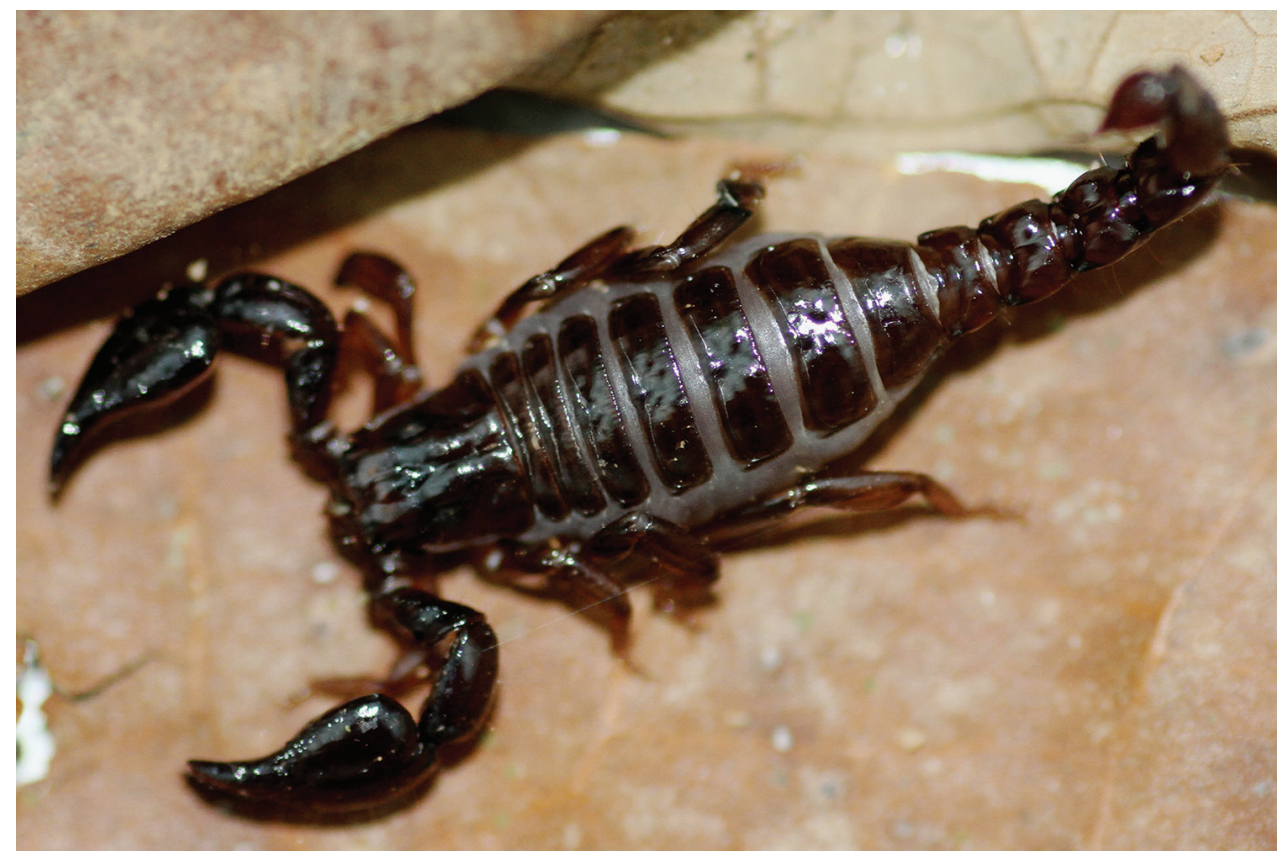

Figure 20. Auyantepuia laurae, female holotype from Saut Sabbat.

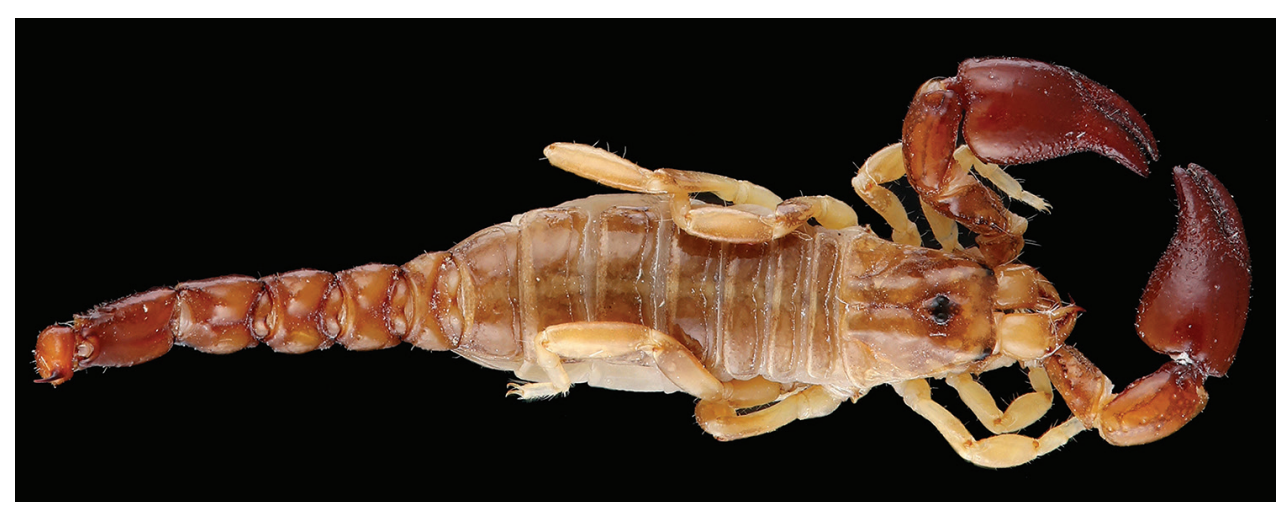

Figure 21. Auyantepuia sissomi, female holotype from upper Oyapock (photograph MNHN / E.-A. Leguin).

Diagnosis. Total length $26.2 \mathrm{~mm}$ for female holotype. General coloration yellowish. Carapace yellowish with light brown spots around the ocular tubercle and on the lateral edges of the carapace; posterior part and furrows lighter; ocular tubercle dark, almost black. Tergites greyish with several confluent lighter spots, yellowish, forming a longitudinal stripe. Venter yellow ochre. All metasomal segments reddish yellow, with greyish spots on lateral sides of I to $\mathrm{V}$ and on ventral side of III to V; ventral side of segments I and II without pigmentation. Vesicle reddish yellow; basis of aculeus reddish and tip of aculeus reddish black. Chelicerae yellowish with greyish spots; fingers 
yellowish with reddish teeth. Pedipalps reddish yellow with longitudinal light brown spots on the patella and chela, the dorsal side of the femur almost entirely covered with light brown spots; chela reddish. Legs pale yellow with several diffuse greyish spots. Carapace without granules, almost smooth; anterior edge very slightly concave. Tergites with few scattered fine granules. Number of pectine teeth ranging from six to seven in females. Sternites smooth with spiracles rounded in shape. Metasomal segment V with spinoid granulation ventrally; dorsal carinae weakly marked on segments I to IV; latero-dorsal carinae well-marked but incomplete on segments I to IV; other carinae absent. Vesicle flattened with few scattered granules ventrally; aculeus of medium size. Pedipalp femur with three carinae well-marked and almost complete; patella and chela with vestigial carinae; dorsal and internal sides of femur granular; dorsal side of chela granular, internal side with few scattered granules; dentate margins on movable fingers with six rows of granules separated by bigger granules.

\section{Genus Broteochactas Pocock, 1893}

\section{Broteochactas delicatus (Karsch, 1879)}

Fig. 22

References. Karsch 1879, Pocock 1897, Lourenço 1983, Fet et al. 2000, Lourenço 2002a, Soleglad and Fet 2005, Prendini and Wheeler 2005, Stockmannn and Ythier 2010.

Material. Camopi, Oyapock Valley, one female, MNHN-RS-3300, mission E. Aubert de la Rüe coll., 20/XII/1948. Camopi, Oyapock Valley, one male and two females, MNHN-RS-3392, mission E. Aubert de la Rüe coll., 18/XII/1948. St Georges de l'Oyapock, one female, W. Lourenço leg., 20/VIII/1982. Inini, Institut Pasteur Station, in forest, one female, MNHN-RS-6271, J.P. Gasc coll., 16/VII/1972. Inini, Institut Pasteur Station, one female, MNHN-RS-6273, J.P. Gasc coll., 13/VII/1972. Saül, six males and six females, MNHN-RS-5287, A.S. Balachowsky coll., 27/X/1969. Saül, inselberg Dashine, under barks on the ground from the standing dead tree, one male, deposited in the MNHN, J.P. Mauries coll., 05/IV/1997. Saül, Gros Arbres trail, two females and eleven immatures, deposited in the RNA, J. Chevalier, B. Tan \& R. Legallic coll., 23/VIII/2017. Saül, Belvédère, one female and four immatures, deposited in the RNA, J. Chevalier, B. Tan \& R. Legallic coll., 21-22/VIII/2017. Saut Sabbat, one female and 17 immatures, MNHN-RS-8202, D. Kopp coll., 9/VII/1976. Saut Sabbat, one female, MNHN-RS-8204, D. Kopp coll., 15/VII/1975. Trinité reserve, Aya River, UV collected, one male, deposited in the MNHN, C. Courtial coll., XII/2010. Nouragues reserve, inselberg, UV collected on a dead trunk, one immature male, deposited in the MNHN, C. Courtial coll., 06-09/XII/2013. Cacao, one male and one female, deposited in the MHNG, W. Lourenço leg., II/1989. Cacao, one female, deposited in the EYPC, EY0030, E. Ythier coll., 03-11/XI/2010. Cacao, beginning of Molokoi path, one male and one female, deposited in the EYPC, EY0104, E. Ythier coll., 03-10/XI/2006. Maripasoula, one female, deposited in the MHNG, 


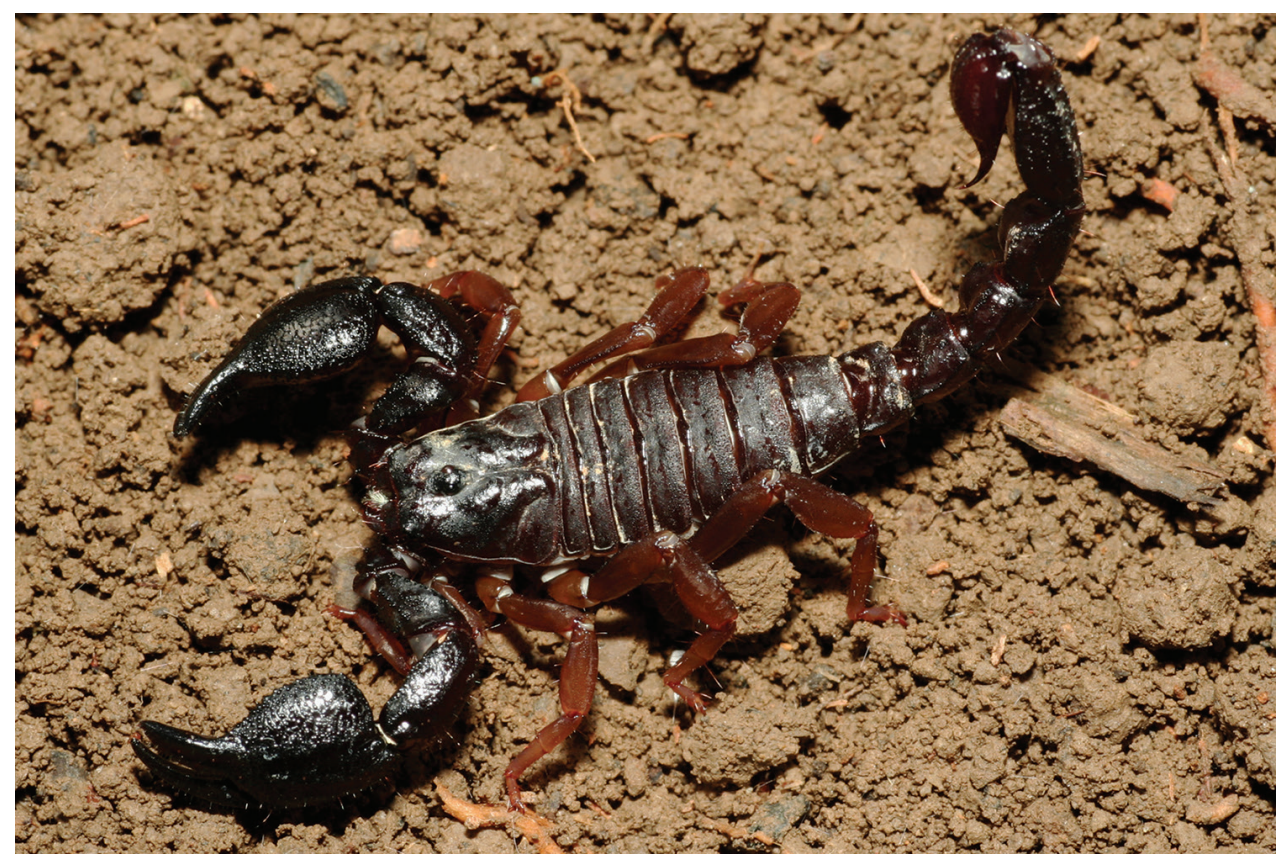

Figure 22. Broteochactas delicatus, male from Cacao.

Marty coll., X/1987. Mitaraka Massif, camp, one female, deposited in the MNHN, MNHN/PNI Guyane 2015, E. Poirier, P.H. Dalens \& J. Touroult coll., 26/II/2015. Mana, path of the Forêt des Sables Blancs, two males and two females, deposited in the RNA, J. Chevalier \& B. Tan coll., 08/VII/2017. Mana, path of the Forêt des Sables Blancs, three immatures, deposited in the RNA, J. Chevalier \& B. Tan coll., 08/ VII/2017. Guyane, one female, MNHN-RS-0755.

Diagnosis. Species of moderate to large size when compared with the average size of the other species within the genus, ranging from 44 to $50 \mathrm{~mm}$ in total length. General coloration reddish to dark reddish. Carapace reddish with some light brown zones on the anterior edge and around the ocular tubercle; the areas between the anterior edge and the ocular tubercle as well as areas of furrows almost without pigmentation; ocular tubercle dark, almost black. Tergites reddish with several yellowish reticular diffuse spots on all tergites. Sternites yellowish with brown spots on lateral edges, especially on sternites VI and VII; pectines and genital operculum yellow ochre. Metasomal segments of same color as the tergites. Vesicle reddish yellow with basis of aculeus reddish and tip of aculeus reddish black. Chelicerae yellowish with longitudinal brown spots; basis of fingers and fingers dark brown. Pedipalps reddish with diffuse and reticular light brown spots on femur and patella. Legs yellowish with diffuse light brown spots. Carapace slightly emarginated, almost straight; almost smooth, with few minute granules only on lateral areas. Tergites almost smooth, with scattered minute granulations. Pectinal tooth count ranging from seven to nine in male and 7-7 in female. Sternites smooth; spiracles oval to round in shape. All metasomal segments with 
dorsal and latero-dorsal carinae well-marked; other carinae weakly marked or absent; segment $\mathrm{V}$ with spinoid granulations ventrally. Vesicle flattened, moderately granular; aculeus of moderate size compared to vesicle. Pedipalp femur with four well-marked carinae; patella with three carinae, chela with two carinae; femur and patella feebly granulated; chela well granulated on dorsal and internal sides, with granules arranged in four longitudinal wide series on external side; fingers about the same length as the chela and with dentate margins on movable fingers with six rows of granules, separated by stronger accessory granules.

\section{Genus Brotheas C. L. Koch, 1837}

\section{Brotheas gervaisii Pocock, 1893}

Fig. 23

References. Pocock 1893a, Pocock 1897, Lourenço 1983, Lourenço 1997b, Fet et al. 2000, Lourenço 2002a, Stockmannn and Ythier 2010.

Material. Downstream from Saut Pararé on Arataye river, Approuague tributary, one female, MNHN-RS-7389, two males, MNHN-RS-7390, J.P. Gasc coll., IV-V/1979. Cayenne, La Chaumière, one male, MNHN-RS-8507, J. Orvoen coll., V/1977. Cayenne, Mont Bourda, one female, deposited in the RNA, J. Chevalier \& B. Tan coll., 09/VII/2017. Coswine river, under flooded wood log, two males and five females, MNHN-RS-8297, J. Fretey coll., 16/V/1977. Upper Oyapock, Upper Camopi, Upstream Saül, Yanioué, one male, MNHN-RS-3295, mission E. Aubert de la Rüe coll., II/1949. Saül, one female, MNHN-RS-3320, mission E. Aubert de la Rüe coll. Saül, two females, MNHN-RS-5288, A.S. Balachowsky coll., 27/X/1969. Saül, one female, deposited in the MHNG, W. Lourenço leg., 23/VII/1987. Saül, one male juvenile, deposited in the MHNG, W. Lourenço leg., 16/VII/1986. Saül, Belvédère, one male, deposited in the RNA, J. Chevalier, B. Tan \& R. Legallic coll., 21-22/ VIII/2017. Saut Hermina, banks of Maroni River, three males, MNHN-RS-3316, H. Lourtau coll., 1901. St. Jean du Maroni, two males, one female and six immatures, MNHN-RS-3306, R. Benoist coll., 1914. Cacao, F-T-574, one male, deposited in the MHNG, T. Freitag coll., XII/1988. Cacao, one male and one female, deposited in the MHNG, W. Lourenço leg., II/1989. Cacao, one female, deposited in the MHNG, Chippaux coll., X/1983. Regina-St. Georges future road, DZ3, one male, deposited in the MHNG, Marty coll., I/1991. Trinité reserve, Aya river, UV collected, on the ground, three females, deposited in the MNHN, C. Courtial coll., XII/2010. Matoury, one female, deposited in the EYPC, EY0041, E. Ythier coll., 25/IX/2005. Matoury, one female and two immatures, deposited in the EYPC, EY0034, E. Ythier coll., 03-11/XI/2010. Fourgassier, one immature, deposited in the EYPC, EY0036, E. Ythier coll., 03-11/XI/2010. Rorota, one immature, deposited in the EYPC, EY0040, E. Ythier \& G. Roy coll., 14-22/I/2015. Apatou, Crevette river, one male, deposited in the RNA, J. Chevalier \& P. Gallier coll., 30/VI/2017. Awala Yalimapo, Kanawa 


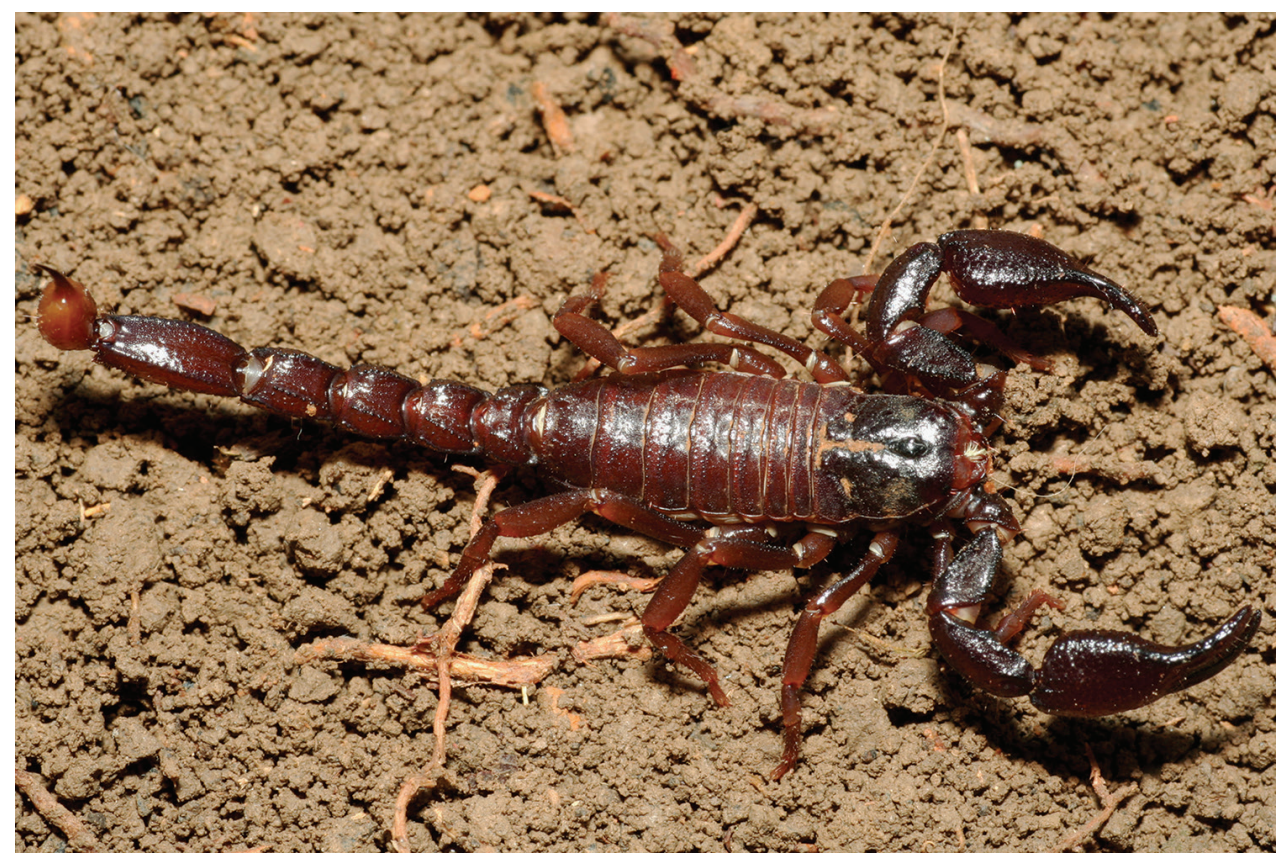

Figure 23. Brotheas gervaisii, male from Matoury.

path, three males, deposited in the RNA, J. Chevalier coll., XI/2017. Awala Yalimapo, Kanawa path, one male, deposited in the RNA, J. Chevalier coll., 03/VIII/2017. Mana, path of the Forêt des Sables Blancs, one male, deposited in the RNA, J. Chevalier \& B. Tan coll., 08/VII/2017. Guyane, one male and one female, MNHN-RS-0741, Lafon coll., 1872. Guyane, one female, MNHN-RS-3308, Le Moult coll., 1910. Guyane, one male, MNHN-RS-0747. Guyane, one male and one female, MNHN-RS0748. Guyane, one female, MNHN-RS-3011. Guyane, one female, MNHN-RS-0737, F. Geay coll., 1900. Guyane, one male, MNHN-RS-0739, Cavalier coll., 1889.

Diagnosis. Species of small to moderate size when compared with the average size of the other species within the genus, ranging from 50 to $57 \mathrm{~mm}$ in total length. General coloration brown to reddish brown. Carapace reddish brown with several black spots corresponding to the granules; ocular tubercle dark, almost black. Tergites paler than the carapace, with distal edge blackish. Sternites reddish with a lighter area, yellowish, at the center of sternites IV and V; pectines and genital operculum yellow ochre. Metasomal segments of same color as the tergites. Vesicle reddish yellow with basis of aculeus reddish and tip of aculeus reddish black. Chelicerae yellowish with longitudinal brown spots, weakly marked; fingers reddish. Pedipalps reddish with blackish pigmentation on carinae. Legs yellowish with several brown spots. Carapace slightly emarginated, almost straight; almost smooth, with few minute granules only on lateral areas; punctate. Tergites almost smooth, with scattered minute granulations. Pectinal tooth count ranging from eight to eleven in male and six to nine in female. Sternites smooth, punctate; spiracles linear, elongated. All metasomal segments with dorsal, 
latero-dorsal and latero-ventral carinae well-marked; other carinae weakly marked or absent; intercarinal tegument punctate; segment $\mathrm{V}$ with spinoid granulations ventrally. Vesicle moderately granular; aculeus short compared to vesicle. Pedipalp femur with five well-marked carinae; patella with three carinae, chela with two carinae; femur and patella moderately granulated; chela well granulated on dorsal and internal sides; dentate margins on movable fingers with six slightly oblique rows of granules, separated by stronger accessory granules.

\section{Brotheas granulatus Simon, 1877}

Fig. 24

References. Simon 1877, Lourenço 1983, Lourenço 1997b, Fet et al. 2000, Lourenço 2002a, Stockmannn and Ythier 2010.

Material. Downstream from Saut Pararé on Arataye river, Approuague tributary, one male, MNHN-RS-6978, J.P. Gasc coll., VII-VIII/1970. Downstream from Saut Pararé on Arataye river, one male and two females, MNHN-RS-7390, J.P. Gasc coll., IV-V/1979. Downstream from Saut Pararé on Arataye river, one male, MNHN-RS-8279, J.P. Gasc coll., 12/VII/1977. Downstream from Saut Pararé on Arataye river, at the base of Astrocaryum paramaca, six males and four females, MNHN-RS-8508, J.P. Gasc coll., I/1981. Cayenne, one male and one female (types), MNHN-RS-0761. Upper Approuague, Culebane river, in forest, one female, MNHN-RS-3302, De Floch coll., III/1946. Inini, Institut Pasteur Station, under a wood log, one male, MNHN-RS-6267, J.P. Gasc coll., 13/VII/1972. Inini, Institut Pasteur Station, one male, MNHN-RS-6274, J.P. Gasc coll., 16/VII/1972. Inini, Institut Pasteur Station, one male, MNHN-RS-6275, J.P. Gasc coll., 14/VII/1972. Saül, one male, one female and six immatures, MNHN-RS-5288, A.S. Balachowsky coll., 27/X/1969. Saut Sabbat, one female, MNHN-RS-8203, D. Kopp coll., 9/VII/1976. Saut Sabbat, one male, MNHN-RS-8204, D. Kopp coll., 15/VII/1975. St. Elie (path), ORSTOM Station, one male and one female, MNHN-RS-7419, J. Lescure coll., 10/ VII/1978. St. Jean du Maroni, five males and one female, MNHN-RS-3303, R. Benoist coll., 1916. Cacao, one female and one immature, deposited in the MHNG, W. Lourenço leg., II/1989. Cacao, one female, deposited in the MHNG, Chippaux coll., X/1983. Cacao, one male, deposited in the MHNG, T. Fretiag coll., XII/1988. Trinité reserve, inselberg, Aya River, five females and six immatures, deposited in the MNHN, C. Courtial coll., XII/2010. Trinité reserve, Aya River, one female and one male, deposited in the MNHN, C. Courtial coll., X/2009. Nouragues reserve, inselberg, UV collected, on a trunk, one female, deposited in the MNHN, C. Courtial coll., 06-09/ XII/2013. Rorota, one female and two males, deposited in the EYPC, EY0026, E. Ythier coll., 28/IX/2005. Matoury, one female and 20 immatures, deposited in the EYPC, EY0035, E. Ythier coll., 03-10/XI/2006. Fourgassier, one male, deposited in the EYPC, EY0046, E. Ythier coll., 03-10/XI/2006. Tresor reserve, three males, deposited in the MNHN, C. Courtial coll., VI/2010. Cayenne and Maroni (?), two 


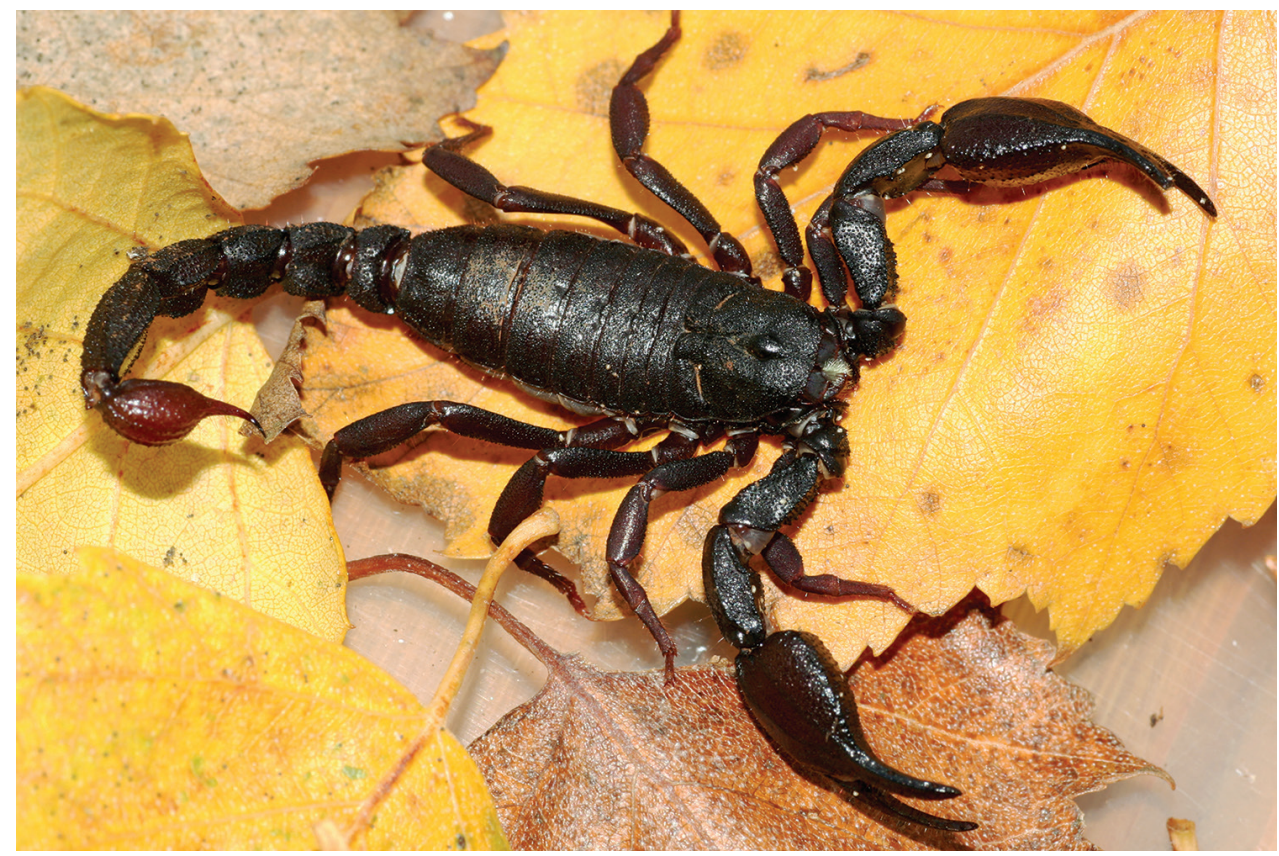

Figure 24. Brotheas granulatus, male from Fourgassier.

females, MNHN-RS-3296, M. Noirot coll. Cayenne and Maroni (?),one male and one female, MNHN-RS-3312, E. Abonnenc coll. Cayenne and Maroni (?),one male, MNHN-RS-3318, M. Noirot coll. Guyane, one male, MNHN-RS-0743, F. Geay coll., 1900. Guyane, four females, MNHN-RS-3313, M. Tartaire coll., 1921. Guyane, two females, MNHN-RS-0749.

Diagnosis. Species of moderate to large size when compared with the average size of the other species within the genus, ranging from 58 to $68 \mathrm{~mm}$ in total length. General coloration brown to blackish brown. Carapace dark brown with several scattered black spots; ocular tubercle dark, almost black. Tergites of same color as the carapace; several paler confluent areas. Sternites brownish yellow, the sternite VII being darker; pectines and genital operculum dark yellowish. Metasomal segments of same color as the tergites; some blackish pigmentation over the carinae. Vesicle reddish yellow with basis of aculeus reddish and tip of aculeus reddish black. Chelicerae dark yellowish with reticular brown spots; basis of fingers and fingers dark browns. Pedipalps blackish brown; chela reddish with longitudinal blackish spots; fingers blackish with tip reddish. Legs yellowish brown with several diffuse dark spots. Carapace weakly emarginated, with strong granulation; ocular tubercle punctate. Tergites with strong granulation similar to the carapace, the tergites VI and VII with stronger granulation. Pectinal tooth count ranging from eight to eleven in male and seven to nine in female. Sternites punctate; spiracles linear, elongated. All metasomal segments with dorsal, latero-dorsal and latero-ventral carinae well-marked; ventral carinae absent on segment I and wellmarked on other segments, with spinoid granules on segments IV and V; other cari- 
nae incomplete; intercarinal tegument moderately punctate. Vesicle with four vestigial carinae on ventral side; lateral and ventral sides weakly granulated; aculeus long compared to vesicle, wide at its basis. Pedipalp femur with five well-marked carinae; patella with four carinae; chela with vestigial carinae; dorsal and internal sides of femur well granulated; patella and chela moderately granulated except on internal side of chela where there are stronger granules; dentate margins on movable fingers with six slightly oblique rows of granules, separated by stronger accessory granules.

\section{Genus Guyanochactas Lourenço, 1998}

\section{Guyanochactas flavus Lourenço \& Ythier, 2011}

Fig. 25

References. Lourenço and Ythier 2011.

Material. Roura-Cacao, Montagne Tortue, at the end of forested road of Bélizon, PK27, under litter and/or log in trail, one male (holotype) and one female (paratype), deposited in the MNHN, J.P. Mauries \& J.M. Betsch coll. 1/II/1992. Montsinéry-Tonnegrande, Anamites, one female (paratype), deposited in the MNHN, E. Ythier coll., XI/2010.

Diagnosis. Total length $38.2 \mathrm{~mm}$ for male holotype and $35 \mathrm{~mm}$ for female paratypes. General coloration reddish yellow to pale yellow. Carapace yellowish with some reddish yellow zones. Tergites yellowish, slightly paler than carapace, with one longitudinal reddish yellow strip. Venter and sternites yellowish; pectines and genital operculum paler than sternites. Metasomal segments yellowish, with reddish yellow zones over carinae. Vesicle yellowish; aculeus reddish yellow at the base and reddish at the tip. Chelicerae yellowish, without spots; fingers reddish yellow with reddish teeth. Pedipalps yellow to reddish yellow with dark reddish zones over carinae. Legs yellow. Carapace slightly emarginated, with minute granulations and punctations; furrows shallow. Tergites acarinate, with only minute granulations and punctations. Pectinal tooth 9-9 in male and from 8-8 to 10-10 in female. Sternites smooth and punctate; VII acarinate; sternite III on female with a strong setation; spiracles oval in shape. Metasomal segments I to III wider than long; metasomal tegument with moderately marked granulations and a few punctations; segment $\mathrm{V}$ with spinoid granulations ventrally; carinae on segments I-V moderately to strongly marked; ventral carina vestigial on segment I, weakly marked on II, moderately marked on III and strongly marked on IV. Pedipalp femur with dorsal internal, dorsal external and ventral internal carinae moderately to strongly marked; ventral internal carina with spinoid granules; ventral external carina weakly marked; all aspects with minute granulations; patella with minute granulations and punctations; dorsal internal, ventral internal, ventral external and external carinae moderately marked; other carinae vestigial; chela with weakly to moderately marked granulations; ventral and dorsal median carina moderately marked; other carinae weakly marked; internal aspect with spinoid granules; dentate margins on movable and fixed fingers with five rows of granules. 


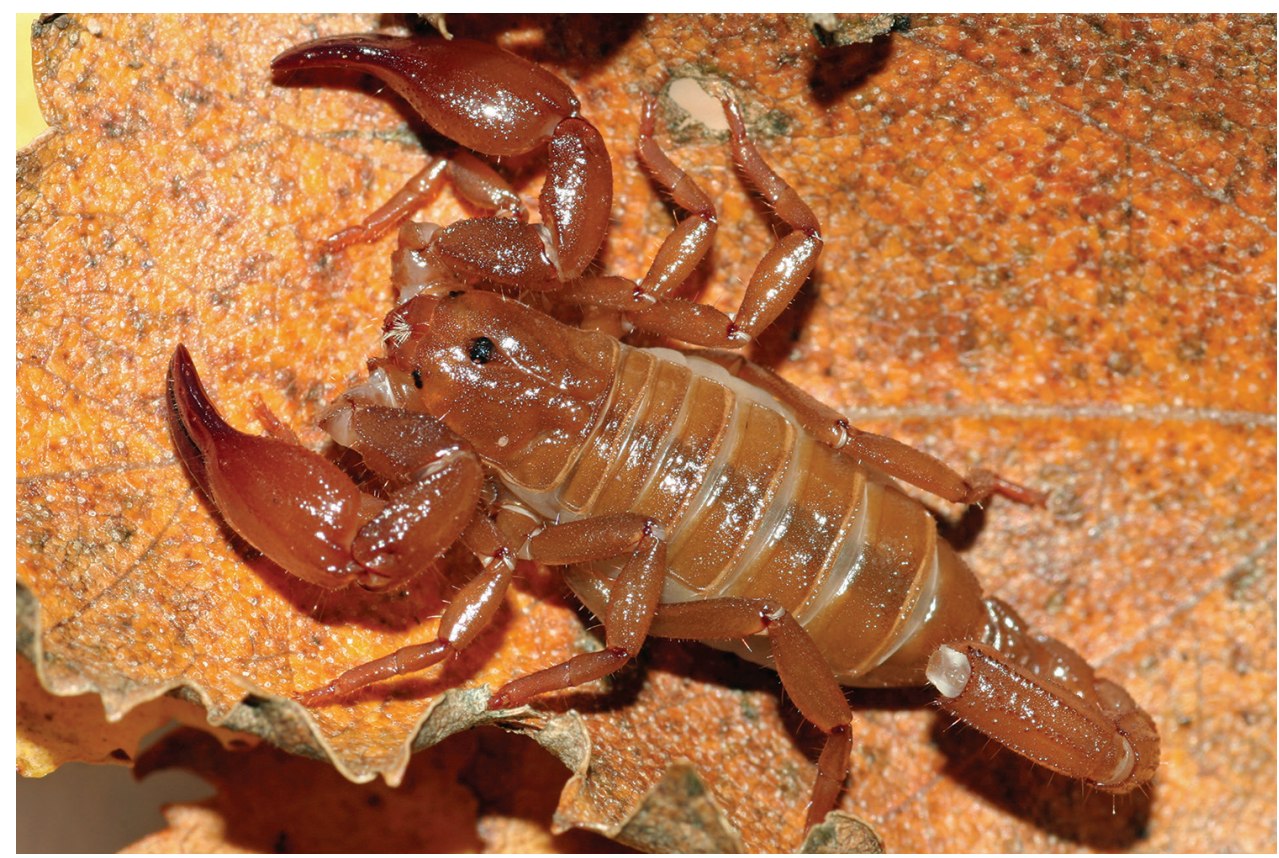

Figure 25. Guyanochactas flavus, female paratype from Anamites.

\section{Guyanochactas gonzalezspongai (Lourenço, 1983)}

Fig. 26

References. Lourenço 1983, Fet et al. 2000, Lourenço \& Pinto-da-Rocha 2000, Soleglad and Fet 2003, Prendini and Wheeler 2005, Stockmannn and Ythier 2010, Lourenço and Ythier 2011.

Material. Antecume-Pata, in forest, one male (holotype), MNHN-RS-6276, one male (paratype), MNHN-RS-6270, one male (paratype) MNHN-RS-6277, one male (paratype) MNHN-RS-6278 and one female (allotype), MNHN-RS-6266, J.P. Gasc coll., 18/VII/1972.

Diagnosis. Species of large size compared to the average size of the other species within the genus ( $45.8 \mathrm{~mm}$ in total length for male holotype and 49.7 for female allotype). General coloration reddish yellow. Carapace dark reddish with several blackish spots, more concentrated in the central part of carapace; ocular tubercle dark, almost black. Tergites reddish, slightly paler than carapace, with several confluent lighter spots. Sternites reddish yellow, the last two ones darker; pectines and genital operculum yellow ochre. Metasomal segments reddish, with some blackish pigmentation on carinae. Vesicle reddish yellow; aculeus reddish at the base and reddish black at the tip. Chelicerae yellowish with longitudinal light brown spots; basis of finger and fingers dark brown. Pedipalps dark reddish with blackish pigmentation over carinae and chela fingers. Legs yellowish with diffuse light brown spots. Carapace slightly emarginated, the anterior third part strongly reduced; minute to medium granulation. Tergites with 


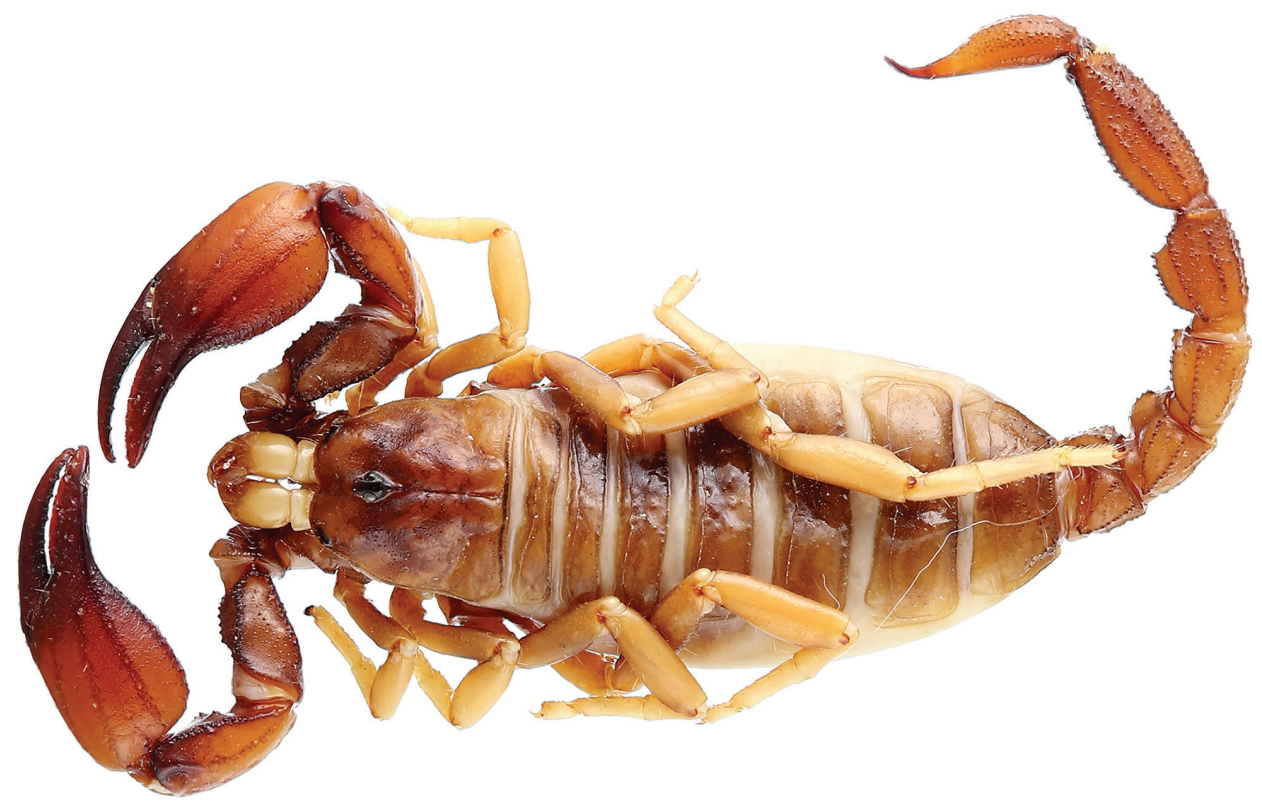

Figure 26. Guyanochactas gonzalezspongai, male holotype from Antecume-Pata (photograph MNHN / E.-A. Leguin).

minute granulations; -several granules on posterior part, especially on sternite VII. Pectinal tooth 11-11 in male and 10-10 in female. Sternites smooth; spiracles oval in shape, almost rounded. All metasomal segments with dorsal, latero-dorsal and lateroventral carinae well-marked; ventral carinae well-marked on segments III to V, weakly marked on II and absent on I; segment $\mathrm{V}$ with spinoid granulations ventrally. Vesicle flattened with ventral and lateral sides well granulated; aculeus short compared to vesicle. Pedipalp femur with five well-marked carinae; patella with four carinae; chela with weakly marked carinae; internal and dorsal sides of femur moderately granular; patella feebly granular; internal side of chela granular, other sides almost smooth; dentate margins on movable fingers with six rows of granules, separated by stronger granules.

\section{Genus Hadrurochactas Pocock, 1893}

\section{Hadrurochactas cristinae sp. $\mathrm{n}$.}

http://zoobank.org/D2AA5704-CB0C-462B-9487-688CA66B4327

Figs $27-28$

Type material. Roura, Stoupan, in litter, one male (holotype), deposited in the MNHN, Q. Uriot \& S. Uriot coll., 2017.

Etymology. The specific name honours Dr. Cristina Benros-Ythier, RomanècheThorins, France, in recognition of her support for the study of scorpions. 


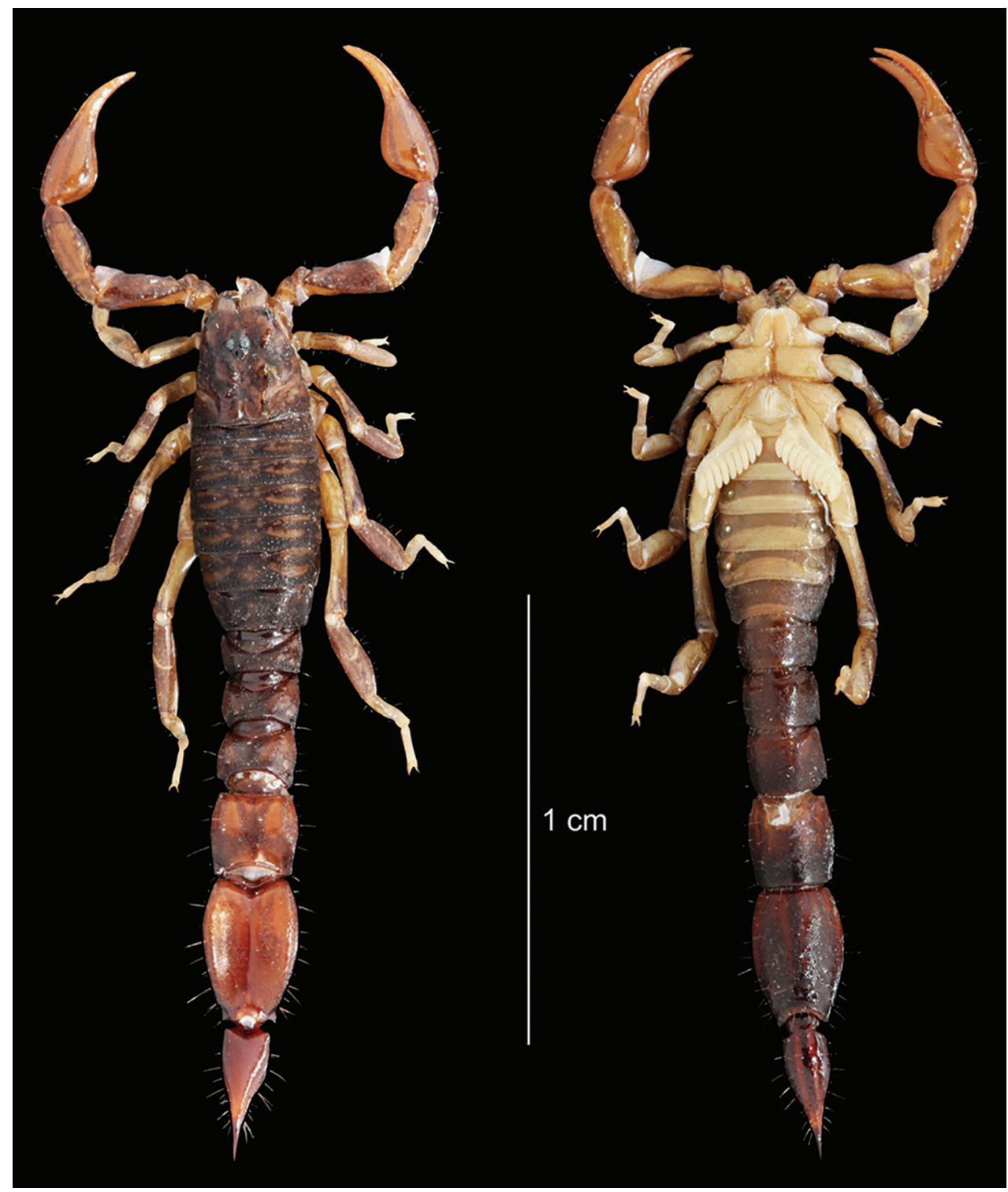

Figure 27. Hadrurochactas cristinae sp. n., male holotype from Roura. Habitus, dorsal and ventral aspect.

Diagnosis. Total length $18.9 \mathrm{~mm}$ for male holotype (see morphometric values after the description). Coloration yellowish brown, densely spotted on the carapace, the tergites and the appendages. Mesosoma yellowish, densely spotted with confluent brown to dark brown spots, without yellowish longitudinal median stripe. Chelicerae yellowish with variegated brownish spots over the entire surface. Legs tarsal segments yellowish with diffused brownish pigmentation. Pectines with 9-9 teeth on male holotype; female unknown. Trichobothrial pattern of type $\mathrm{C}$, neobothriotaxic (majorante) 'major neobothriotaxy'. 
Description based on male holotype. Coloration. General coloration yellowish brown, densely spotted on the carapace, the tergites and the appendages. Prosoma yellowish with brownish variegated spots on anterior, lateral and posterior edges; eyes surrounded by black pigment. Mesosoma yellowish, densely spotted with confluent brownish spots, darker on the posterior edge of the tergites; the remaining yellowish coloration does not form a confluent longitudinal median stripe. Sternites yellowish, the VII slightly darker; coxapophysis and sternum yellowish; genital operculum and pectines pale yellow. Metasomal segments yellowish to reddish yellow with brownish spots. Telson reddish yellow with brownish spots; aculeus reddish. Chelicerae yellowish with variegated brownish spots over the entire surface; fingers yellowish almost entirely covered with brownish spots; teeth reddish yellow. Pedipalps reddish yellow with brownish longitudinal stripes on femur, patella, and chela; femur darker than the other segments. Legs with femur, patella, and tibia yellowish with brownish longitudinal stripes; basitarsus and telotarsus yellowish with diffused brownish pigmentation.

Morphology. Carapace weakly granular to smooth; anterior margin very weakly emarginated; carinae absent; all furrows weakly pronounced; postero-median furrow finely granular; median ocular tubercle distinctly anterior to the center of the carapace; two pairs of small lateral eyes. All tergites with minute granulation and a few indistinct bigger granules on the posterior margin. Pectinal tooth count 9-9 in male holotype, fulcra absent. Sternites smooth and shiny except VI and VII which have some minute granulations; spiracles rounded; carinae absent; genital operculum longitudinally divided, each half with a sub-triangular shape. Dorsal carinae granular on metasomal segments I-IV, absent on segment V; dorsolateral carinae granular on all segments; ventrolateral and ventral carinae weakly pronounced or absent on all segments; dorsal surface smooth on all segments; lateral surfaces weakly granular to smooth on all segments; ventral surface smooth on segments I to IV; with some thin granules on V. Telson with small-sized spine-like granules and one larger spinoid granule under the aculeus; dorsal side smooth; aculeus relatively short and weakly curved. Pedipalp femur pentacarinate, moderately granular; patella and chela with weakly marked to unconspicuous carinae; fixed and movable fingers with seven rows of linear granules. Legs with long thin setae. Cheliceral dentition characteristic of the family Chactidae (Vachon, 1963). Trichobothriotaxy of type C, neobothriotaxic (majorante) 'major neobothriotaxy' (Vachon, 1974). Morphometric values (in mm) of the male holotype. Total length including telson, 18.9. Carapace: length, 2.3; anterior width, 1.3; posterior width, 2.4. Mesosoma length, 4.8. Metasomal segments. I: length, 0.9; width, 1.9; II: length, 1.2; width, 1.9; III: length, 1.2; width, 1.9; IV: length, 2.0; width, 1.9; V: length, 3.4; width, 2.2; depth, 1.4. Telson: length, 3.1; width, 0.9; depth, 0.6. Pedipalp: femur length, 1.9, width, 0.9; patella length, 2.3, width, 0.8; chela length, 3.7, width, 1.2, depth, 1.2; movable finger length, 2.2.

Relationships. Hadrurochactas cristinae sp. n. can be readily distinguished from the other species of the genus Harurochactas and, in particular, from $H$. schaumii (the only other species described from French Guiana), by the following main features: (i) smaller general size (21.1 to $26.5 \mathrm{~mm}$ in total length for $H$. schaumii), (ii) male 

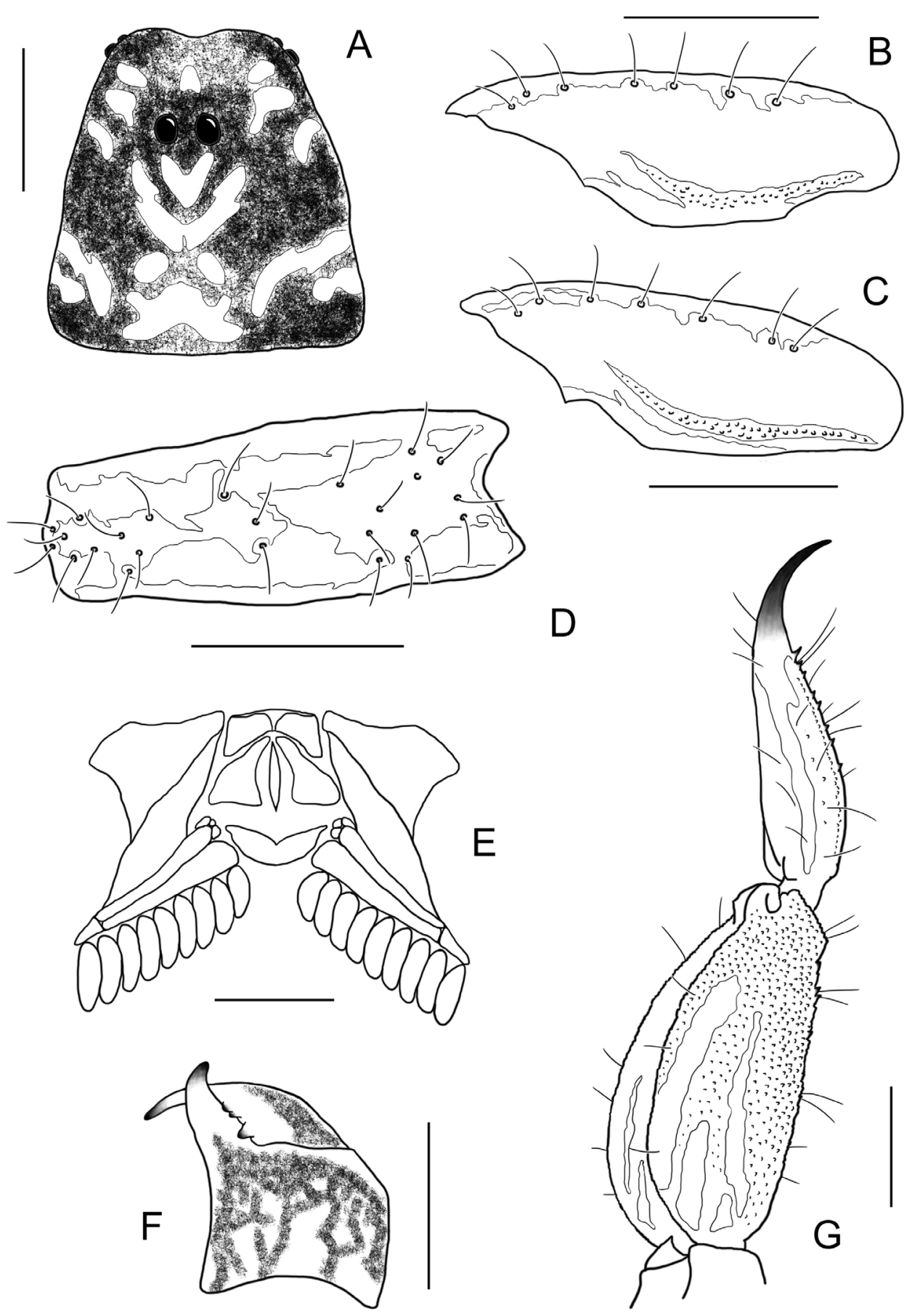

Figure 28. Hadrurochactas cristinae sp. n., male holotype. A Carapace B-C Patella, dorsal aspect of $H$. cristinae (B) and H. schaumii (C) D Patella, external aspect E Sternum, genital operculum and pectines $\mathbf{F}$ Chelicera $\mathbf{G}$ Metasomal segment $V$ and telson, lateral aspect. Scale bars: $1 \mathrm{~mm}$ except chelicera $0.5 \mathrm{~mm}(\mathbf{F})$. 
pectines with only 9-9 teeth (ranging from 10-11 in H. schaumii), (iii) general coloration yellowish brown (reddish brown in $H$. schaumii) without confluent yellowish longitudinal median stripe on mesosoma (reddish yellow longitudinal median stripe in H. schaumii), (iv) chelicerae yellowish with variegated brownish spots over the entire surface (without spots in $H$. schaumii), (v) legs tarsal segments yellowish with diffused brownish pigmentation (no pigmentation in $H$. schaumii), (vi) trichobothria on ventral side of pedipalp patella (V1 to V7) situated at different positions.

\section{Hadrurochactas schaumii (Karsch, 1880)}

Fig. 29

References. Karsch 1880, Gonzaléz-Sponga 1978, Lourenço 1988b, Fet et al. 2000, Monod and Lourenço 2001, Lourenço 2002a, Stockmannn and Ythier 2010, Lourenço 2010 .

Material. Downstream from Saut Pararé on Arataye River, Approuague tributary, one male and one female, MNHN-RS-7389, one female, MNHN-RS-7390, J.P. Gasc coll., IV/V/1979. Downstream from Saut Pararé on Arataye River, at base of Astrocaryum paramaca, two females, MNHN-RS-8509, J.P. Gasc coll., I/1981. Kaw, road to Kaw, Patawa, one female, deposited in the EYPC, EY0026, E. Ythier coll., 30/IX/2005. Cacao, beginning of Molokoi path, one male, deposited in the EYPC, EY0104, E. Ythier coll., 03-10/XI/2006. Mana, Laussat, white sand, leaf litter, pifall, two males, deposited in the MNHN, LA15-0284-12, LA15-0304-18, J. Orivel, M. Fichaux, Jackie \& N. Milhomme coll., 01/X/2015. Mana, Laussat, white sand, leaf litter, pitfall, two immatures, deposited in the MNHN, LA15-0151-13, LA15-022318, J. Orivel, M. Fichaux, Jackie \& N. Milhomme coll., 28/VIII/2015. Saint Eugène Research station, on the Courcibo stream, tributary of Sinnamary River, two males and two females, deposited in the MNHN, J.-C. de Massary leg.

Diagnosis. Species of medium size when compared with the average size of the other species of the genus, ranging from $21.1 \mathrm{~mm}$ (male) to $26.5 \mathrm{~mm}$ (female) in total length. General coloration reddish brown. Carapace reddish with reddish brown spots. Tergites reddish brown with a confluent reddish yellow longitudinal median stripe. Venter and sternites light reddish brown; pectines yellowish. Metasomal segments reddish with brownish spots. Vesicle reddish; aculeus reddish at the base and black at the tip. Chelicerae yellowish without variegated spots over their entire surface, and with only a dark thin zone at the base of the fingers; fingers yellowish with reddish teeth. Pedipalps reddish brown with reticular brownish spots forming longitudinal stripes. Legs with femur, patella and tibia yellowish brown with dark brown spots; tarsal segments yellowish. Carapace densely covered with minute granulation with bigger granules in furrows and smooth areas mainly between the ocular tubercle and lateral eyes. Tergites with minute granulation in male, VII with bigger granules; tergites I-IV smooth and shiny in female. Pectinal tooth count ranging from 10-11 in male and from 8-10 in female. Sternites III/IV smooth and shiny in male, others with minute granulations; all sternites smooth 


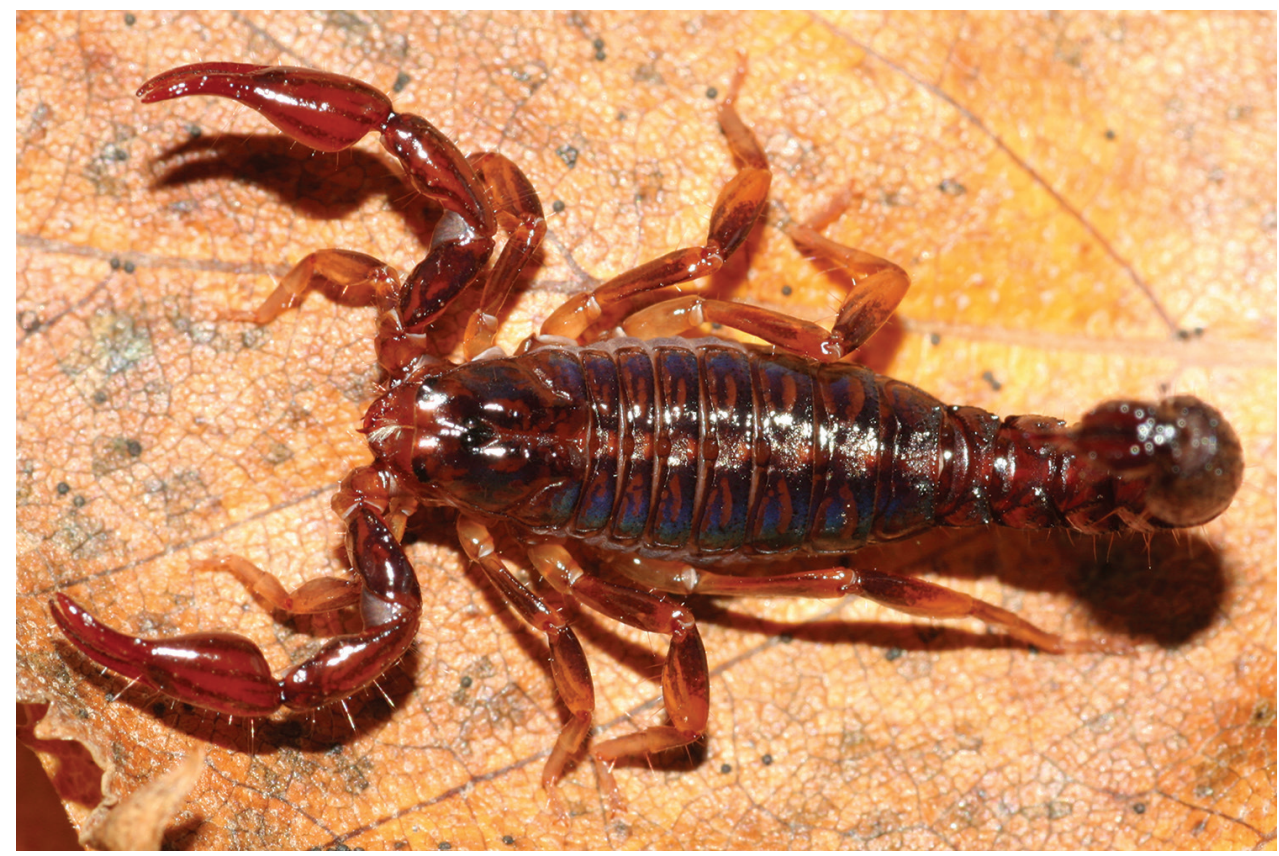

Figure 29. Hadrurochactas schaumii, male from Cacao.

and shiny in female; spiracles small and semi-oval in shape. Metasomal segments very strong in relation to the body; carinae only on dorsal and latero-dorsal sides; ventral side of metasomal segment I-IV in female and I-III in male smooth, the IV with fine granulation in male; segment $\mathrm{V}$ with ventral and lateral sides smooth in female and with granules in male. Telson smooth dorsally, granular with spinoid granules on lateral and ventral sides; aculeus weakly curved with a spinoid subaculear tooth. Pedipalp femur smooth in female and with granules on lateral sides in male, with five carinae; patella smooth and shiny, with three carinae; chela smooth and shiny, without granules and carinae; fingers about the same length as chela; fixed and movable fingers with seven rows of linear granules. Legs smooth, without granules and carinae.

\section{Genus Spinochactas Lourenço, 2016}

\section{Spinochactas mitaraka Lourenço, 2016}

Fig. 30

References. Lourenço 2016a.

Material. Mitaraka South, $640 \mathrm{~m}$, one female (holotype), deposited in the MNHN, J.M. Betsch leg., 15/III/2001.

Diagnosis. Total length $12.9 \mathrm{~mm}$ for female holotype. General coloration yellow to reddish yellow; only carapace and tergites are slightly marbled with brownish. Venter 


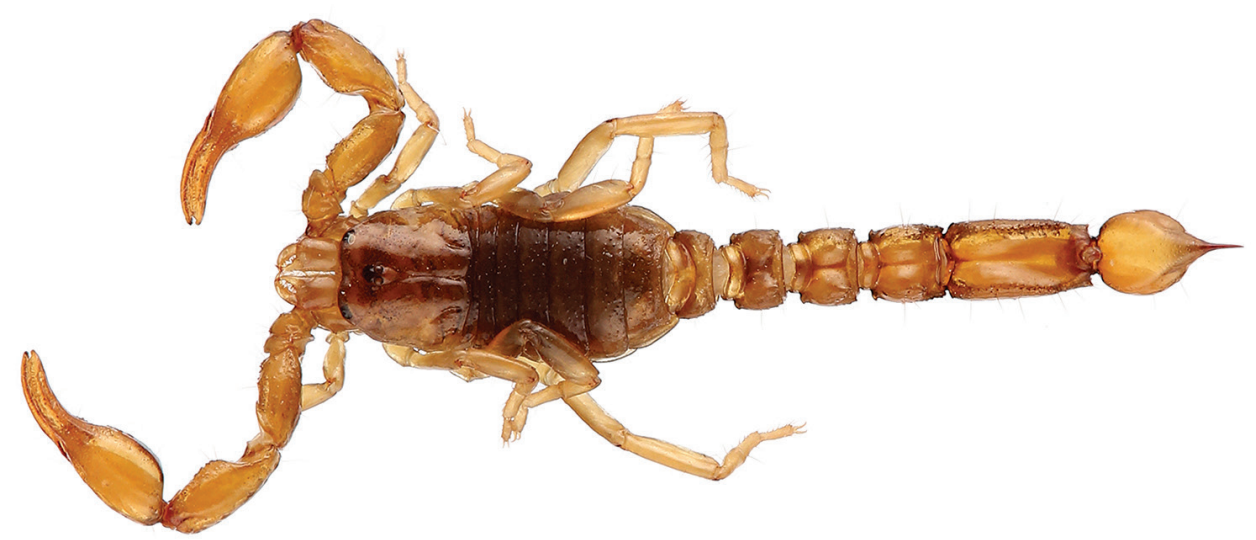

Figure 30. Spinochactas mitaraka, female holotype from Mitaraka massif (photograph MNHN / E.-A. Leguin; 2016 Elsevier Masson SAS).

and sternites yellow; pectines pale yellow. Metasomal segments yellow. Chelicerae yellow without spots; fingers yellow with reddish teeth. Pedipalps yellow to reddish yellow. Legs pale yellow. Carapace lustrous and slightly punctate; carinae absent; furrows shallow. Tergites acarinate, with minute granulations only. Pectinal tooth count 6-6 in female. Sternites smooth and shiny; spiracles strongly reduced and rounded. Metasomal segments I to IV wider than long; metasomal tegument punctate except for some granulations on the ventral surface of segment $\mathrm{V}$; ventral carinae absent from segments I to V; metasomal segments II to IV with dorsal and dorso-lateral carinae ending by a strong spinoid granule. Telson globular with a short aculeus; subaculear tooth or spine absent; some granulations present including on the dorsal side. Pedipalps slender with fingers strongly curved; femur with dorsal internal, dorsal external and ventral internal carinae moderately marked; ventral external carina vestigial; dorsal and ventral sides with minute granulations; internal side weakly granular; patella smooth and lustrous; dorsal internal, ventral internal, ventral external and external carinae weakly marked; other carinae vestigial; chela smooth and lustrous; carinae vestigial; internal side with granulations better marked on the base of fixed fingers; dentate margins on fixed and movable fingers with seven almost linear rows of granules, separated only by reduced internal accessory granules; edge of movable finger with three granules.

\section{Family HORMURIDAE Laurie, 1896}

Genus Opisthacanthus Peters, 1861

\section{Opisthacanthus heurtaultae Lourenço, 1980}

References. Lourenço 1980, Lourenço 1983, Fet et al. 2000, Lourenço and Fé 2003, Lourenço 2017. 


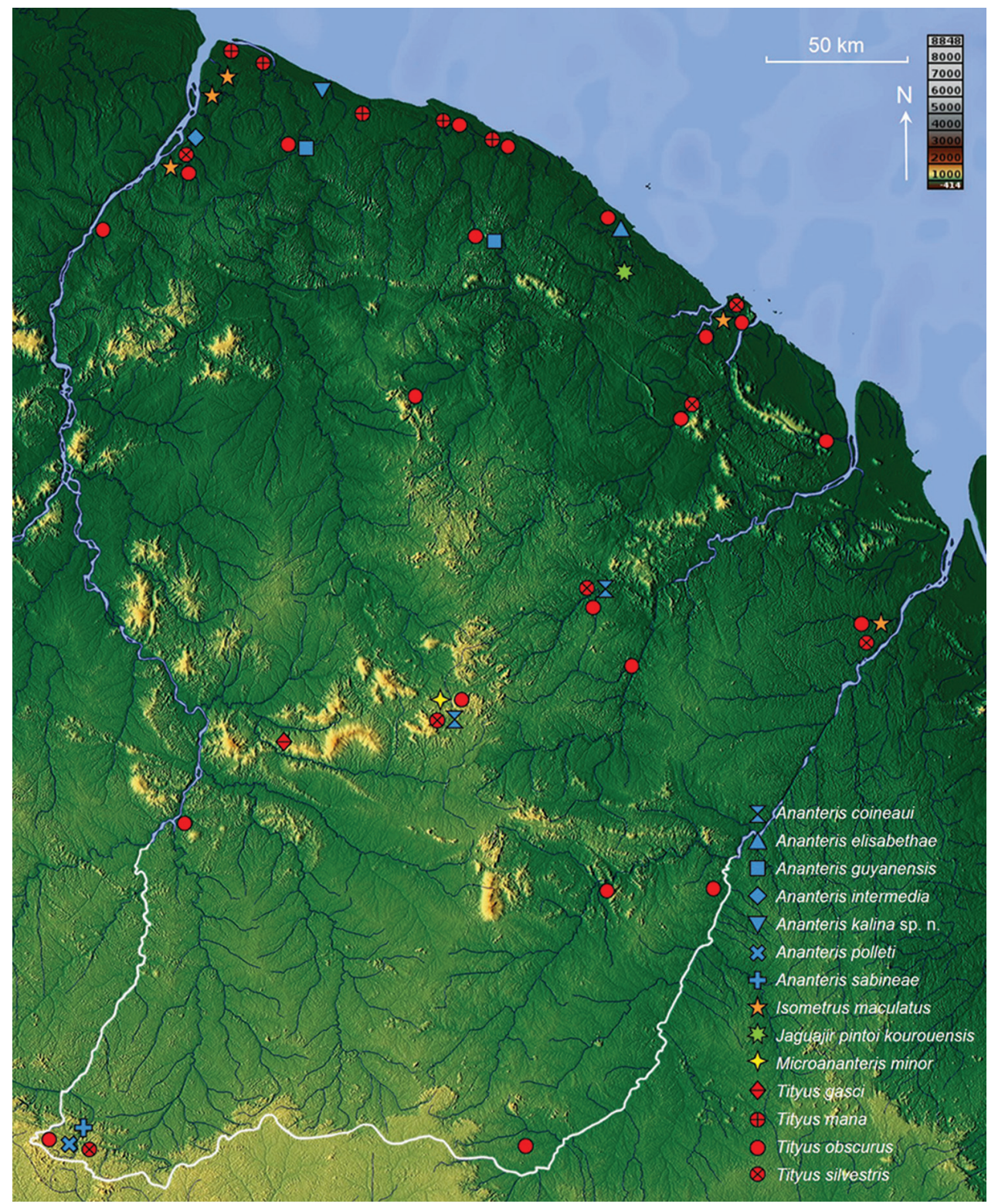

Figure 3 I. Topographic map of French Guiana showing the distribution of species of the family Buthidae.

Material. Degrad Saramaca, surroundings of Kourou, forest patches of Degrad path, one male (holotype), MNHN-RS-8085, mission M. Boulard \& P. Pompanon coll., 18/VIII/1975.

Diagnosis. Total length $63.9 \mathrm{~mm}$ for male holotype. General coloration reddish brown. Carapace dark brown with some lighter zones; ocular tubercle slightly darker. Tergites dark brown with some lighter zones in the middle of tergites. Sternites greyish 


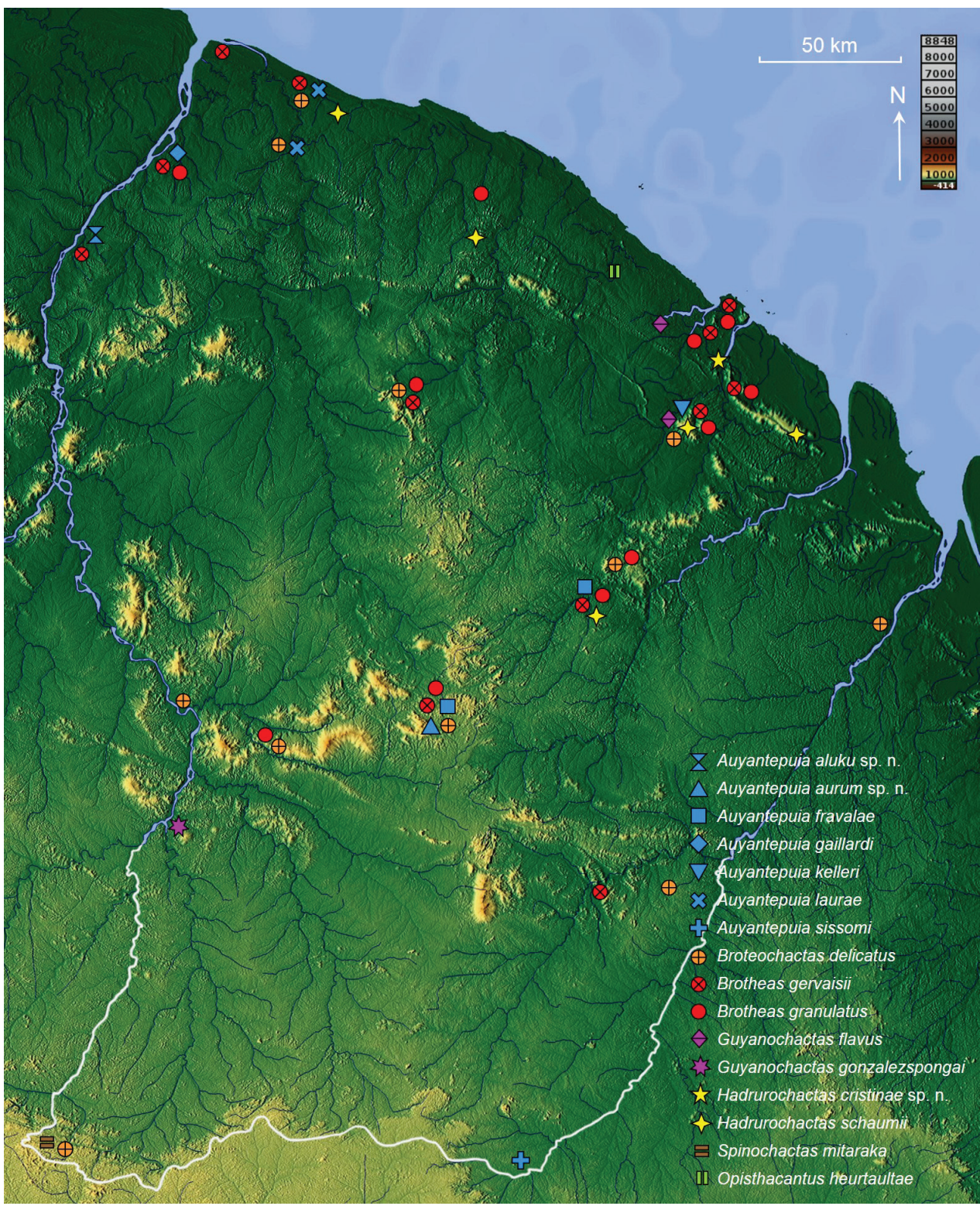

Figure 32. Topographic map of French Guiana showing the distribution of species of the families Chactidae and Hormuridae.

yellow, the VII darker; pectines and genital operculum greyish yellow, lighter than the sternites. Metasomal segments dark reddish brown with some lighter zones forming reddish yellow spots. Vesicle yellowish, darker around the articulation with metasomal segment V; aculeus yellowish at the base and reddish at the tip. Chelicerae dark yellow with reddish fingers. Pedipalps reddish brown with some darker zones; fingers darker. Legs reddish brown with some lighter spots, yellowish. Carapace strongly emarginated, 


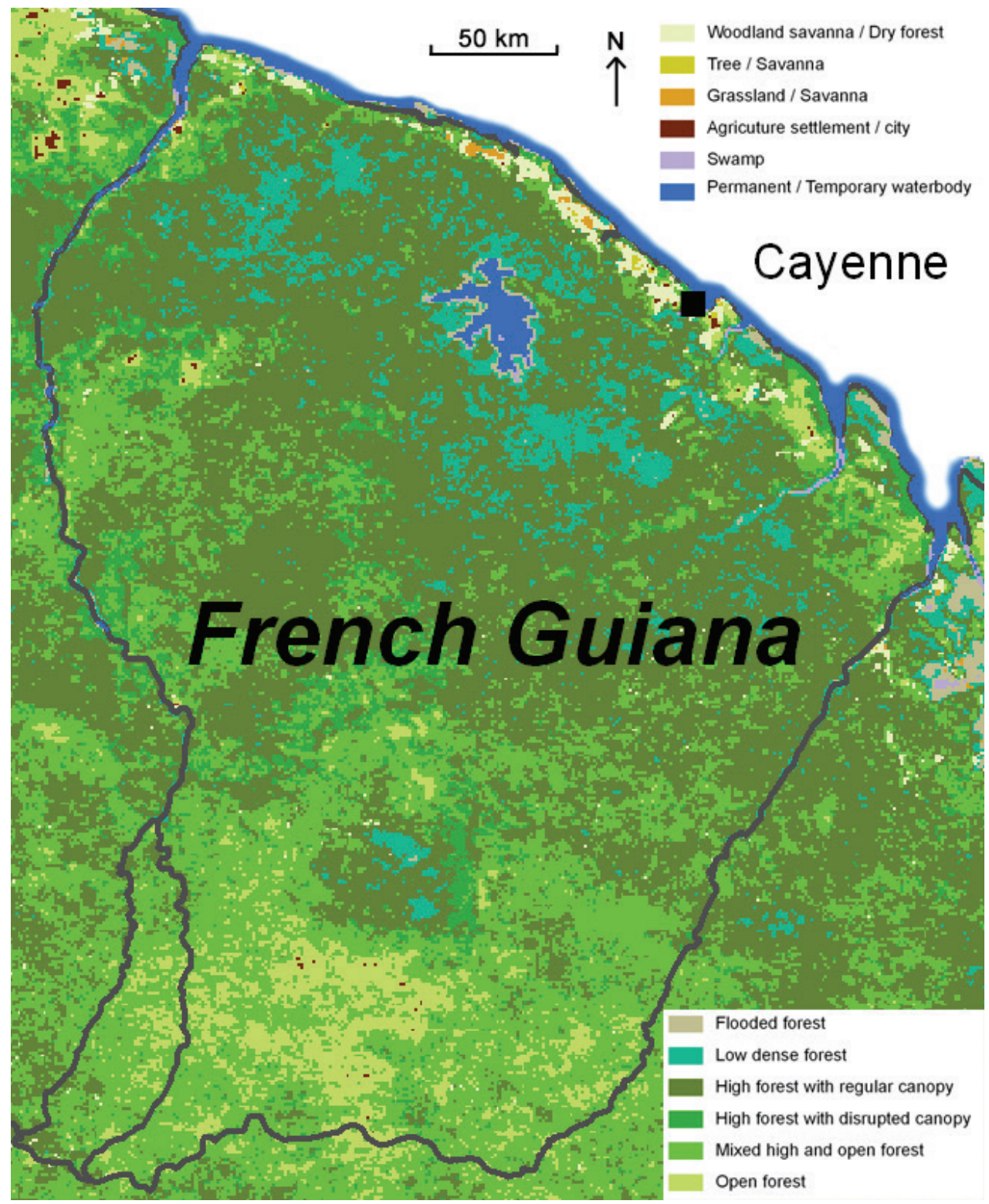

Figure 33. Vegetation map of French Guiana (modified from Gond et al. 2011).

with moderate granulation. Tergites with moderate granulation, better marked posteriorly. Pectinal tooth count 11-10 in male. Sternites smooth; spiracles linear. Metasomal segments rounded, all carinae weakly marked; segment $\mathrm{V}$ with spinoid granulations ventrally. Telson elongate, without any carinae; aculeus quite short compared to vesicle. Pedipalp femur with five carinae, four well-marked and one vestigial, intercarinal space smooth; patella and chela with several big granules forming incomplete carinae; 


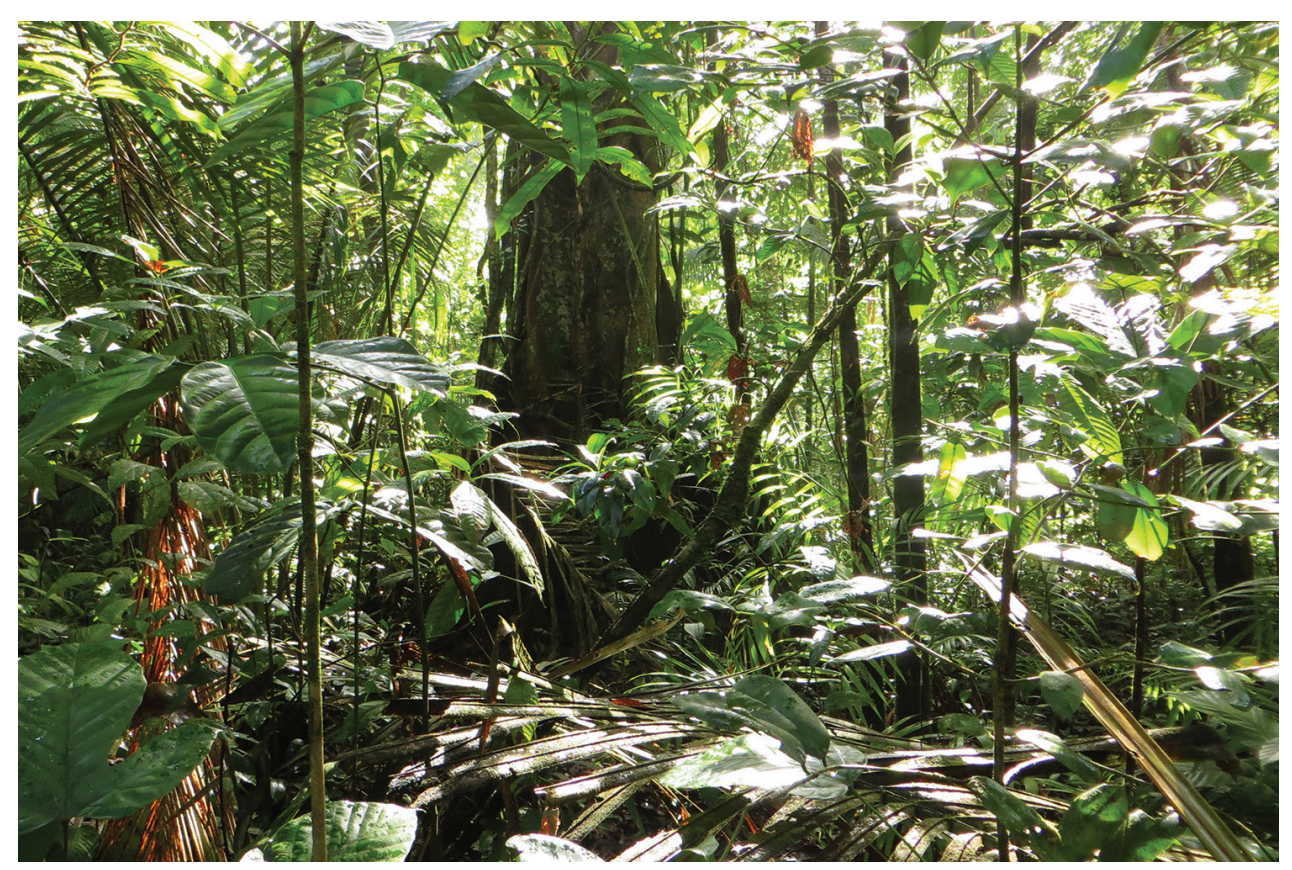

Figure 34. Lowland tropical rainforest habitat (Montsinéry-Tonnegrande, French Guiana).

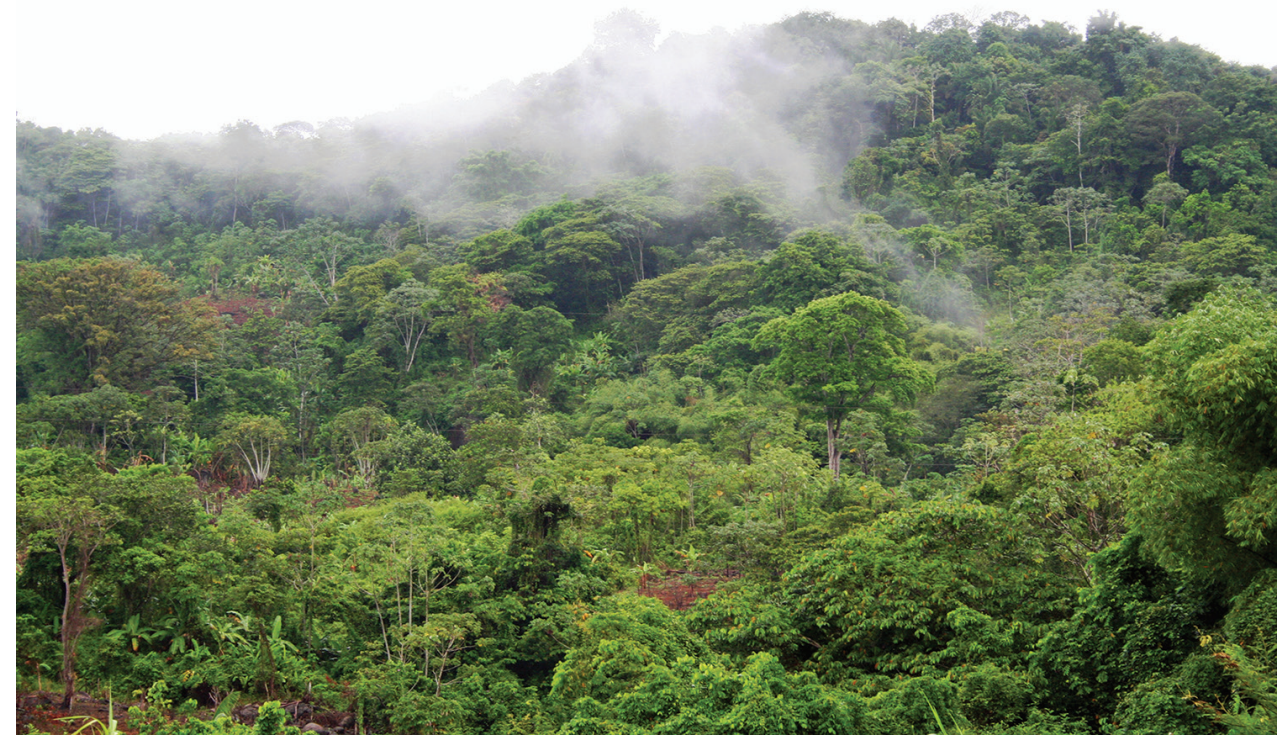

Figure 35. Altitude tropical rainforest habitat (Saül, French Guiana). 


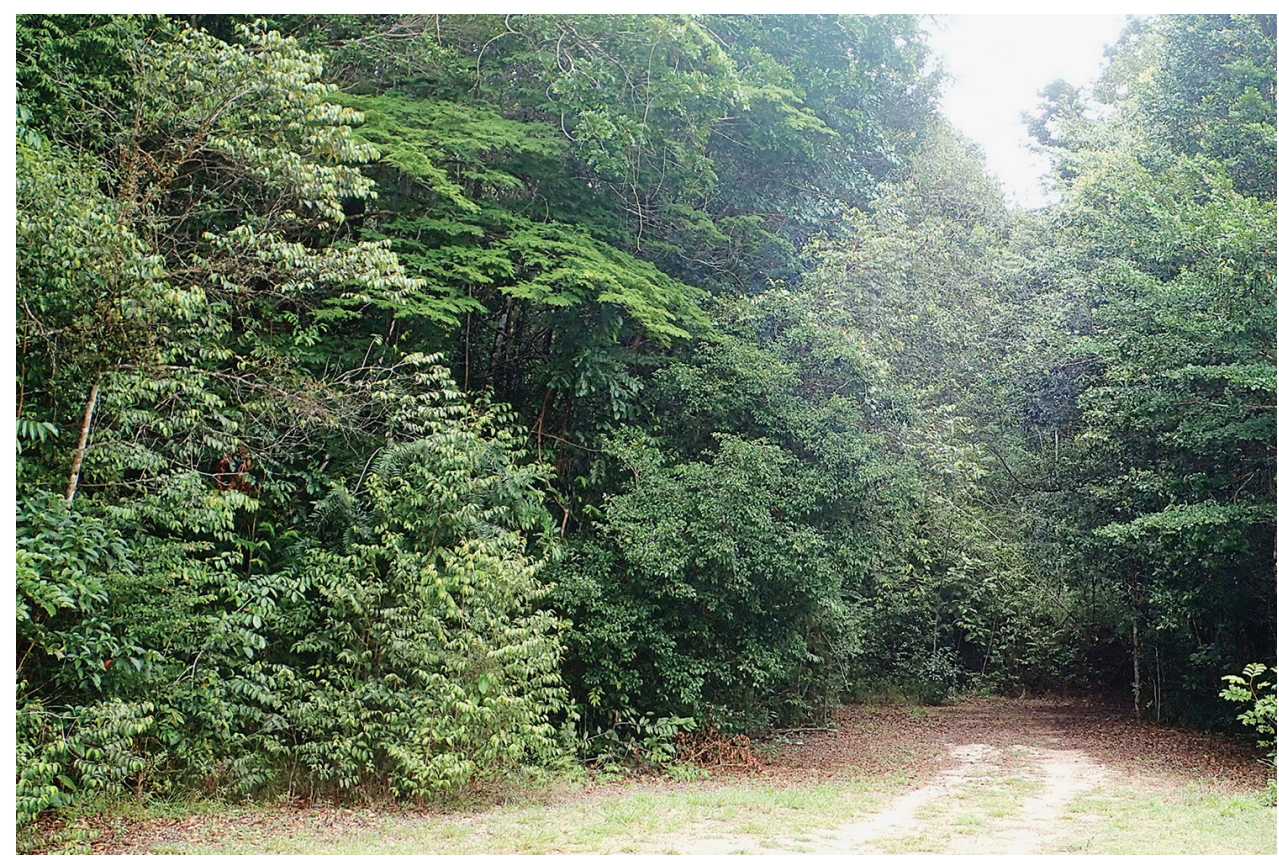

Figure 36. Coastal dry forest habitat (Mana, French Guiana). Photograph J. Chevalier.

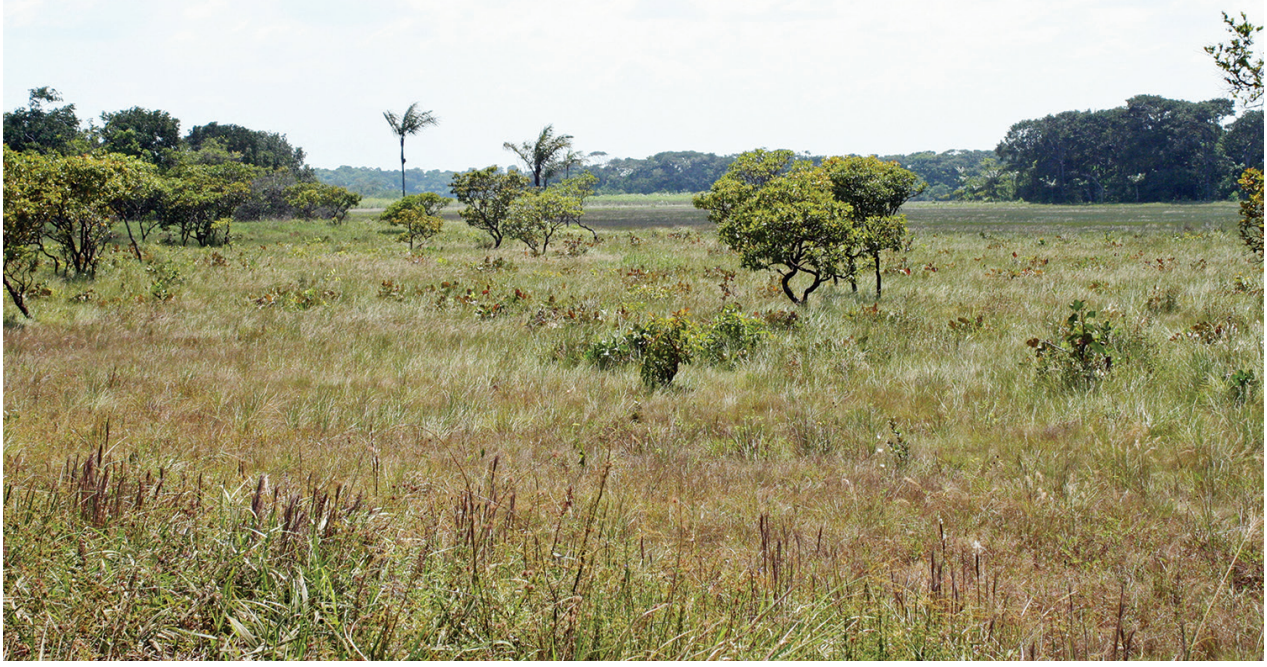

Figure 37. Coastal savanna habitat (Sinnamary, French Guiana). 
chela long and flattened, dorsal and ventral sides smooth and shiny, lateral sides with strong granulations; fingers smooth, movable finger with a basal lobe. Numerous reddish yellow setae on the body, pedipalps, legs, and vesicle.

\section{Key to the species of scorpions described from French Guiana}

The following key is proposed for the 30 species described from French Guiana and presented in this work. This key is based on previous keys proposed by Lourenço (1983, 2002b). This key must be considered as imperfect, provisional and susceptible to possible exceptions, hence it is to be used with caution and should not be the only tool for identifying a specimen. If there is any doubt, more thorough diagnoses presented in this paper or even detailed descriptions (see publications indicated in the references) should also be consulted.

1 Sternum subtriangular; pedipalp tibia without ventral trichobothria

Family Buthidae: 3

Retrolateral pedal spurs absent; anterior margin of carapace with a strong concavity; three lateral eyes; three ventral trichobothria on the tibia....

Family Hormuridae, Genus Opisthacanthus, O. heurtaultae

Retrolateral pedal spurs present; anterior margin of carapace without a strong concavity; two lateral eyes in most species; four to seven ventral trichobothria on the tibia

Family Chactidae: 16

Dentate margins of pedipalp chela fingers composed of 6/7 longitudinal rows of granules, without supernumerary granules

Dentate margins of pedipalp chela fingers composed of 8 to 17 oblique rows of granules

Small species; very small pectines (pectinal tooth count 10-10) with distal teeth rounded Genus Microananteris, M. minor Small to large species; pectines small to long (pectinal count ranging from 11 to 19$)$, distal teeth not rounded Genus Ananteris: 6 Chelicerae with reticular pattern

Chelicerae without reticular pattern

General coloration yellow to pale yellow; very small species $(9 \mathrm{~mm})$

A. intermedia

Darker general coloration, brownish yellow; larger species $(14-33 \mathrm{~mm})$.....8 Chelicerae reticular pattern incomplete, only a dark brown spot anteriorly at the base of fingers 
10 General coloration pale yellow without spots or pigmented zones on the body and its appendages; movable fingers with six linear rows of granules...... A. elisabethae General coloration brownish yellow marbled with dark reddish brown spots; movable fingers with seven linear rows of granules 11

11 Movable fingers with one accessory granule present at the base of each row....

A. guyanensis

Movable fingers with two accessory granules present at the base of each row ....

A. sabineae

12 Dentate margins of pedipalp chela fingers composed of $8 / 9$ oblique rows of granules, with supernumerary granules present in the adults

Genus Jaguajir, Jaguajir pintoi kourouensis

Dentate margins of pedipalp chela fingers composed of 12 to 17 oblique rows of granules, without supernumerary granules

Genus Tityus: 13

13 Small species ranging from 25 to $45 \mathrm{~mm}$ in total length with variegated pigmentation and a very rhomboidal subaculear tooth. Species of medium or large size, ranging from 63 to $100 \mathrm{~mm}$ in total length; pigmentation varying from yellowish to brown and black; spinoid subaculear tooth

Dorsolateral keels of metasomal segments I to IV with a moderate spinoid posterior granule.

T. mana

Dorsolateral keels of metasomal segments I to IV without a spinoid posterior granule.

T. silvestris

Species of medium size (63 $\mathrm{mm}$ in total length); coloration rather pale varying from yellowish to reddish brown or brownish, never black; basal middle lamellae of female pectines not dilated.

Large species, ranging from 75 to $100 \mathrm{~mm}$ in total length; pigmentation blackish in the adult and yellowish/variegated in immature individuals; basal middle lamellae of female pectines dilated

T. obscurus

Spiracles oval or round; tarsus with setae or rows of spines

Tarsus with rows of spines

Genus Guyanochactas: 29

Scorpions of medium size, from 44 to $50 \mathrm{~mm}$ in total length; spiracles round to round/oval Metasomal segments stocky in relation to the body, especially segments IV-V; fingers about the same length as chela hand .... Genus Hadrurochactas: 20

20 General coloration reddish brown, with a confluent yellowish longitudinal median stripe over the tergites; chelicerae yellowish without spots; male pectinal tooth count ranging from 10-11 H. schaumii

- General coloration yellowish brown, without confluent yellowish longitudinal median stripe; chelicerae with variegated brownish spots over the entire surface; male pectinal tooth count 9-9 
21 Pedipalp chela stocky; fingers shorter than chela hand...Genus Auyantepuia: 22

- $\quad$ Pedipalp chela slender with fingers strongly curved; spinoid granules on dorsal and dorso-lateral carinae of metasomal segments II-IV.

Genus Spinochactas, S. mitaraka

22 Pedipalps with chelae weakly granulated, almost smooth ........................23

- $\quad$ Pedipalps with chelae moderately to strongly granulated ...........................26

23 Ventral side of several metasomal segments yellowish, without spots ........24

Ventral side of all metasomal segments well pigmented, brownish to dark reddish.

24 Posterior half of ventral side of segments I to IV yellowish, without spots; confluent yellowish longitudinal median stripe on tergites.... A. aluku sp. $\mathbf{n}$. Ventral side of metasomal segments I to III yellowish, without spots; no median stripe on tergites.

A. laurae

25 Body, pedipalps, legs and chelicerae without variegated brownish spots

A. gaillardi

Body, pedipalps, legs and chelicerae marked with variegated brownish spots.....

A. kelleri

26 Ventral side of metasomal segments I to II yellowish, without spots; confluent yellowish longitudinal median stripe on tergites Ventral side of all metasomal segments well pigmented, brownish to dark reddish; no median stripe on tergites

A. fravalae General coloration reddish brown; metasomal tegument with medium size granulation on ventral side of segments III to $\mathrm{V}$

A. aurum sp. n.

- $\quad$ General coloration yellowish; only metasomal segment V granulated ventrally

A. sissomi

Carapace and tergites strongly granular; general coloration blackish brown...

B. granulatus

Carapace feebly granular; tergites punctate; general coloration reddish brown

B. gervaisii

29 General coloration reddish yellow with some blackish spots; chela fingers with six rows of granules

G. gonzalezspongai

- $\quad$ General coloration pale yellowish, without any dark spots; chela fingers with five rows of granules.

G. flavus

\section{Acknowledgements}

I am most grateful to Dr. Wilson R. Lourenço (Muséum national d'Histoire naturelle, Paris, France) for his comments and review of the manuscript and to three anonymous referees for useful comments and suggestions. I also want to express my sincere gratitude to Mr. Johan Chevalier (Reserve Naturelle de l'Amana, Awala-Yalimapo, French Guiana, France) for providing the collected specimens of the new species described in this work and for permission to use some of his photos. Thank you also to the Muséum national 
d'Histoire naturelle (Paris, France), Ms. Elise-Anne Leguin (MNHN, Paris, France), Mr. Anthony Thillien (Le Mans, France), Mr. Giorgio Molisani (Bürglen, Switzerland), and Elsevier Masson SAS (Paris, France) for permission to use some of their photos.

\section{References}

Botero-Trujillo R, Noriega JA (2011) On the identity of Microananteris, with a discussion on pectinal morphology, and description of a new Ananteris from Brazil (Scorpiones, Buthidae). Zootaxa 2747: 37-52.

Degeer C (1778) Mémoires pour servir à l'histoire des insectes. Impr. Pierre Hesselberg, Stockholm, 7: 1-950 (p. 337).

Esposito LA, Yamaguti YH, Souza CA, Pinto-da-Rocha R, Prendini L (2017) Systematic revision of the neotropical club-tailed scorpions, Physoctonus, Rhopalurus, and Throglorhopalurus, revalidation of Heteroctenus, and descriptions of two new gerena and three new species (Buthidae: Rhopalurusinae). Bulletin of the American Museum of Natural History, Number 45, 134 pp. Gervais P (1843) Les principaux résultats d'un travail sur la famille des Scorpions. Société philomatique de Paris. Extraits des procès-verbaux des séances, vol. 5 (7): 129-131.

Gonzaléz-Sponga MA (1978) Escorpiofauna de la region oriental del Estado Bolivar en Venezuela. Roto-Impresos C.A., 1-217.

Ehrenberg FG (1829) Arachnoidea, Scorpiones. In: Hemprich \& Ehrenberg. Symbolae physicae seu icones et descriptiones animalium evertebratorum sepositis insectis quae ex itinere per Africanum borealem et Asiam occidentalem. Percensuit editit Dr. C.G. Ehrehberg. Decas I. Berolini ex officina Academica, venditur a Mittlero, Berlin.

Fet V, Sissom WD, Lowe G, Braunwalder ME (2000) Catalog of the Scorpions of the World (1758-1998). New York, New York Ento-mological Society, 690 pp.

Gond V, Freycon V, Molino JF, Brunaux O, Ingrassia F, Joubert P, Pekel JF, Prévost MF, Thierron V, Trombe PJ, Sabatier D (2011) Broad scale patterns of forest landscape in Guiana Shield rain forests. International journal of Applied Earth Observation and Geoinformations, 13: 357-367. https://doi.org/10.1016/j.jag.2011.01.004

Hjelle JT (1990) Anatomy and morphology. In: Polis GA (Ed.) The Biology of Scorpions. Stanford University Press, Stanford, pp 9-63.

Karsch F (1879) Scorpionologische Beiträge. Part II. Mitteilungen des Münchener entomologischen Vereins 3: 97-136.

Karsch F (1880) Arachnologische bluter. X. Scorpionologische Fragmente. Z. ges. Naturw. Halle 53: 404-409.

Koch CL (1836) Die arachniden. Zeh'schen Buchhandlung, Nürnberg, 3: 17-104.

Laurie M (1896) Further notes on the anatomy and developpment of scorpions and their bearing on the classification of the order. Annals and Magazine of Natural History, sér. 6, vol. 18: 121-133. https://doi.org/10.1080/00222939608680422

Lourenço WR (1980) A proposito de duas novas espécies de Opisthacanthus para a régiao neotropical. Opisthacanthus valerioi da "Isla del Coco ", Costa Rica e Opisthacanthus heurtaultae da Guiana francesa (Scorpionidae). Revista Nordestina de Biologia 3 (2): 179-194. 
Lourenço WR (1981) Tityus gasci, nouvelle espèce de scorpion Buthidae de Guyane française. Bulletin du Muséum national d'Histoire naturelle, Paris, 48 sér., 3, sect. A, (3): 841-845.

Lourenço WR (1982) Révision du genre Ananteris Thorell, 1891 (Scorpiones, Buthidae) et description de six espèces nouvelles. Bulletin du Muséum national d'Histoire naturelle, Paris, 4e sér. 4 (A1/2): 119-151.

Lourenço WR (1983) La faune des scorpions de Guyane française. Bulletin du Muséum national d'Histoire naturelle, Paris, 4e sér. 5 (A3): 771-808.

Lourenço WR (1984) Analyse taxonomique des scorpions du groupe Tityus clathratus Koch, 1845 (Scorpiones, Buthidae). Bulletin du Muséum national d'Histoire naturelle, Paris, 4e ser., 6, section A, 2: 349-360.

Lourenço WR (1986) Biogéographie et phylogénie des scorpions du genre Rhopalurus Thorell, 1876 (Scorpiones, Buthidae). Mémoires de la Société Royal Belge d'Entomologie 33: 129-137.

Lourenço WR (1988a) Diversité biologique et modalités de la spéciation chez les scorpions amazoniens; Tityus silvestris Pocock, un cas particulier de polymorphisme. Comptes rendus des séances de l'Académie des sciences, Ser. III Sci. Vie 306 (15): 463-466.

Lourenço WR (1988b) Première évidence de la présence d'une faune scorpionique amazonienne relictuelle dans les «Brejos» de la Caatinga du Nord-Est du Brésil. Comptes rendu du Xème Colloque Européen d'Arachnologie Bulletin de la Société Scientifique de Bretagne, 59, nº h.s. 1: 147-154.

Lourenço WR (1991) La "Province" biogéographique guyanaise; étude de la biodiversité et des centres d'endémisme en vue de la conservation des patrimoines génétiques. Comptes rendus des séances de la Société de Biogéographie 67 (2): 113-131.

Lourenço WR (1992) Biogéographie des espèces du groupe naturel «Tityus clathratus» (Chelicerata, Scorpiones, Buthidae). Bulletin du Muséum national d'Histoire naturelle, Paris, 4e sér., 14, section A, 2: 473-481.

Lourenço WR (1993) A review of the geographical distribution of the genus Ananteris Thorell (Scorpiones: Buthidae), with description of a new species. Revista de Biologia Tropical 41(3): 697-701.

Lourenço WR (1997b) Additions à la faune de scorpions néotropicaux (Arachnida). Revue Suisse de Zoologie 104 (3): 687-604. https://doi.org/10.5962/bhl.part.80012

Lourenço WR (1998) Un nouveau genre de scorpion amazonien appartenant à la famille des Chactidae (Chelicerata, Scorpiones). Revue Arachnologique 12(12): 129-134.

Lourenço WR (1999) A new species of Ananteris Thorell from French Guyana (Scorpiones, Buthidae), Revue Suisse de Zoologie 106: 301-306. https://doi.org/10.5962/bhl.part.80080

Lourenço WR (2001a) Scorpion diversity in tropical South America: implications for conservation programs. In: Brownell P, Polis GA (Eds) Scorpion biology and research, Oxford University Press, 406-416.

Lourenço WR (2001b) Description of a new species of Ananteris (Scorpiones, Buthidae) from the South of French Guyana. Zoosystema 23(4): 689-693.

Lourenço WR (2002a) Scorpions of Brazil. Les Editions de l'IF, Paris, 320 pp.

Lourenço WR (2002b) Scorpions. In: Adis J (Ed.) Amazonian Arachnida and Myriapoda. Pensoft Publishers, Series Faunistica No 24, Sofia-Moscow, 399-438.

Lourenço WR (2003a) The genus Ananteris Thorell (Scorpiones, Buthidae) in French Guyana. Revista Ibérica de Aracnología 7: 183-188. 
Lourenço WR (2003b) Humicolous buthoid scorpions: a new genus and species from French Guiana. Comptes Rendus Biologies, 326: 1149-1155. https://doi.org/10.1016/j. crvi.2003.09.003

Lourenço WR (2008) The geographic pattern of distribution of the genus Rhopalurus Thorell, 1876 in the Guayana-Amazon region (Scorpiones: Buthidae), Euscorpius, No. 73: 1-14.

Lourenço WR (2010) The disrupted pattern of distribution of the genus Hadrurochactas Pocock; evidence of past connections between Amazon and the Brazilian Atlantic forest. Comptes Rendus Biologies 333: 41-47. https://doi.org/10.1016/j.crvi.2009.11.002

Lourenço WR (2012c) Humiculous scorpions: on the genera Ananteris Thorell, 1891 and Microananteris Lourenço, 2004 (Scorpiones: Buthidae), with the description of a new species from French Guiana. Comptes Rendus Biologies 335: 555-561. https://doi.org/10.1016/j.crvi.2012.06.005

Lourenço WR (2012d) Further considerations on Tityus (Archaeotityus) clathratus C. L. Koch, 1844 and description of two associated new species (Scorpiones, Buthidae). Boletín de la Sociedad Entomológica Aragonesa 50: 277-283.

Lourenço WR (2016a) Scorpions from the Mitaraka Massif in French Guiana; description of one new genus and species (Scorpiones: Chactidae). Comptes Rendus Biologies 339: 141-146. https://doi.org/10.1016/j.crvi.2016.02.003

Lourenço WR (2016b) Scorpions from the Mitaraka Massif in French Guiana II. Description of one new species of Ananteris Thorell, 1891 (Scorpiones: Buthidae). Comptes Rendus Biologies 339: 214-221. https://doi.org/10.1016/j.crvi.2016.04.002

Lourenço WR (2017) Description of a new species of Opisthacanthus Peters (Scorpiones: Hormuridae) from Suriname/Brazil border with some biogeographic considerations. Acta Biologica Paranaense Curitiba 46 (1-2): 9-22. https://doi.org/10.5380/abpr.v46i0.50350

Lourenço WR, Cuellar O (1999) A new all-female scorpion and the first probable case of arrhenotoky in scorpions. The Journal of Arachnology 27: 149-153.

Lourenço WR, Duhem B (2010) A new species of Auyantepuia Gonzáles-Sponga, 1978 (Scorpiones, Chactidae) from Suriname. Entomologische Mitteilungen aus dem Zoologischen Museum Hamburg 15 (182): 137-146.

Lourenço WR, Fé NF (2003) Description of a new species of Opisthacanthus Peters (Scorpiones, Liochelidae) to Brazilian Amazonia. Revista Ibérica de Aracnología 7: 81-88.

Lourenço WR, Monod L (1999) A new species of Ananteris Thorell from French Guyana (Scorpiones, Buthidae). Revue suisse de Zoologie 106 (2): 301-306. https://doi.org/10.5962/ bhl.part. 80080

Lourenço WR, Pinto-da-Rocha R (1997) A reappraisal of the geographic distribution of the genus Rhopalurus Thorell (Scorpiones, Buthidae) and description of two new species. Biogeographica 73 (4): 181-191.

Lourenço WR, Pinto-da-Rocha (2000) Additions to the knowledge of the Chactidae of Brazilian Amazonia (Arachnida: Scorpiones). Amazoniana 16 (112): 259-274.

Lourenço WR, Qi JX (2007) Additions à la faune des scorpions de l'Etat du Amapâ, Brésil (Chelicerata, Scorpiones). Revue suisse de Zoologie 114 (1): 3-12. https://doi.org/10.5962/ bhl.part. 80384

Lourenço WR, Ythier E (2011) A new species of Guyanochactas Lourenço, 1998 (Scorpiones, Chactidae) from French Guiana. Boletín de la Sociedad Entomológica Aragonesa 48: 203-206. 
Monod L, Lourenço WR (2001) A new species of Brotheochactas Pocock, 1890 from Brazilian Amazonia (Scorpiones: Chactidae). In: Fet V, Selden PA (Eds) Scorpions 2001. Memoriam Gary A. Polis, 195-202.

Mori SA (1991) The Guayana lowland floristic province. Comptes Rendu de la Société de Biogéographie 67: 67-75.

Peters W (1861) Ueber eine neue Eintheilung der Skorpione und ueber die von ihm in Mossambique gesammelten Arten von Skorpionen, aus welchem hier ein Auszug mitgetheilt wird. Monatsberichte der Königlichen Preussischen Akademie der Wissenschaften zu Berlin, vol. 1861, (1): 507-516.

Pocock RI (1893a) A contribution to the study of neotropical scorpions. Annals and Magazine of Natural History, ser. 6, 12: 77-103. https://doi.org/10.1080/00222939308677589

Pocock RI (1893b) Notes on the classification of Scorpions, followed by some observations upon synonymy, with descriptions of new genera and species. Annals and Magazine of Natural History, ser. 6, 12: 303-330.

Pocock RI (1893c) Contribution to our knowledge of the Arthropod fauna of the West Indies. Part I. Scorpiones and Pedipalpi. Scorpiones. Journal of the Linnaean Society 24: 374-404. Pocock RI (1897) Report upon the scorpiones and pedipalpi obtained on the Lower Amazons by Messrs E. E. Austen and F. Pickard-Cambridge during the trip of Mr Siemens Steamship 'Faraday'. Annals and Magazine of Natural History, ser. 6, 19: 357-368. https://doi. org/10.1080/00222939708680549

Prendini L, Wheeler WC (2005) Scorpion higher phylogeny and classification, taxonomic anarchy, and standards for peer review in online publishing. Cladistics 21: 446-494. https:// doi.org/10.1111/j.1096-0031.2005.00073.x

Simon E (1877) Etudes arachnologiques. Ge mémoire. X. Arachnides nouveaux ou peu connus, Annales de la Société Entomologique de France 5 (7): 225-242.

Stahnke HL (1970) Scorpion nomenclature and mensuration. Entomological News, 81: 297-316. Soleglad ME, Fet V (2003) High-level systematics and phylogeny of the extant scorpions (Scorpiones: Orthosterni). Euscorpius 11: 1-210.

Soleglad ME, Fet V (2005) The Genus Auyantepuia González-Sponga, 1978 is confirmed as a synonym of Broteochactas Pocock, 1893 (Scorpiones: Chactidae). Euscorpius 29: 1-16.

Stockmann R, Ythier E (2010) Scorpions of the World. NAP Editions, Paris, 572 pp.

Thorell T (1891) Nova species Brasiliana ordinis scorpionum, Entomologisk Tidskrif, 12: 65-70.

Vachon M (1963) De l'utilité, en systématique, d'une nomenclature des dents des chélicères chez les scorpions. Bulletin du Muséum national de Histoire naturelle, Paris 2è sér., 35 (2): 161-166.

Vachon M (1974) Etude des caractères utilisés pour classer les familles et les genres de scorpions (Arachnides). 1. La trichobothriotaxie en arachnologie. Sigles trichobothriaux et types de trichobothriotaxie chez les Scorpions. Bulletin du Muséum national de Histoire naturelle, Paris, 3è sér., n 140, Zool. 104: 857-958.

Ythier E (2015) A new species of Auyantepuia González-Sponga, 1978 (Scorpiones, Chactidae) from French Guiana. ZooKeys 539: 97-109. https://doi.org/10.3897/zookeys.539.6664 